\title{
Rufomycins or llamycins: Naming Clarifications and Definitive Structural Assignments
}

Bin Zhou, Prabhakar S. Achanta, Gauri Shetye, Shao-Nong Chen, Hyun

Lee, Ying-Yu Jin, Jinhua Cheng, Mi-Jin Lee, Joo-Won Suh, Sanghyun Cho, Scott G. Franzblau, Guido F. Pauli, James B. McAlpine

- SUPPORTING INFORMATION 


\section{Table of Contents}

Chart S1. Clarification of rufomycin 4 and its related three diastereomers (rufomycins 5-7).

Figure S1. ${ }^{1} \mathrm{H}$ NMR spectrum of rufomycin 4 in $\mathrm{CD}_{3} \mathrm{OD}$ at $600 \mathrm{MHz}$.......................5

Figure S2. ${ }^{13} \mathrm{C}$ NMR spectrum of rufomycin 4 in $\mathrm{CD}_{3} \mathrm{OD}$ at $150 \mathrm{MHz}$.....................5

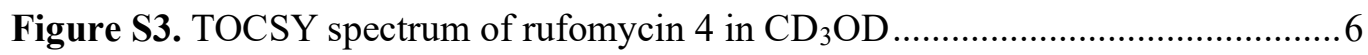

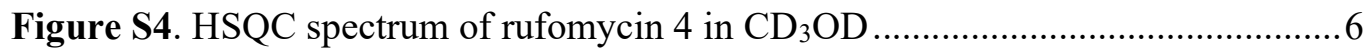

Figure S5. HMBC spectrum of rufomycin 4 in $\mathrm{CD}_{3} \mathrm{OD}$ at $\left(600 \mathrm{MHz},{ }^{1} \mathrm{H}\right) \ldots \ldots \ldots \ldots \ldots . . . .7$

Figure S6. ROESY spectrum of rufomycin 4 in $\mathrm{CD}_{3} \mathrm{OD}$........................................ 7

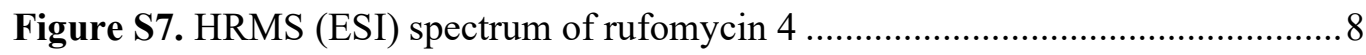

Figure S8. ${ }^{1} \mathrm{H}$ NMR spectrum of rufomycin 5 in $\mathrm{CD}_{3} \mathrm{OD}$ at $600 \mathrm{MHz}$..................... 8

Figure S9. ${ }^{13} \mathrm{C}$ NMR spectrum of rufomycin 5 in $\mathrm{CD}_{3} \mathrm{OD}$ at $150 \mathrm{MHz}$.....................

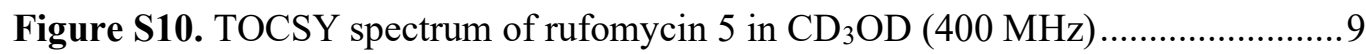

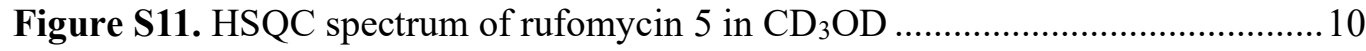

Figure S12. HMBC spectrum of rufomycin 5 in $\mathrm{CD}_{3} \mathrm{OD}\left(400 \mathrm{MHz},{ }^{1} \mathrm{H}\right) \ldots \ldots \ldots \ldots \ldots . . . . . . .10$

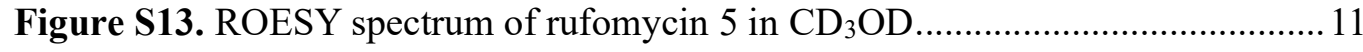

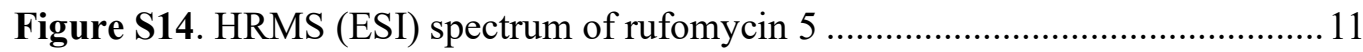

Figure S15. ${ }^{1} \mathrm{H}$ NMR spectrum of rufomycin 6 in $\mathrm{CD}_{3} \mathrm{OD}$ at $600 \mathrm{MHz}$.................... 12

Figure S16. ${ }^{13} \mathrm{C}$ NMR spectrum of rufomycin 6 in $\mathrm{CD}_{3} \mathrm{OD}$ at $150 \mathrm{MHz}$..................12

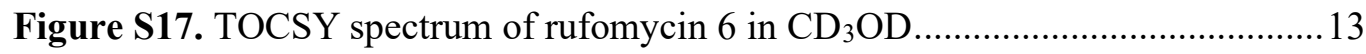

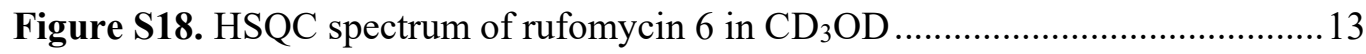

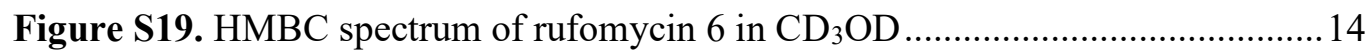

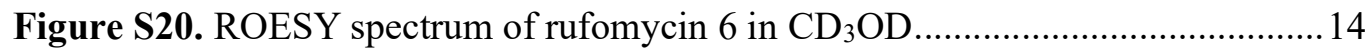

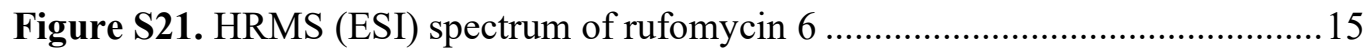

Figure S22. ${ }^{1} \mathrm{H}$ NMR spectrum of rufomycin 7 in $\mathrm{CD}_{3} \mathrm{OD}$ at $600 \mathrm{MHz}$...................15

Figure S22-1. Selected ${ }^{1} \mathrm{H}$ NMR peak of rufomycin 7 ............................................15

Figure S23. ${ }^{13} \mathrm{C}$ NMR spectrum of rufomycin 7 in $\mathrm{CD}_{3} \mathrm{OD}$ at $150 \mathrm{MHz}$...................16

Figure S24. TOCSY spectrum of rufomycin 7 in $\mathrm{CD}_{3} \mathrm{OD}(400 \mathrm{MHz}) \ldots \ldots \ldots \ldots \ldots \ldots \ldots . . . . . . . .16$

Figure S25. HSQC spectrum of rufomycin 7 in $\mathrm{CD}_{3} \mathrm{OD}\left(400 \mathrm{MHz},{ }^{1} \mathrm{H}\right) \ldots \ldots \ldots \ldots \ldots \ldots . . . . . . . .17$

Figure S26. HMBC spectrum of rufomycin 7 in $\mathrm{CD}_{3} \mathrm{OD}\left(400 \mathrm{MHz},{ }^{1} \mathrm{H}\right) \ldots \ldots \ldots \ldots \ldots . . . . .17$

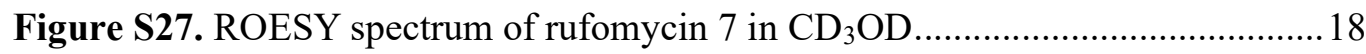

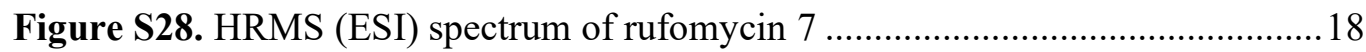

Figure S29. ${ }^{1} \mathrm{H}$ NMR spectrum of rufomycinSS 1 in $\mathrm{CD}_{3} \mathrm{OD}$ at $600 \mathrm{MHz}$................19

Figure S30. ${ }^{13} \mathrm{C}$ NMR spectrum of rufomycinSS 1 in $\mathrm{CD}_{3} \mathrm{OD}$ at $150 \mathrm{MHz}$............... 19

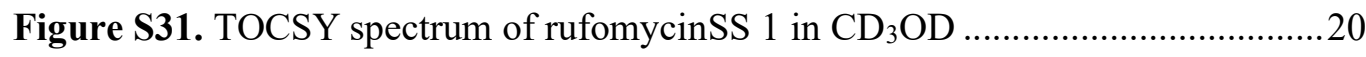

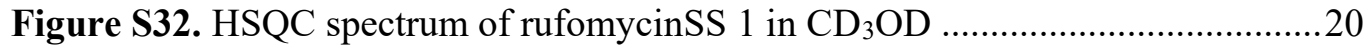

Figure S33. HMBC spectrum of rufomycinSS 1 in $\mathrm{CD}_{3} \mathrm{OD}$...................................21

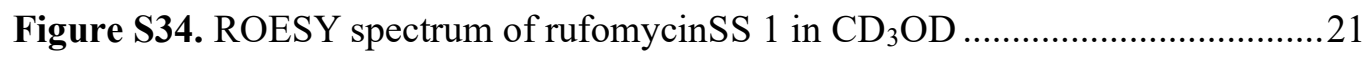

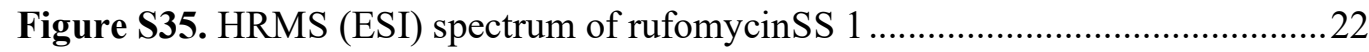

Figure S36. ${ }^{1} \mathrm{H}$ NMR spectrum of rufomycinSS 2 in $\mathrm{CD}_{3} \mathrm{OD}$ at $600 \mathrm{MHz}$................22

Figure S37. ${ }^{13} \mathrm{C}$ NMR spectrum of rufomycinSS 2 in $\mathrm{CD}_{3} \mathrm{OD}$ at $150 \mathrm{MHz}$..............2 23 
Figure S38. TOCSY NMR spectrum of rufomycinSS 2 in $\mathrm{CD}_{3} \mathrm{OD}$..........................23

Figure S39. HSQC spectrum of rufomycinSS 2 in $\mathrm{CD}_{3} \mathrm{OD}$...................................24

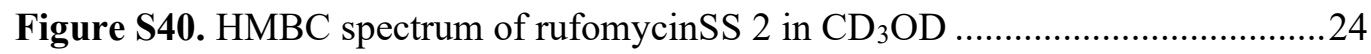

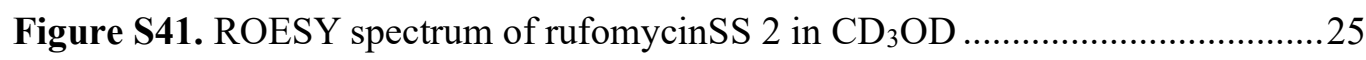

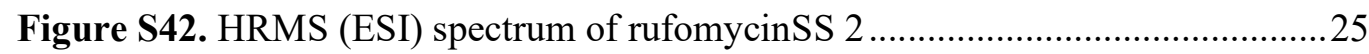

Figure S43. ${ }^{1} \mathrm{H}$ NMR spectrum of rufomycinSS 3 in $\mathrm{CD}_{3} \mathrm{OD}$ at $600 \mathrm{MHz}$...............26

Figure S44. ${ }^{13} \mathrm{C}$ NMR spectrum of rufomycinSS 3 in $\mathrm{CD}_{3} \mathrm{OD}$ at $150 \mathrm{MHz}$...............26

Figure S45. TOCSY NMR spectrum of rufomycinSS 3 in $\mathrm{CD}_{3} \mathrm{OD}$........................27

Figure S46. HSQC spectrum of rufomycinSS 3 in $\mathrm{CD}_{3} \mathrm{OD}$.................................27

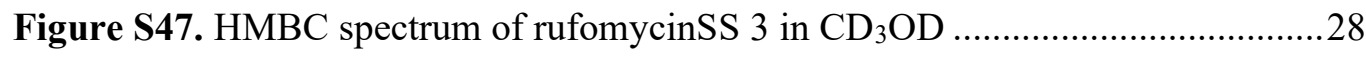

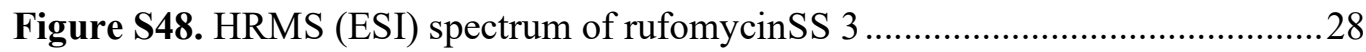

Figure S49. ROESY spectrum of rufomycinSS 3 in $\mathrm{CD}_{3} \mathrm{OD}$..................................29

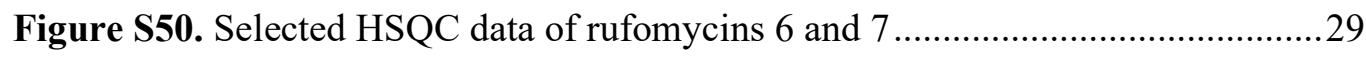

Figure S51. ${ }^{1} \mathrm{H}$ NMR spectrum of rufomycin 21 in $\mathrm{CD}_{3} \mathrm{OD}$ at $400 \mathrm{MHz}$..................30

Figure S52. ${ }^{13} \mathrm{C}$ NMR spectrum of rufomycin 21 in $\mathrm{CD}_{3} \mathrm{OD}$ at $100 \mathrm{MHz}$.................30

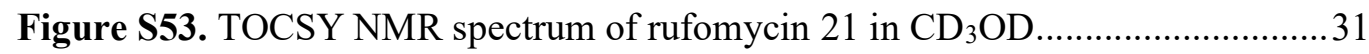

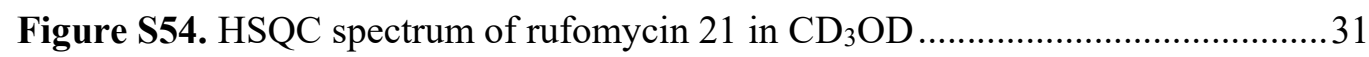

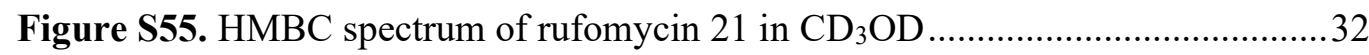

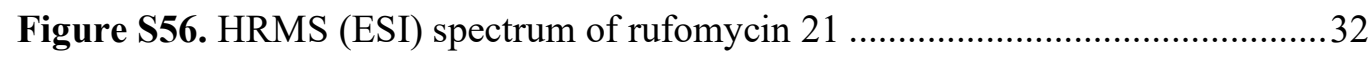

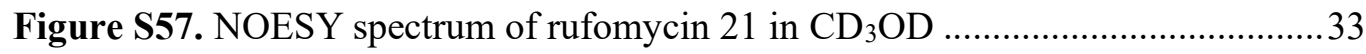

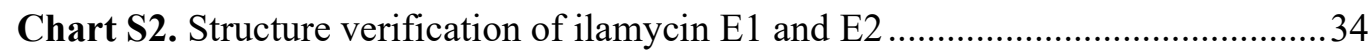

Figure S58. RufomycinSS 2 and 3 showed distinct conformers based on the ${ }^{13} \mathrm{C}$ NMR

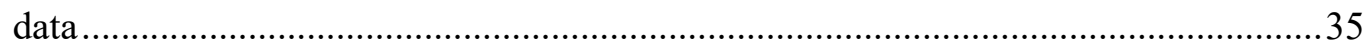


Chart S1. Clarification of rufomycin 4 and its related three diastereomers (rufomycins 5-7)

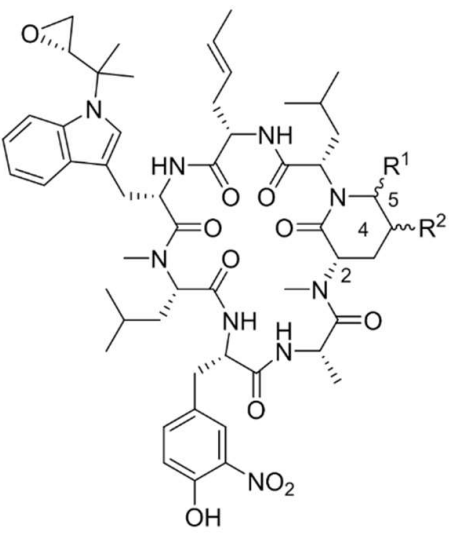

Rufomycin $4 \quad \mathrm{R}^{1}=\alpha-\mathrm{OH} ; \mathrm{R}^{2}=\beta-\mathrm{CH}_{3}$ Rufomycin $5 \quad \mathrm{R}^{1}=\beta-\mathrm{OH} ; \mathrm{R}^{2}=\beta-\mathrm{CH}_{3}$ Rufomycin $6 \quad \mathrm{R}^{1}=\alpha-\mathrm{OH} ; \mathrm{R}^{2}=\alpha-\mathrm{CH}_{3}$ Rufomycin $7 \quad \mathrm{R}^{1}=\beta-\mathrm{OH} ; \mathrm{R}^{2}=\alpha-\mathrm{CH}_{3}$

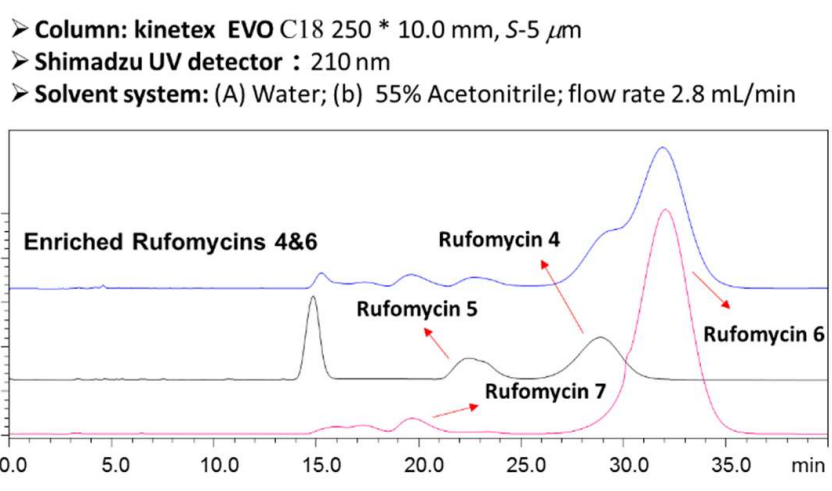

$\left.\begin{array}{l}\text { Rufomycin 4, same as Ilamycin } \mathrm{C}^{1} \\ \text { Rufomycin 5, same as Ilamycin } \mathrm{C} 2^{1}\end{array}\right]$ interchangable Rufomycin 6, same as RUF $\|^{2}$

Rufomycin 7, unreported interchangable

\section{References}

[1] Ma, J.; Huang, H.; Xie, Y.; Liu, Z.; Zhao, J.; Zhang, C.; Jia, Y.; Zhang, Y.; Zhang, H.; Zhang, $\mathrm{T}$.; Ju, J. Biosynthesis of ilamycins featuring unusual building blocks and engineered production of enhanced anti-tuberculosis agents. Nature communication 2017, 8, 1-10.

[2] Choules, M. P.; Wolf, N. M.; Lee, H.; Anderson, J. R.; Grzelak, E. M.; Wang, Y.; Ma, R.; Gao, W.; McAlpine, J. B.; Jin, Y. Y.; Cheng, J.; Lee, H.; Suh, J. W.; Duc, N. M.; Paik, S.; Choe, J. H.; Jo, E. K.; Chang, C. L.; Lee, J. S.; Jaki, B. U.; Pauli, G. F.; Franzblau, S. G.; Cho, S. rufomycin Targets ClpC1 Proteolysis in Mycobacterium tuberculosis and M. abscessus. Antimicrob Agents Chemother 2019, 63, e02204-e02218. 
Figure S1. ${ }^{1} \mathrm{H}$ NMR spectrum of rufomycin 4 in $\mathrm{CD}_{3} \mathrm{OD}$ at $600 \mathrm{MHz}$

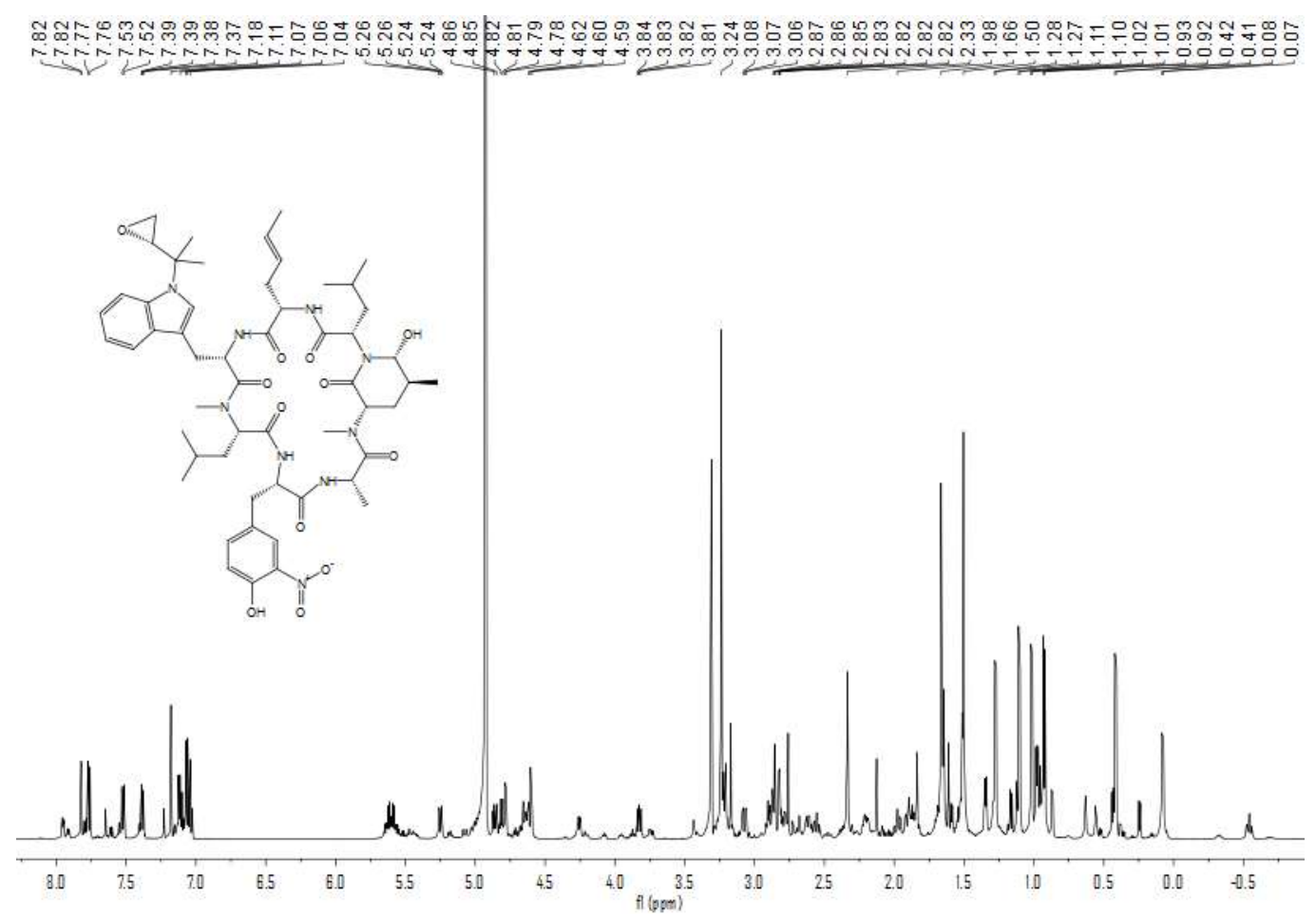

Figure S2. ${ }^{13} \mathrm{C}$ NMR spectrum of rufomycin 4 in $\mathrm{CD}_{3} \mathrm{OD}$ at $150 \mathrm{MHz}$

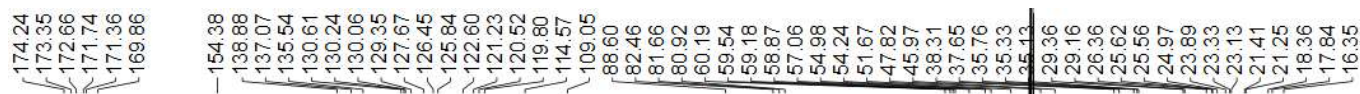
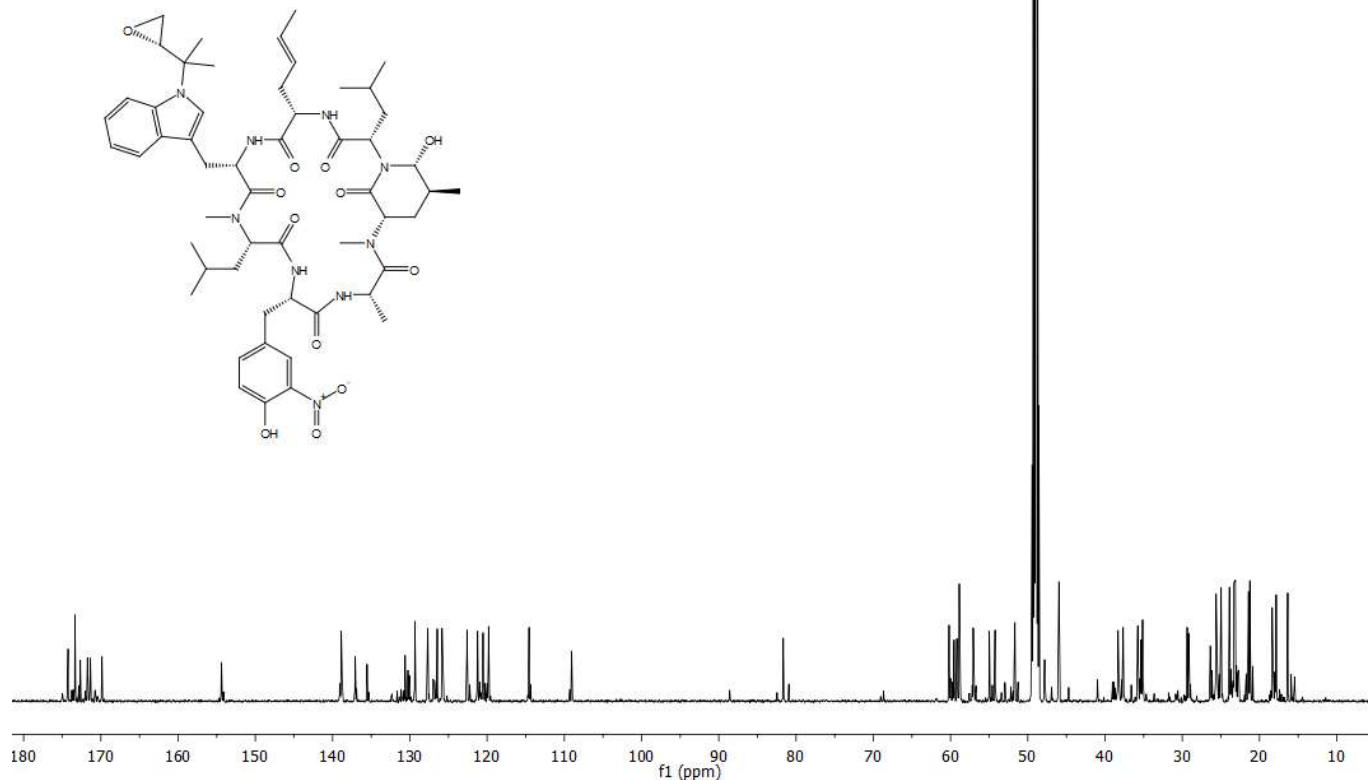
Figure S3. TOCSY spectrum of rufomycin 4 in $\mathrm{CD}_{3} \mathrm{OD}$

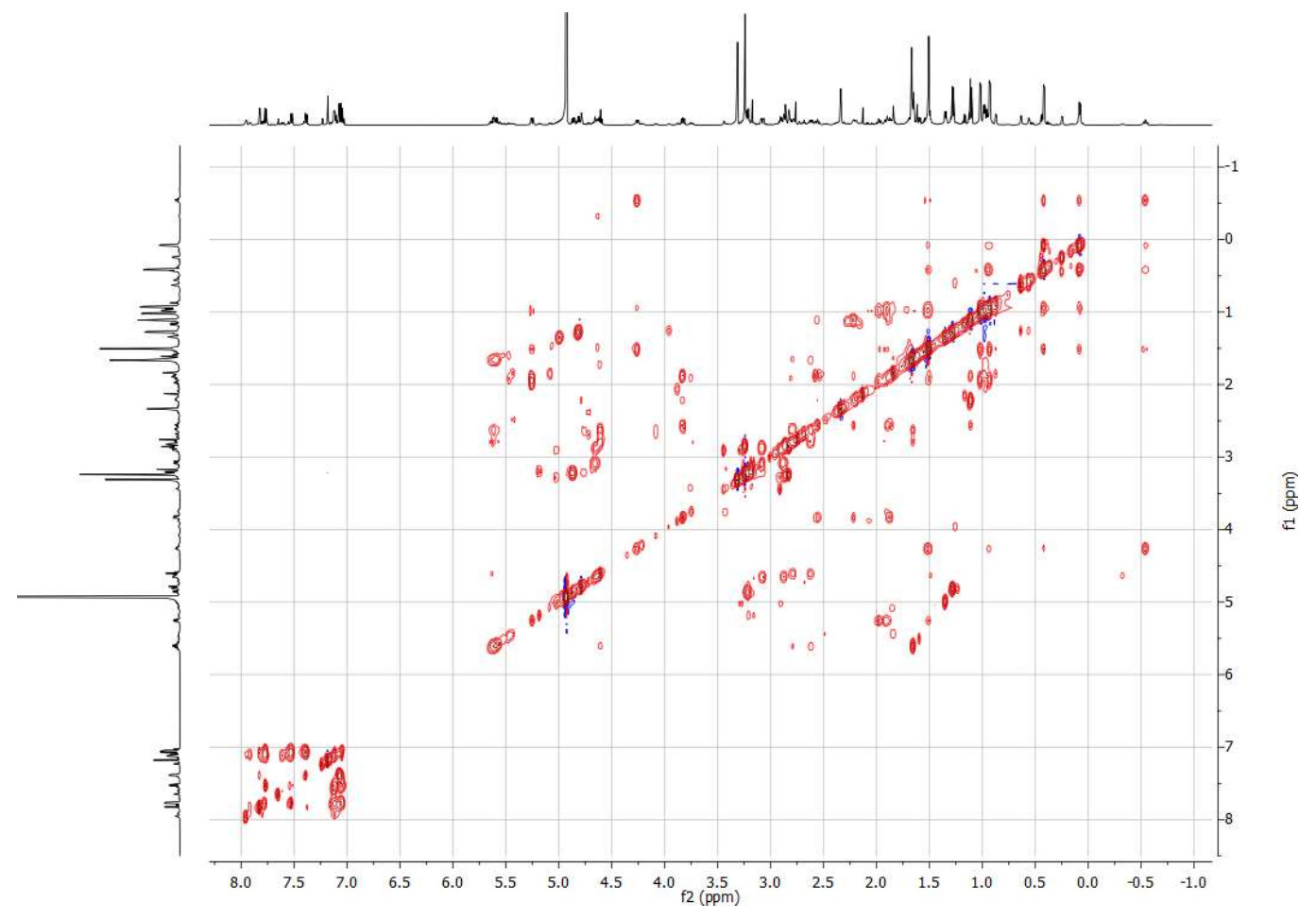

Figure S4. HSQC spectrum of rufomycin 4 in $\mathrm{CD}_{3} \mathrm{OD}$

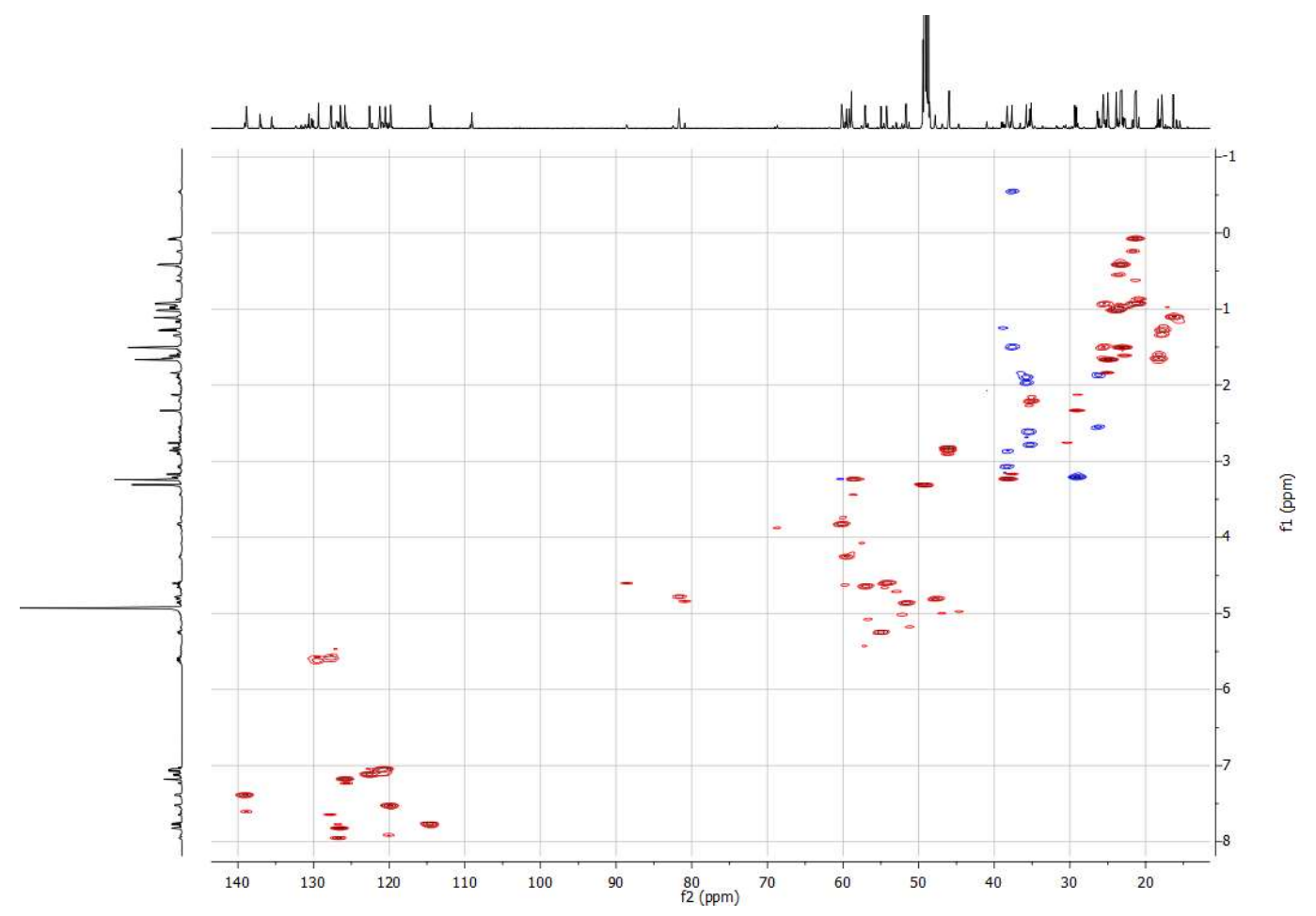


Figure S5. HMBC spectrum of rufomycin 4 in $\mathrm{CD}_{3} \mathrm{OD}$ at $\left(600 \mathrm{MHz},{ }^{1} \mathrm{H}\right)$

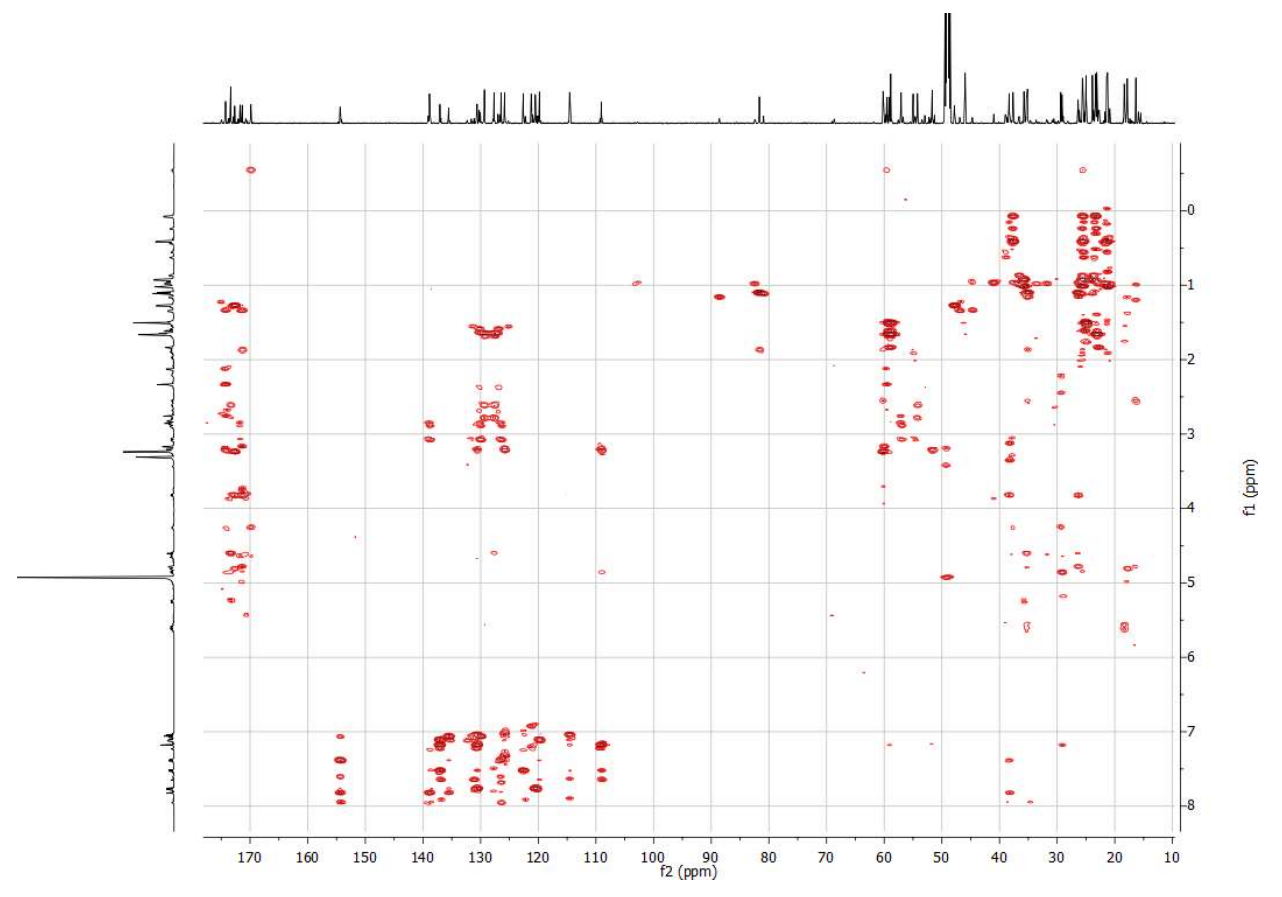

Figure S6. ROESY spectrum of rufomycin 4 in $\mathrm{CD}_{3} \mathrm{OD}$

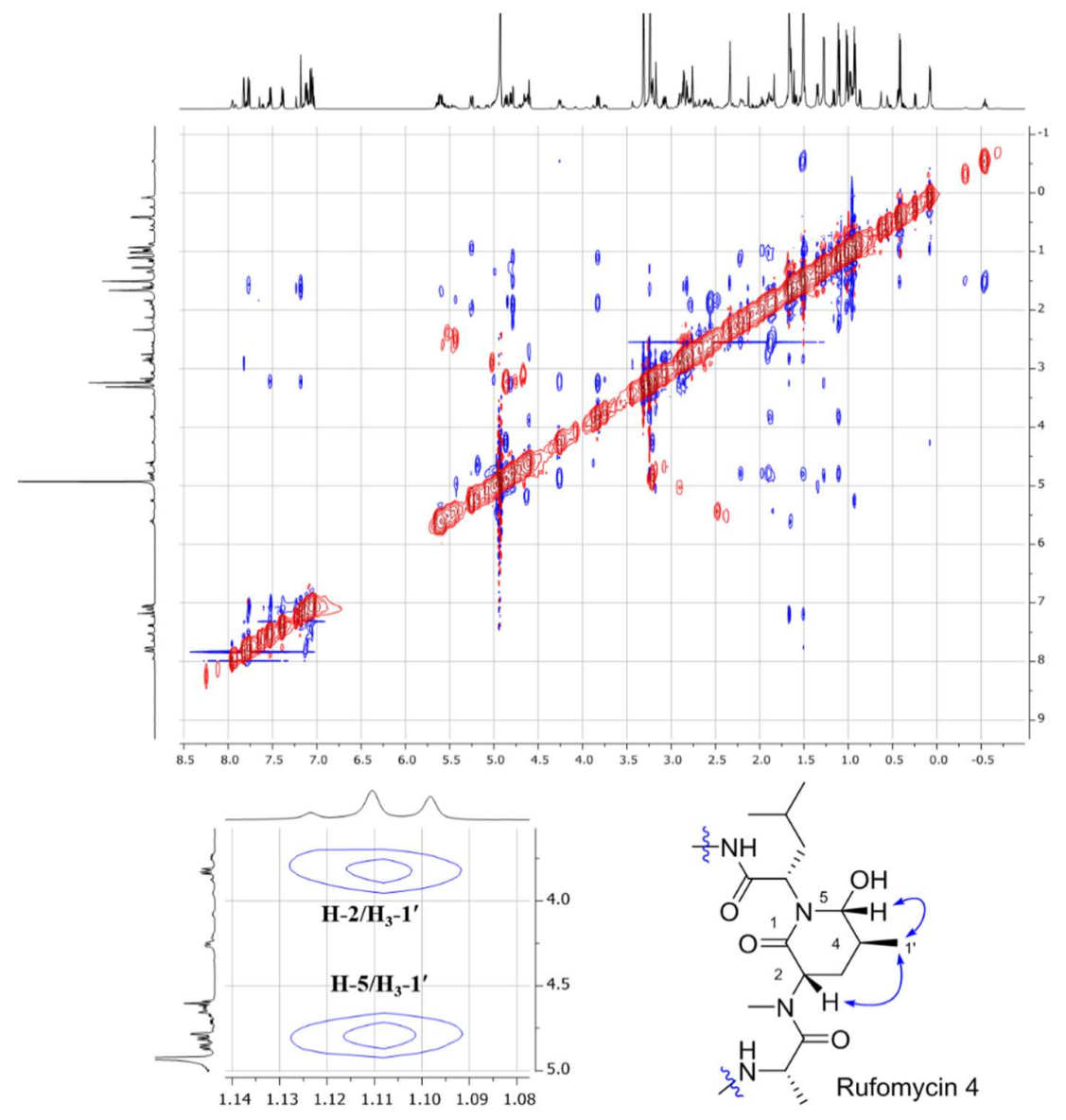


Figure S7. HRMS (ESI) spectrum of rufomycin 4

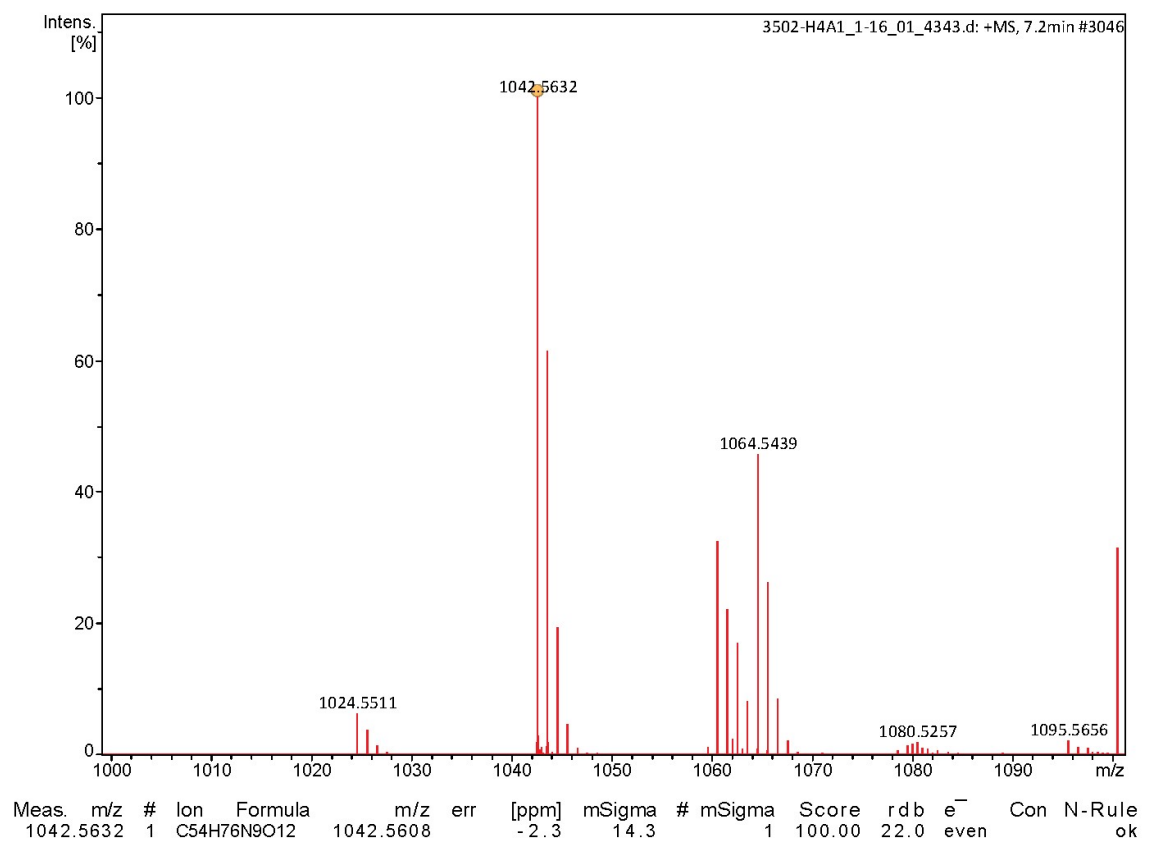

Figure S8. ${ }^{1} \mathrm{H}$ NMR spectrum of rufomycin 5 in $\mathrm{CD}_{3} \mathrm{OD}$ at $600 \mathrm{MHz}$

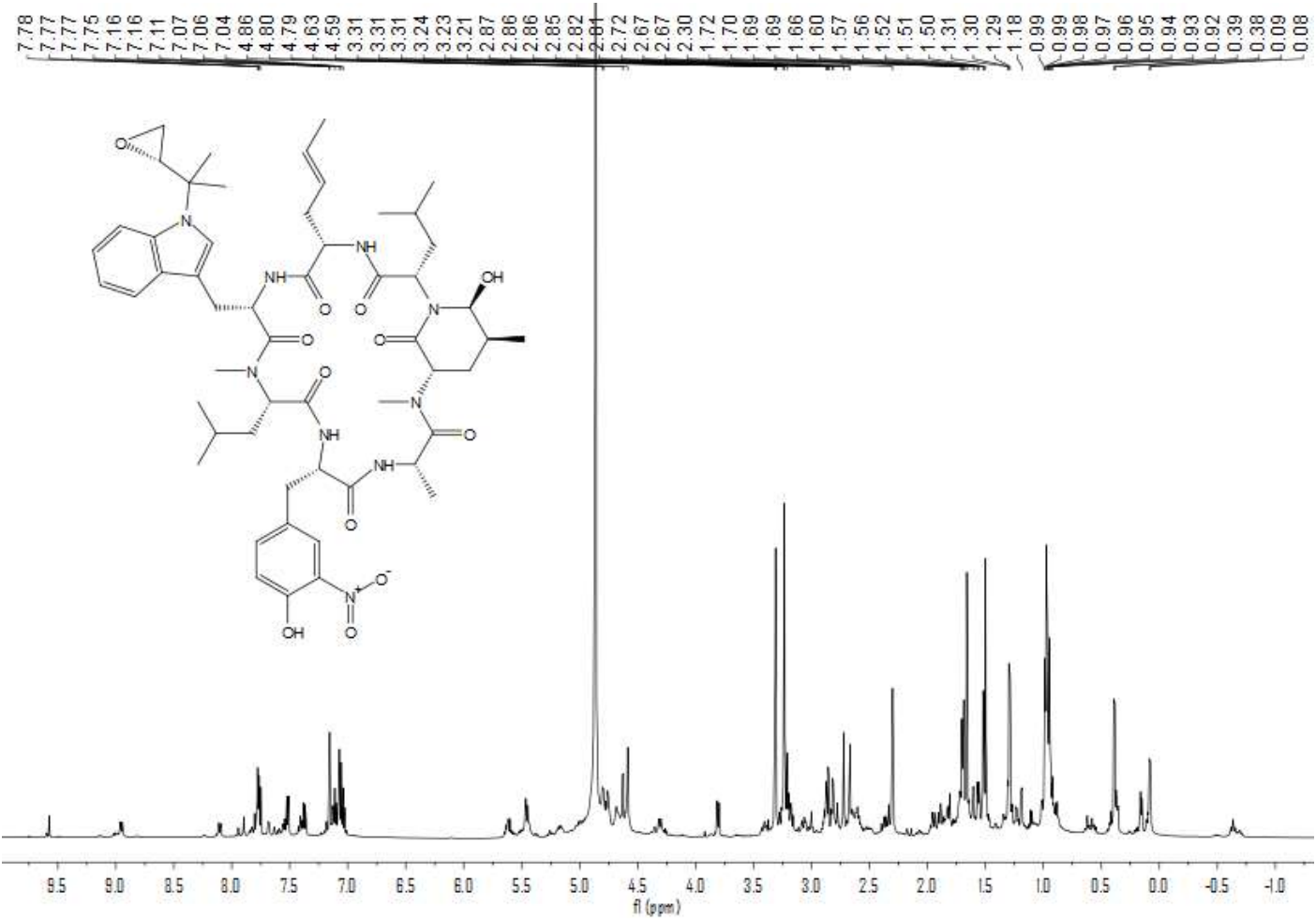


Figure S9. ${ }^{13} \mathrm{C}$ NMR spectrum of rufomycin 5 in $\mathrm{CD}_{3} \mathrm{OD}$ at $150 \mathrm{MHz}$
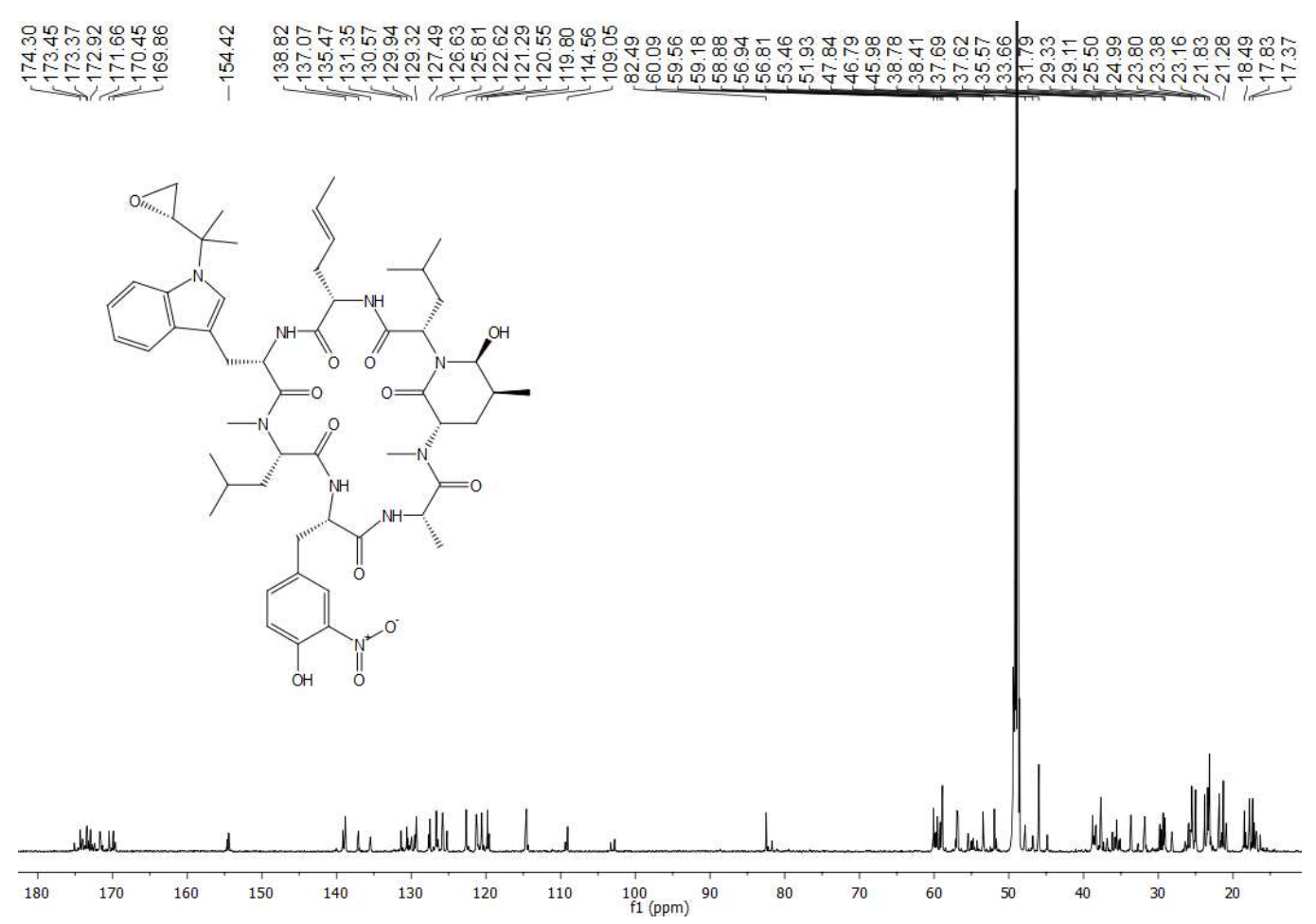

Figure S10. TOCSY spectrum of rufomycin 5 in $\mathrm{CD}_{3} \mathrm{OD}(400 \mathrm{MHz})$

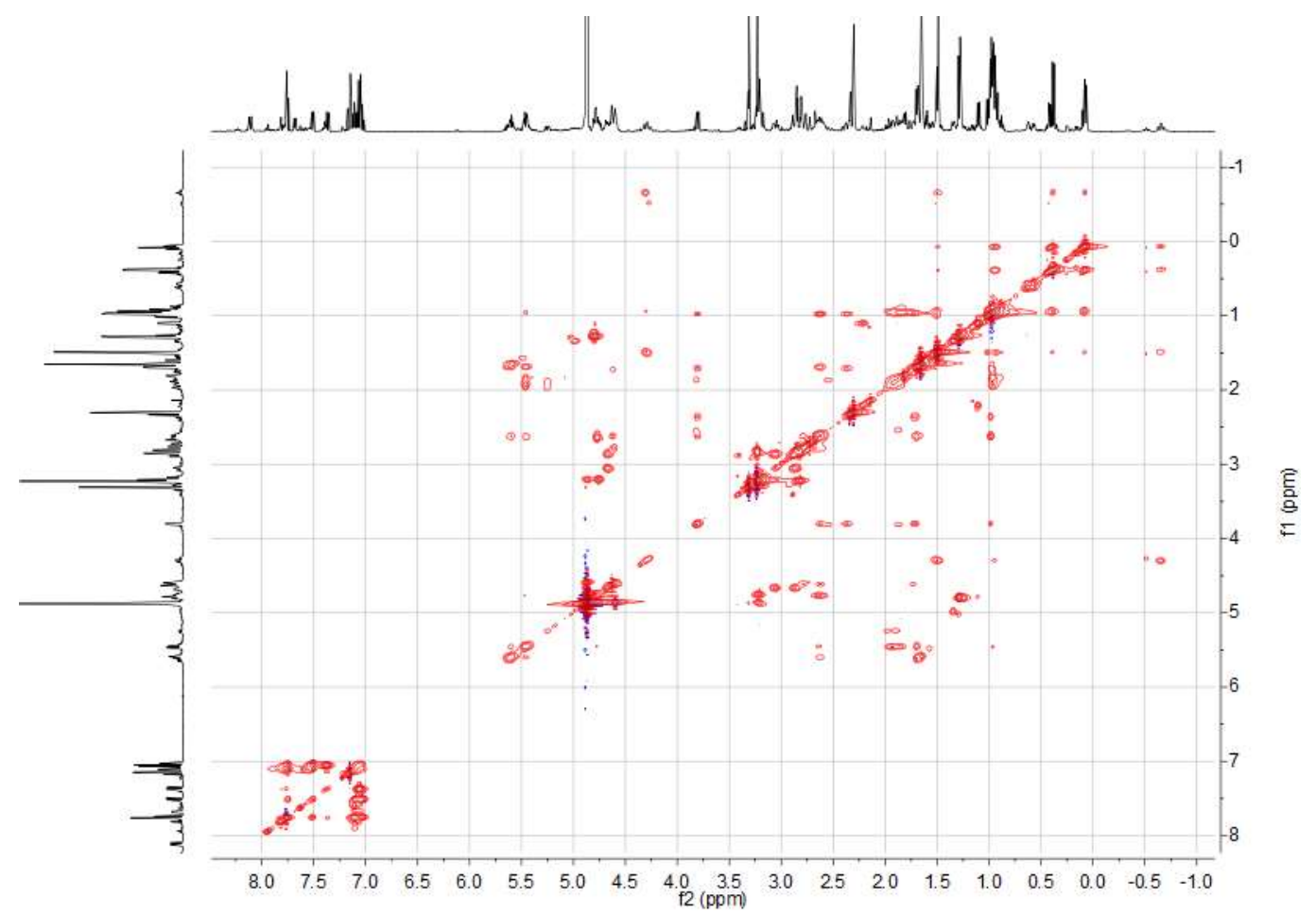


Figure S11. HSQC spectrum of rufomycin 5 in $\mathrm{CD}_{3} \mathrm{OD}$

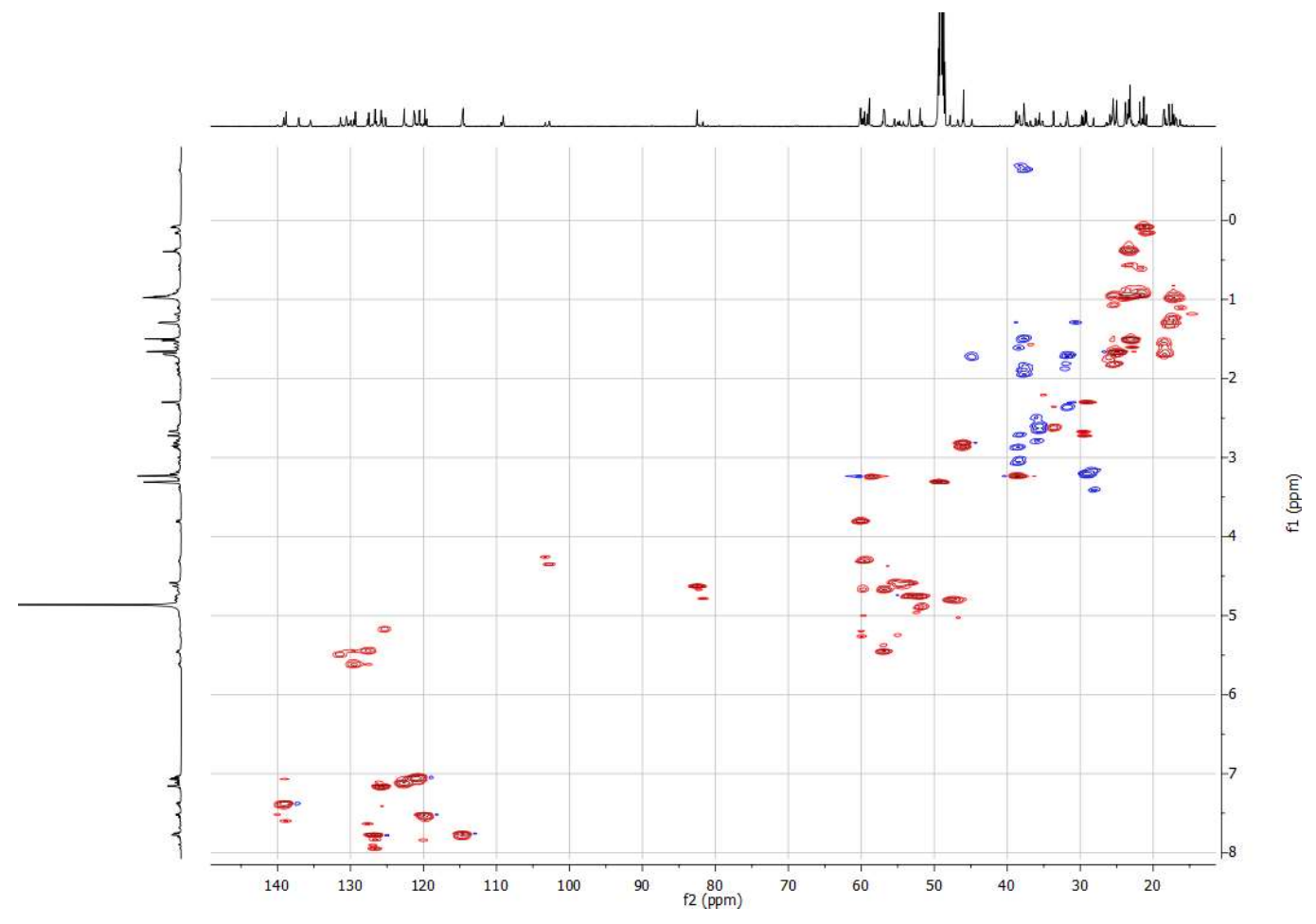

Figure S12. HMBC spectrum of rufomycin 5 in $\mathrm{CD}_{3} \mathrm{OD}\left(400 \mathrm{MHz},{ }^{1} \mathrm{H}\right)$

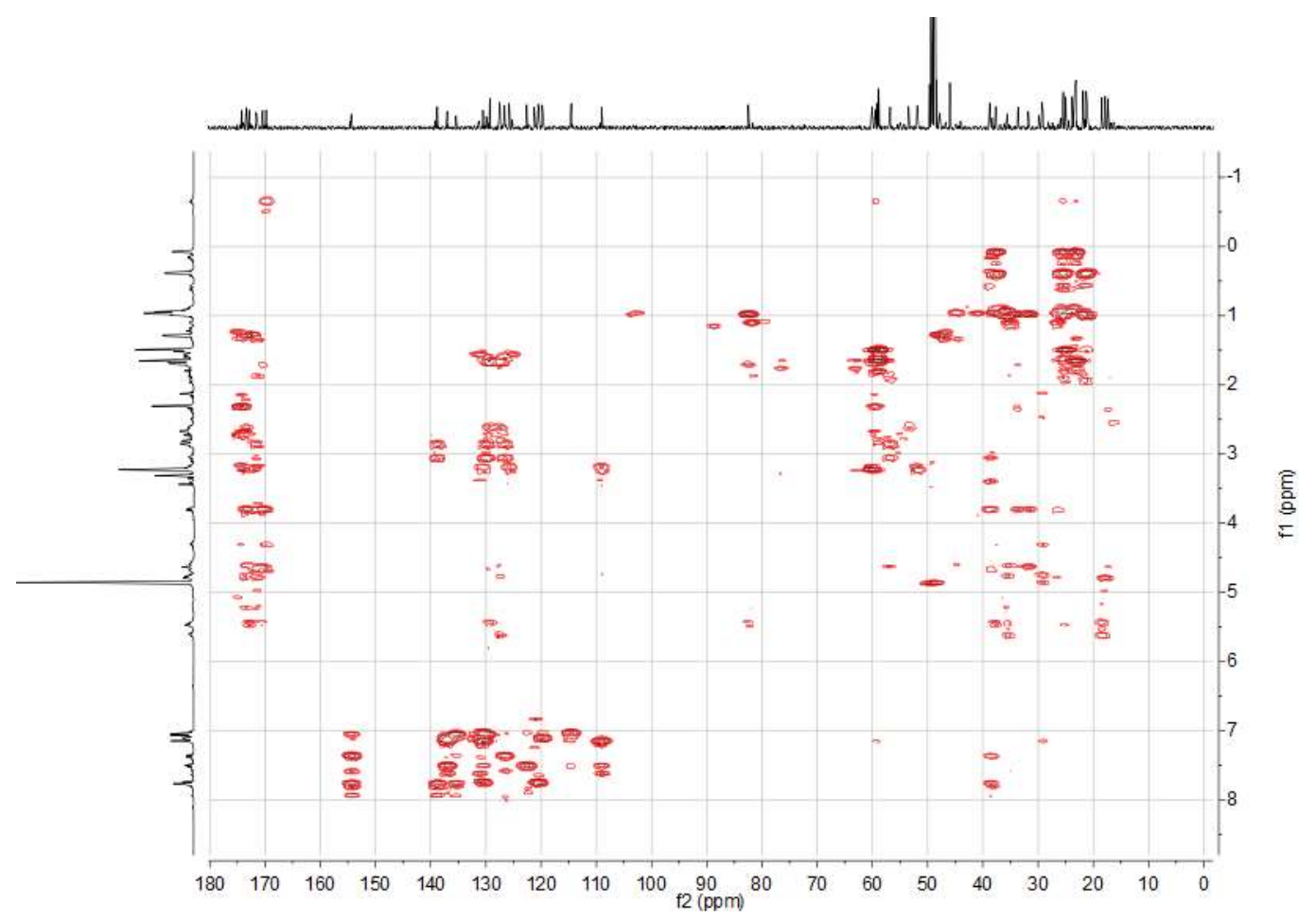


Figure S13. ROESY spectrum of rufomycin 5 in $\mathrm{CD}_{3} \mathrm{OD}$

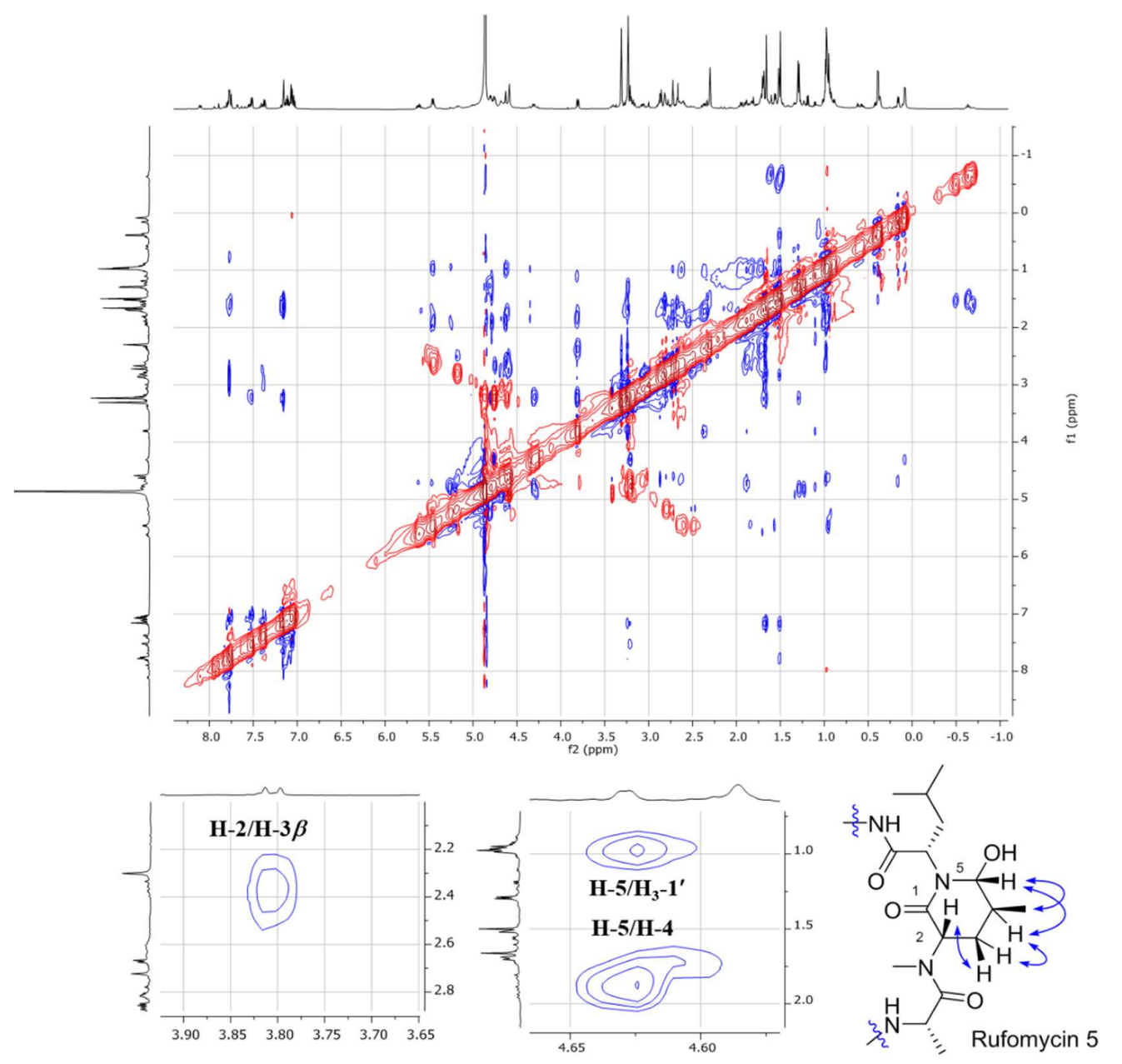

Figure S14. HRMS (ESI) spectrum of rufomycin 5

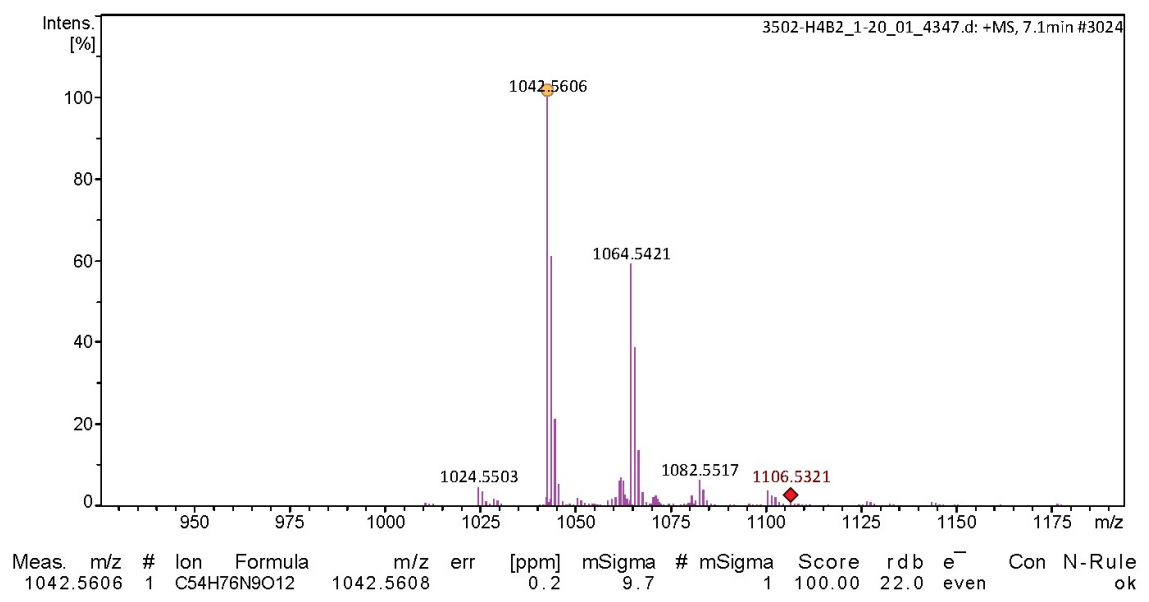


Figure S15. ${ }^{1} \mathrm{H}$ NMR spectrum of rufomycin 6 in $\mathrm{CD}_{3} \mathrm{OD}$ at $600 \mathrm{MHz}$

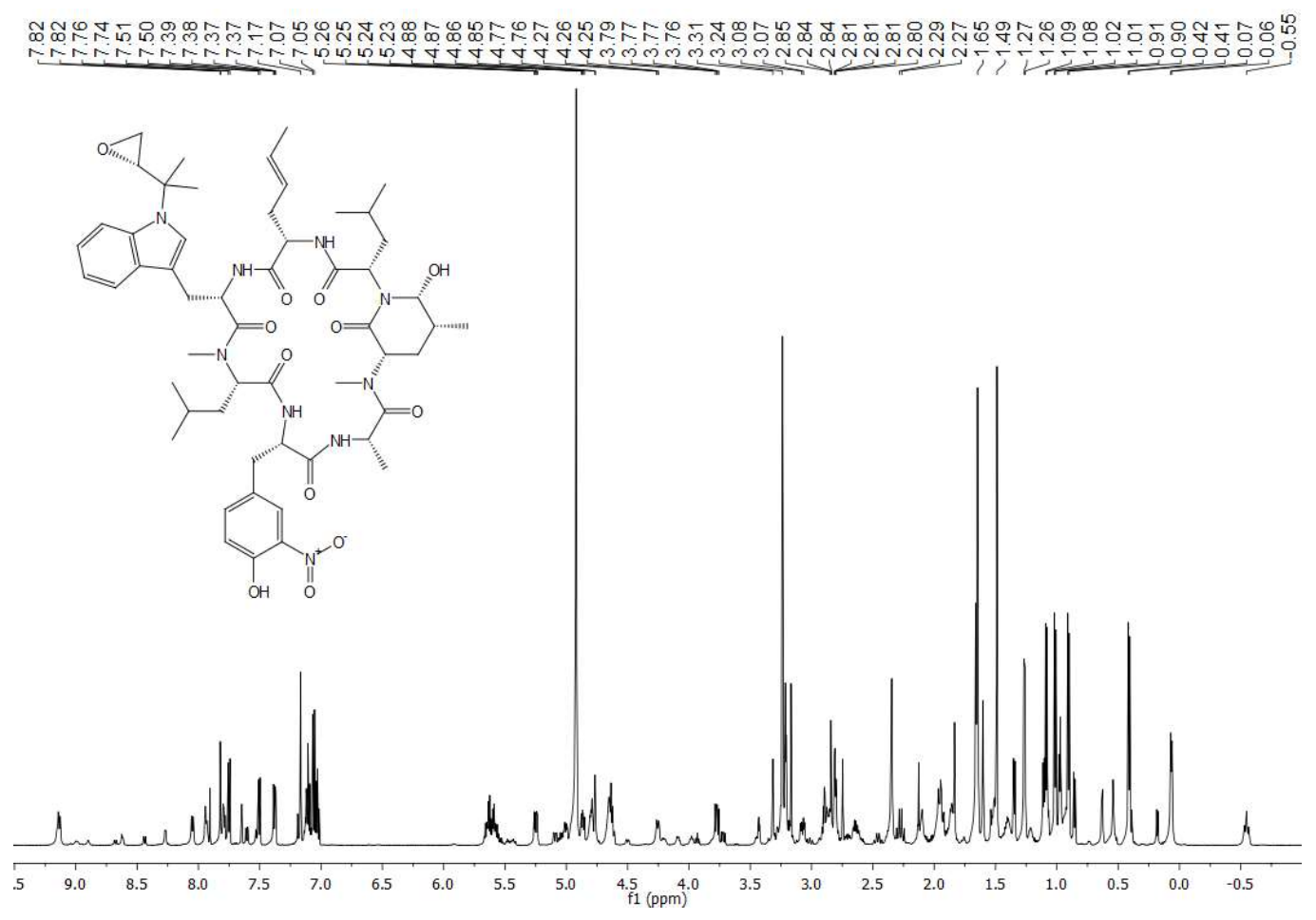

Figure S16. ${ }^{13} \mathrm{C}$ NMR spectrum of rufomycin 6 in $\mathrm{CD}_{3} \mathrm{OD}$ at $150 \mathrm{MHz}$
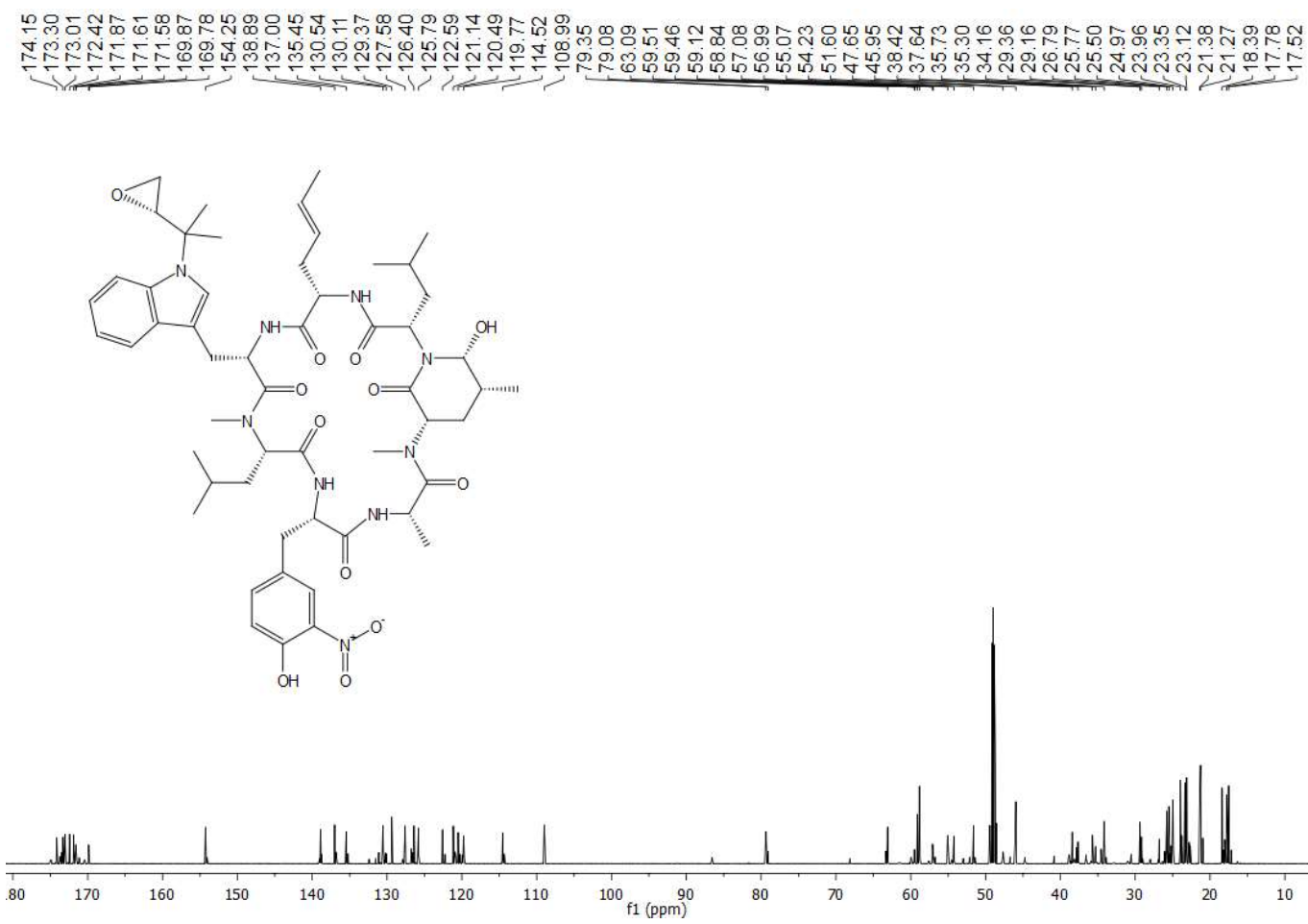
Figure S17. TOCSY spectrum of rufomycin 6 in $\mathrm{CD}_{3} \mathrm{OD}$

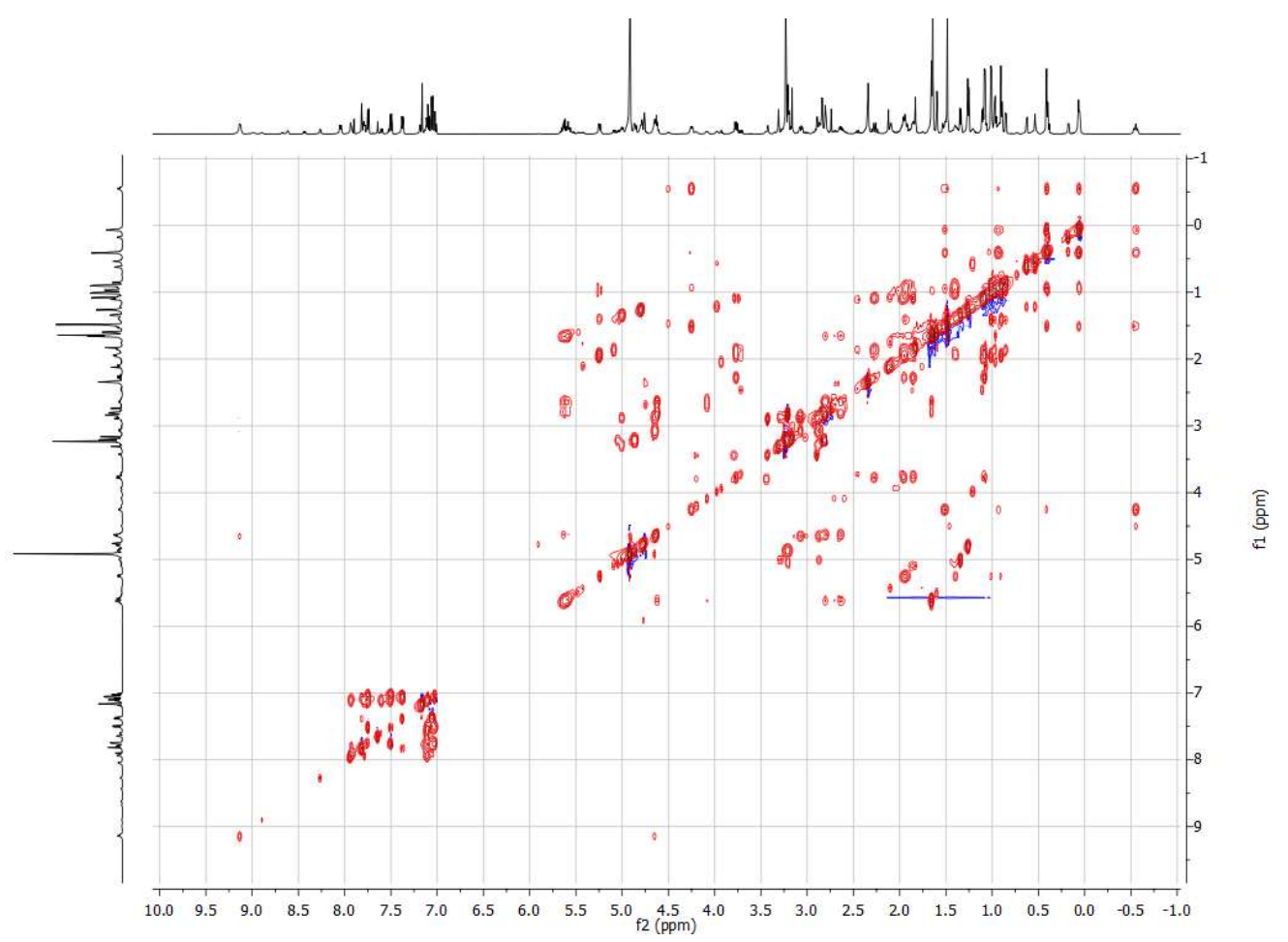

Figure S18. HSQC spectrum of rufomycin 6 in $\mathrm{CD}_{3} \mathrm{OD}$

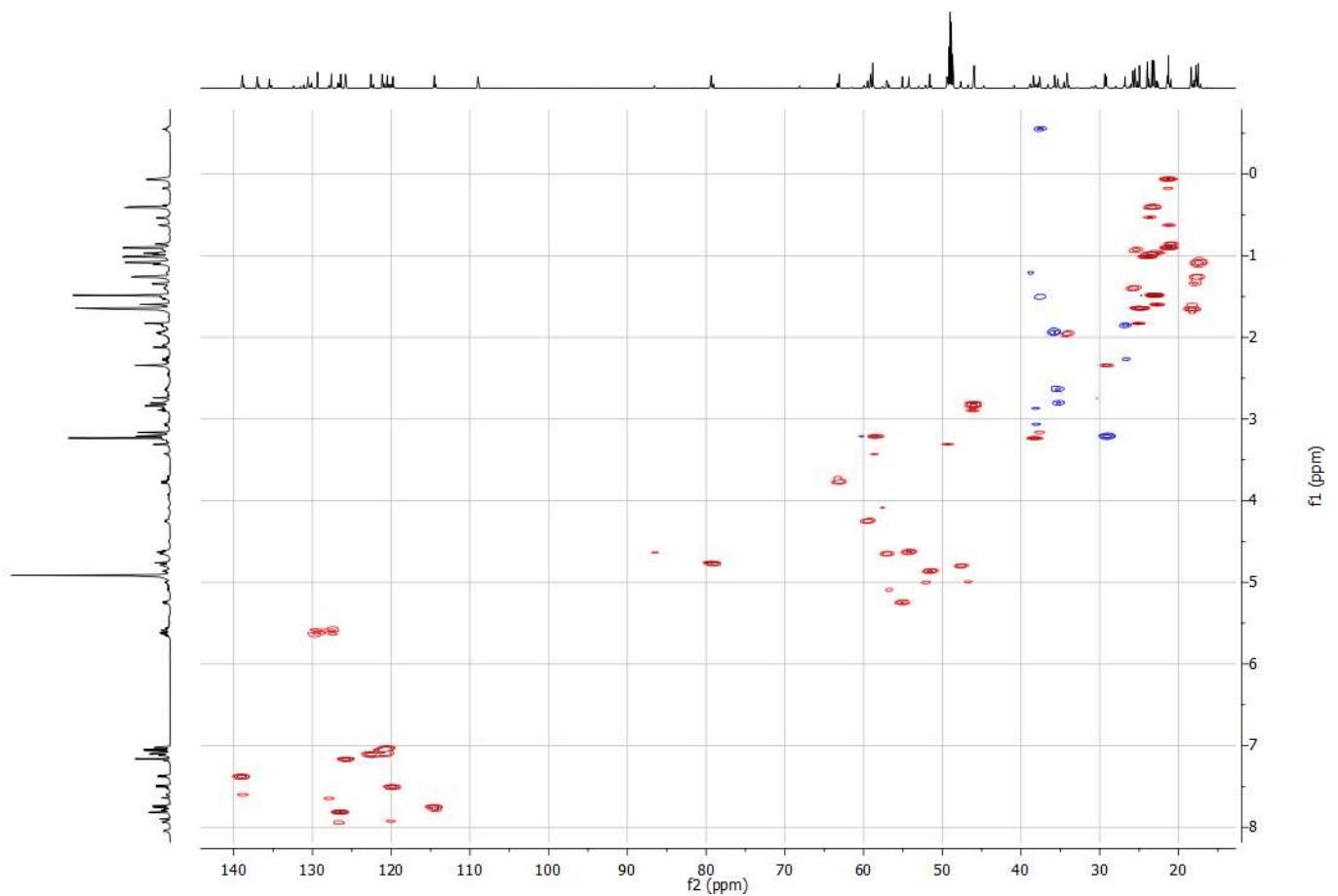


Figure S19. HMBC spectrum of rufomycin 6 in $\mathrm{CD}_{3} \mathrm{OD}$

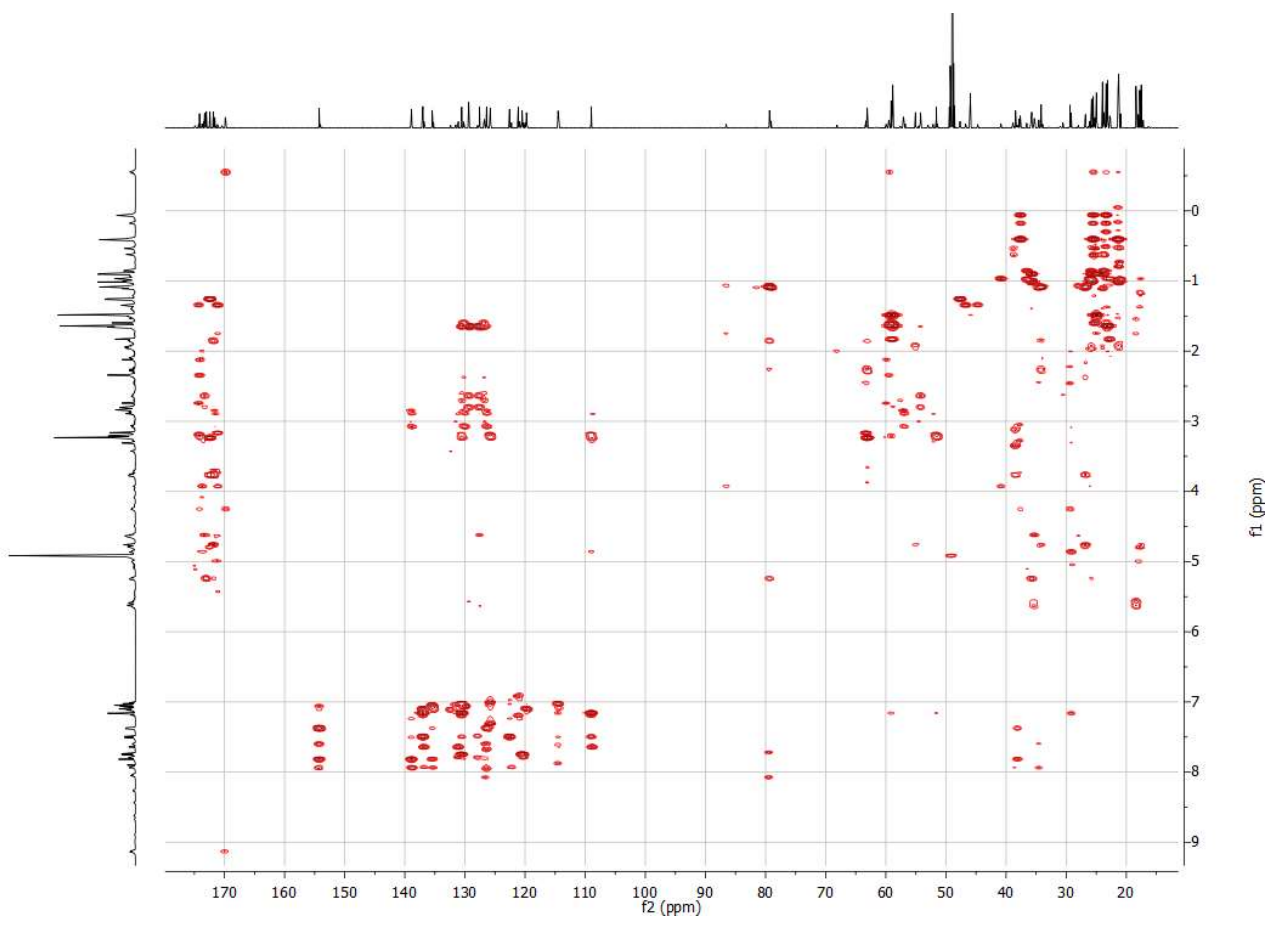

Figure S20. ROESY spectrum of rufomycin 6 in $\mathrm{CD}_{3} \mathrm{OD}$

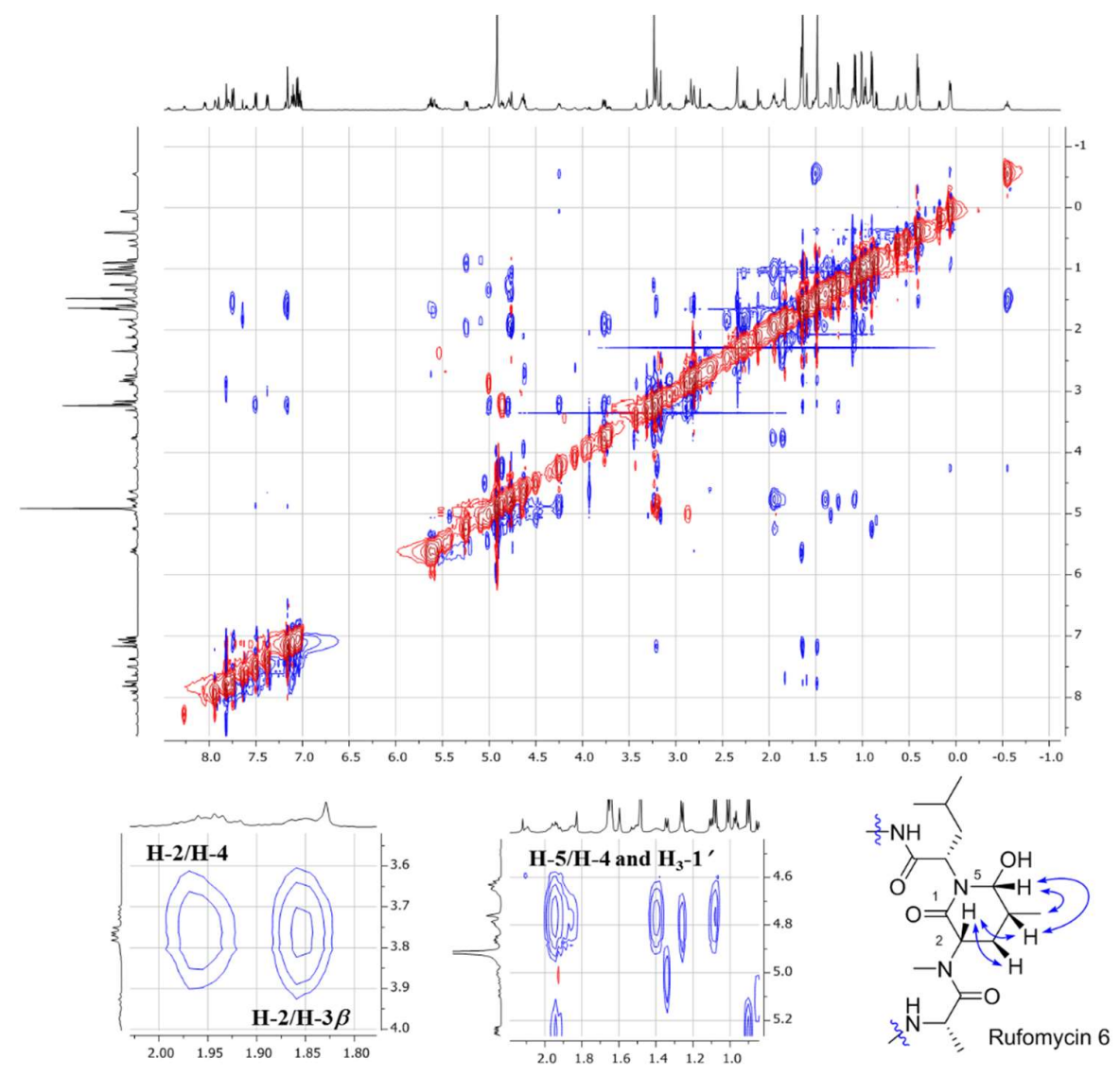


Figure S21. HRMS (ESI) spectrum of rufomycin 6

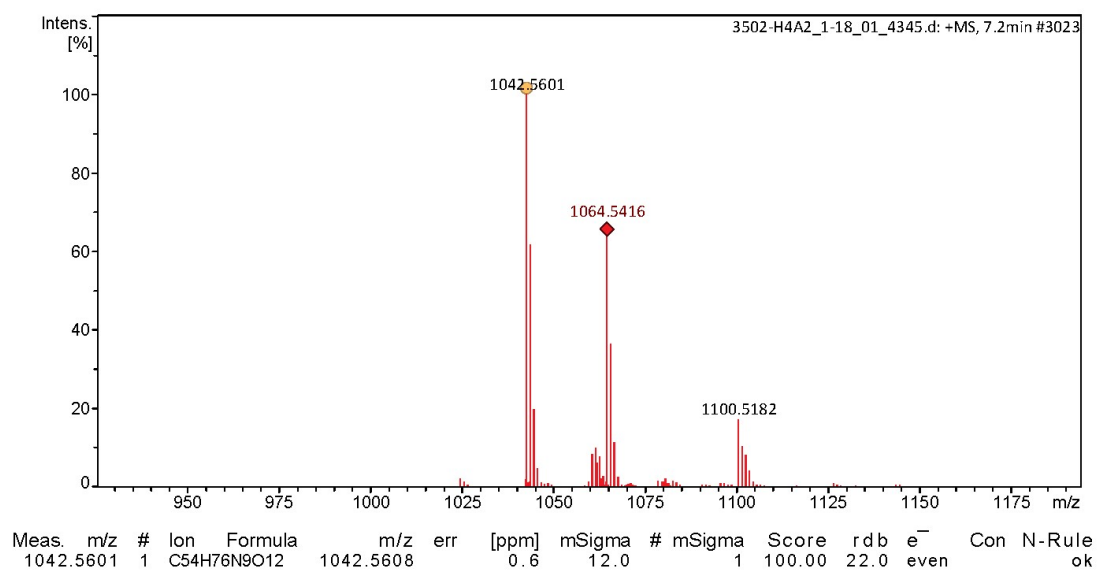

Figure S22. ${ }^{1} \mathrm{H}$ NMR spectrum of rufomycin 7 in $\mathrm{CD}_{3} \mathrm{OD}$ at $600 \mathrm{MHz}$

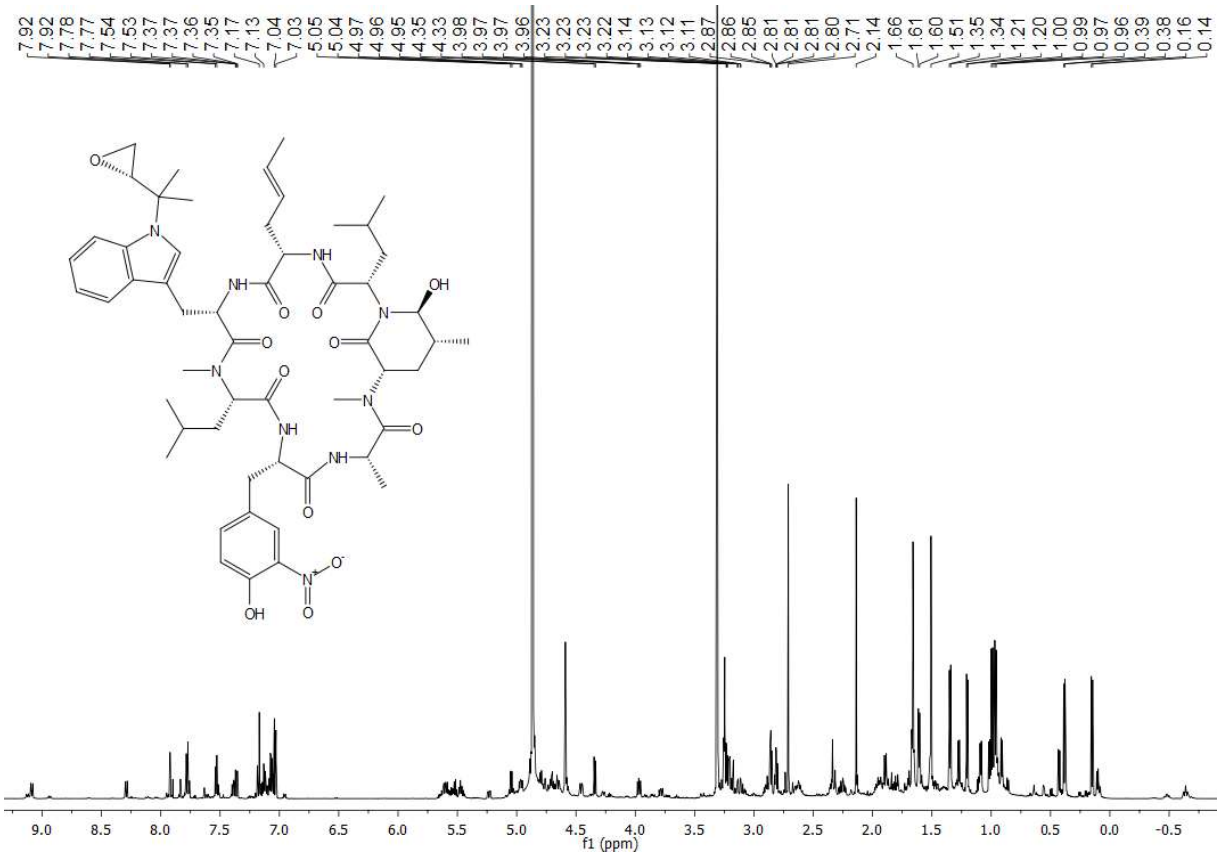

Figure S22-1. Selected ${ }^{1} \mathrm{H}$ NMR peak of rufomycin 7

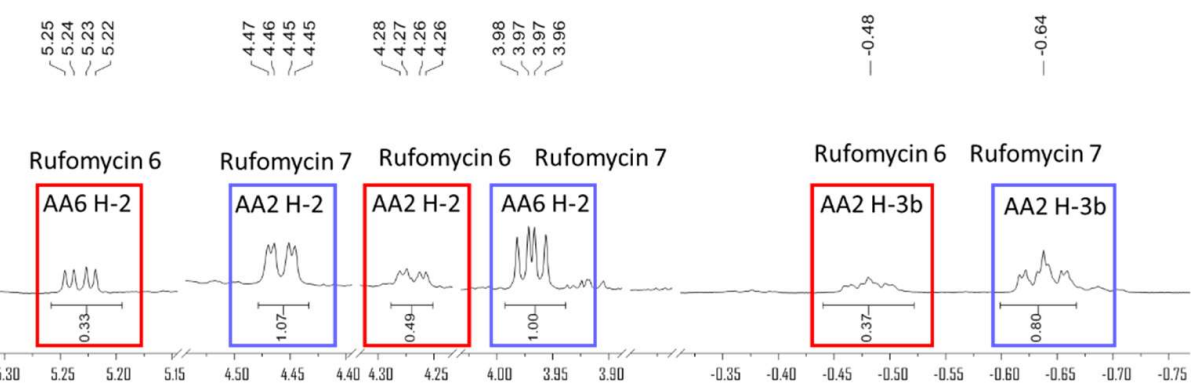


Figure S23. ${ }^{13} \mathrm{C}$ NMR spectrum of rufomycin 7 in $\mathrm{CD}_{3} \mathrm{OD}$ at $150 \mathrm{MHz}$

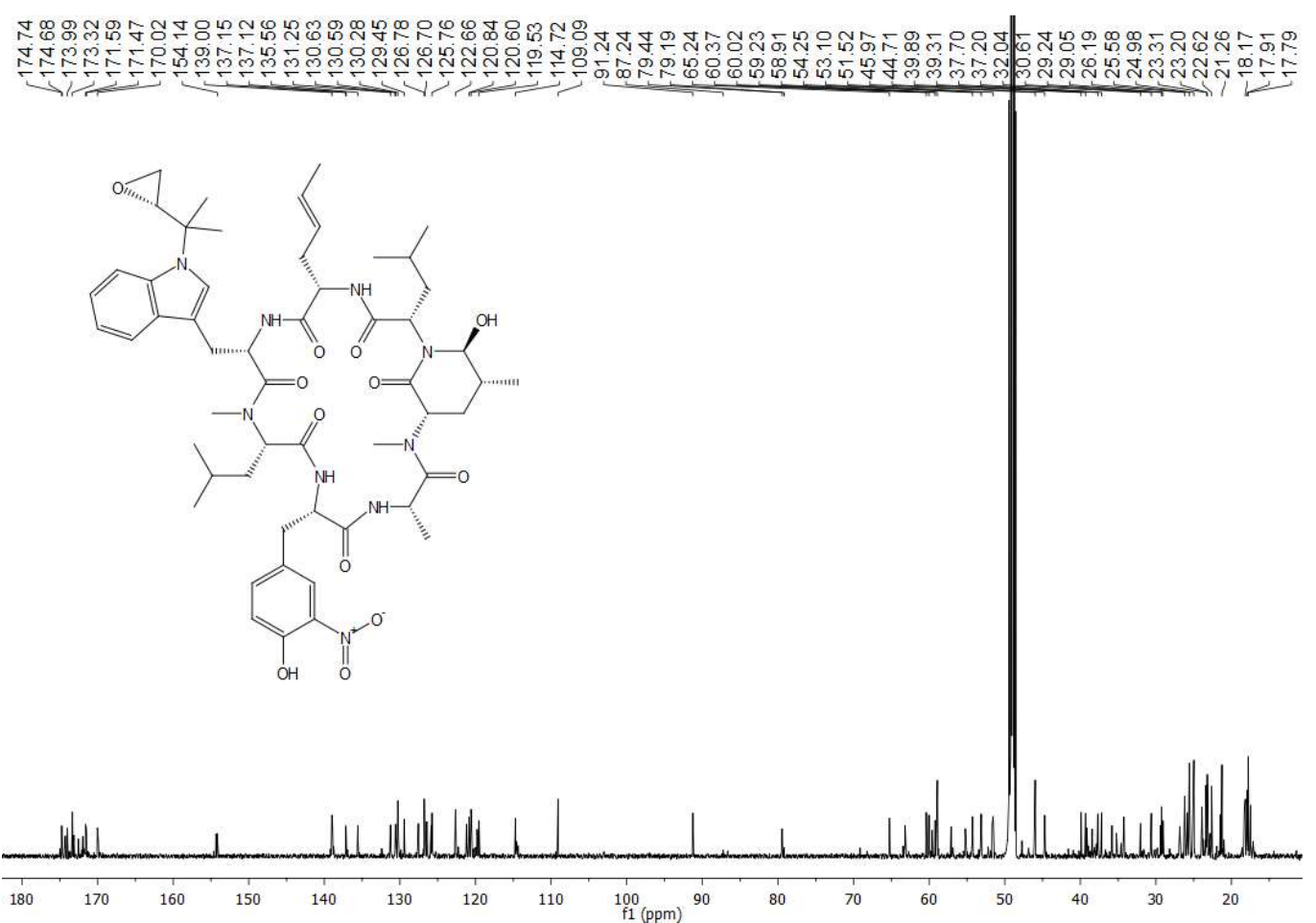

Figure S24. TOCSY spectrum of rufomycin 7 in $\mathrm{CD}_{3} \mathrm{OD}(400 \mathrm{MHz})$

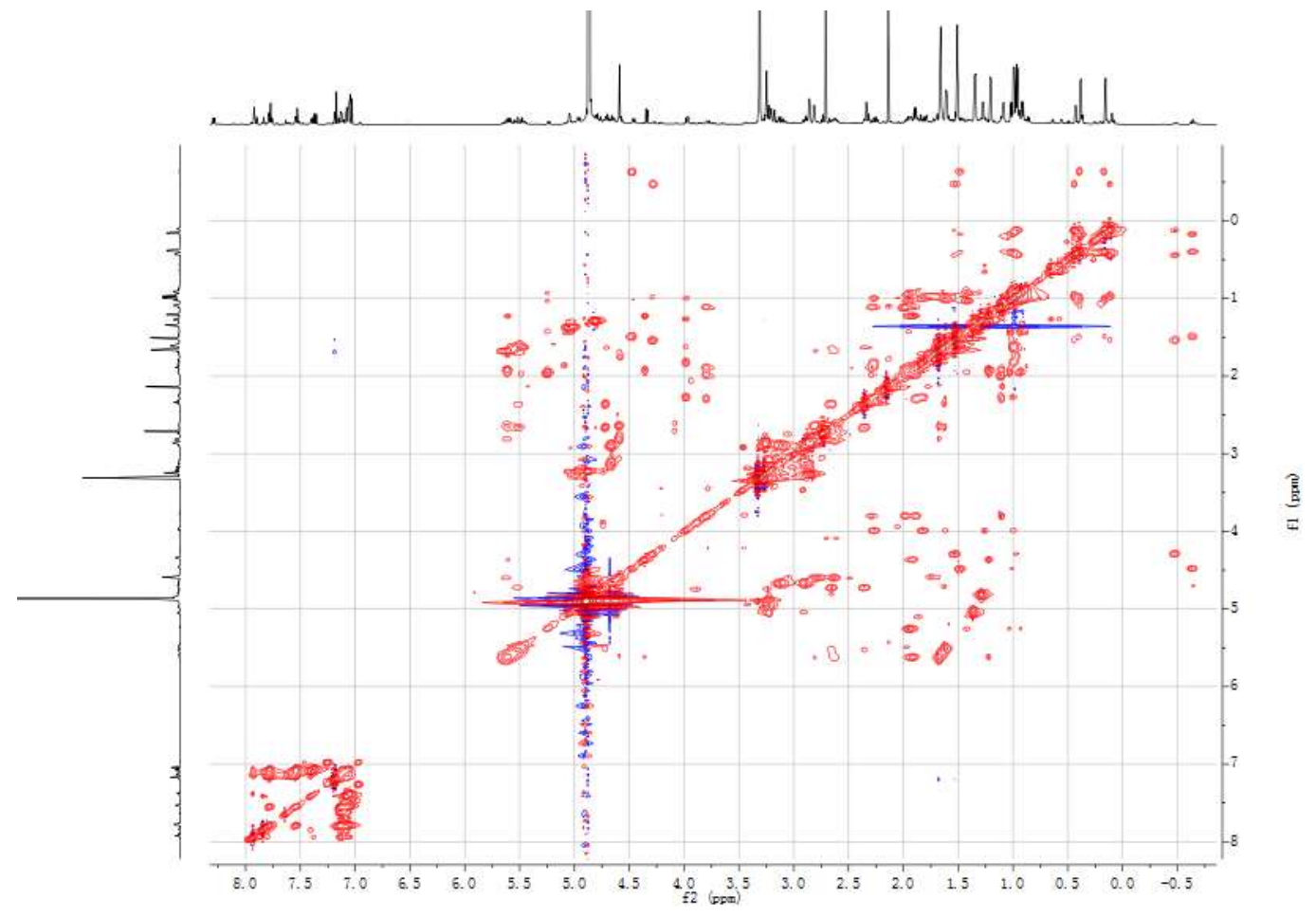


Figure S25. HSQC spectrum of rufomycin 7 in $\mathrm{CD}_{3} \mathrm{OD}\left(400 \mathrm{MHz},{ }^{1} \mathrm{H}\right)$

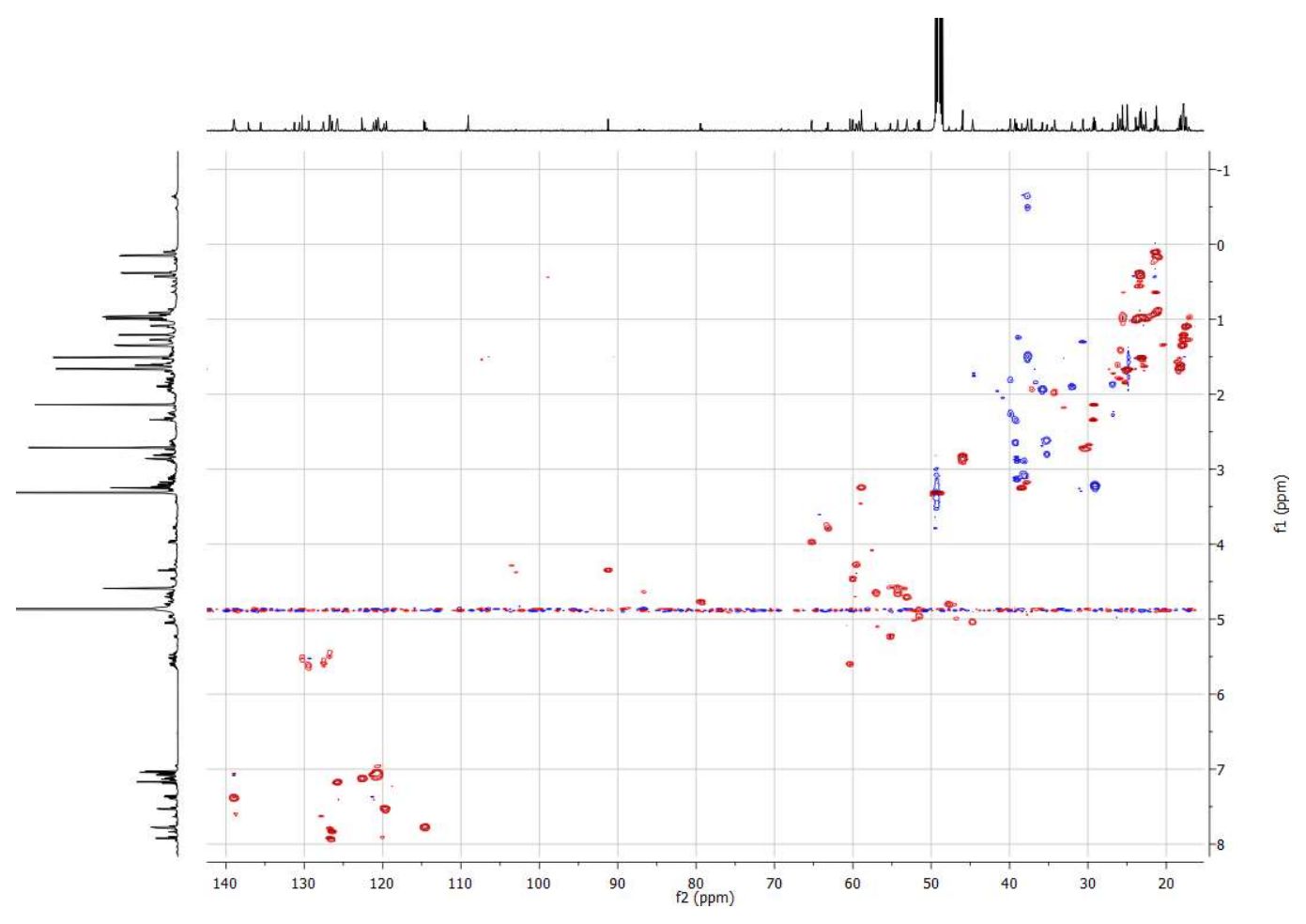

Figure S26. $\mathrm{HMBC}$ spectrum of rufomycin 7 in $\mathrm{CD}_{3} \mathrm{OD}\left(400 \mathrm{MHz},{ }^{1} \mathrm{H}\right)$

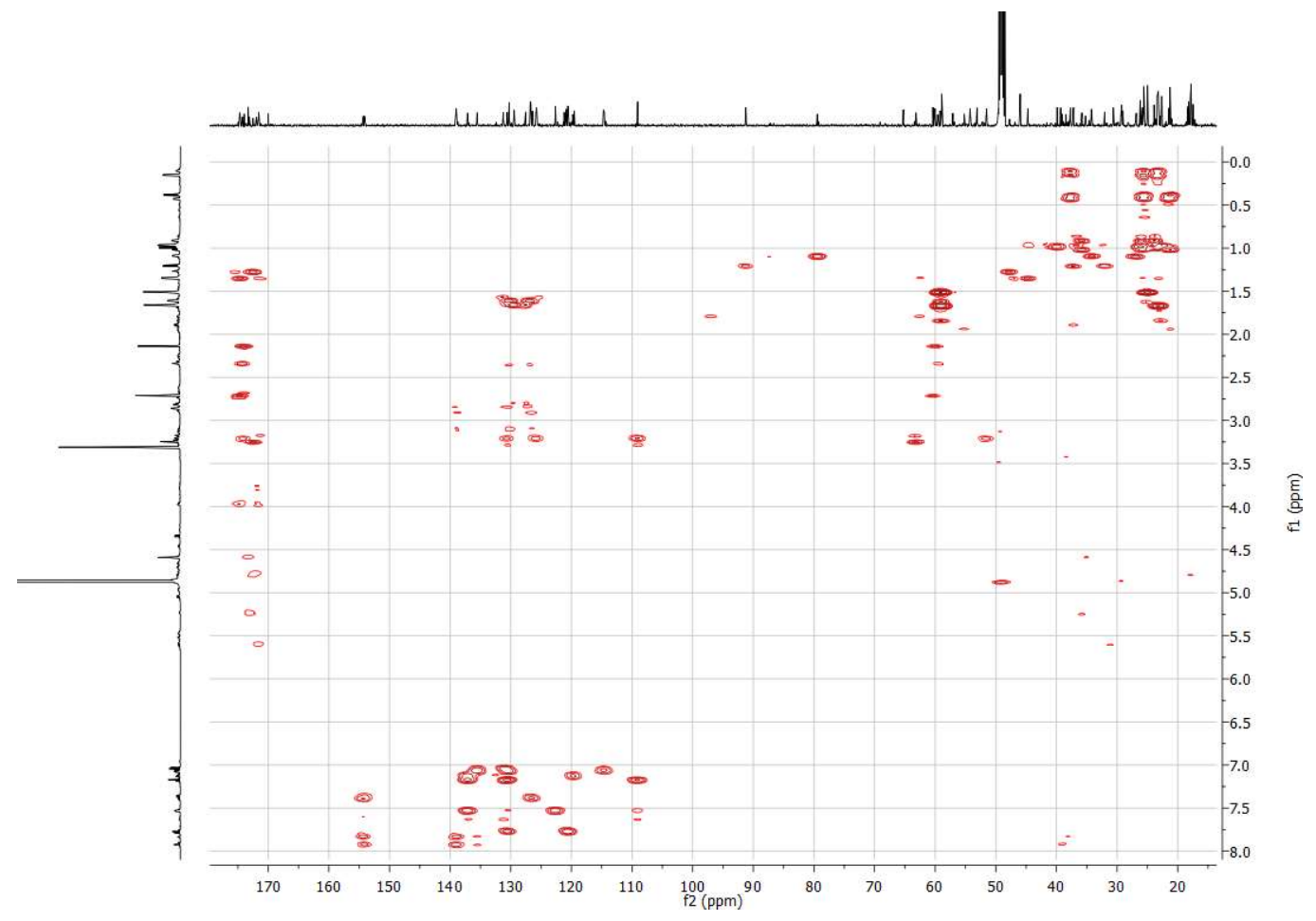


Figure S27. ROESY spectrum of rufomycin 7 in $\mathrm{CD}_{3} \mathrm{OD}$

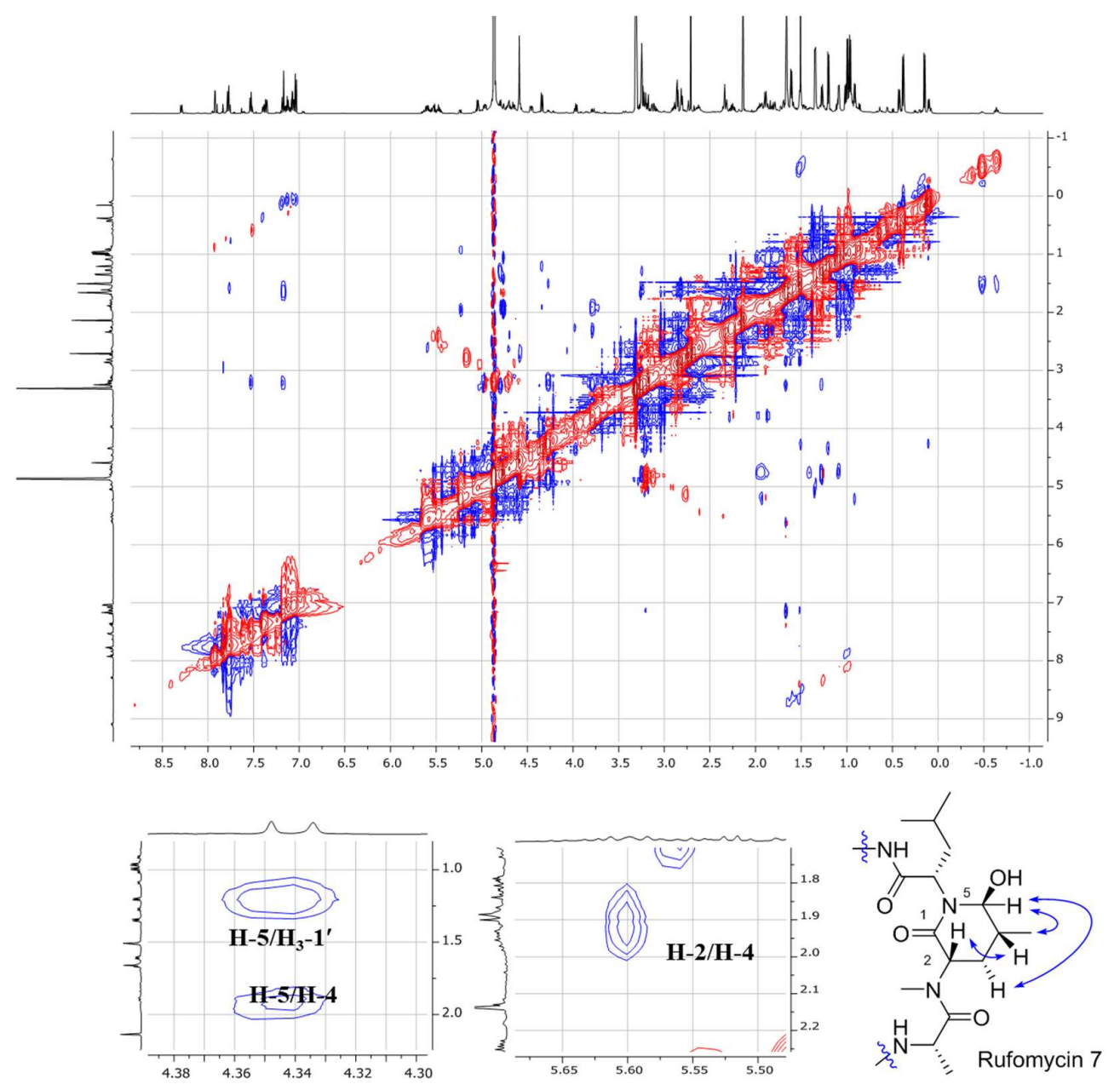

Figure S28. HRMS (ESI) spectrum of rufomycin 7

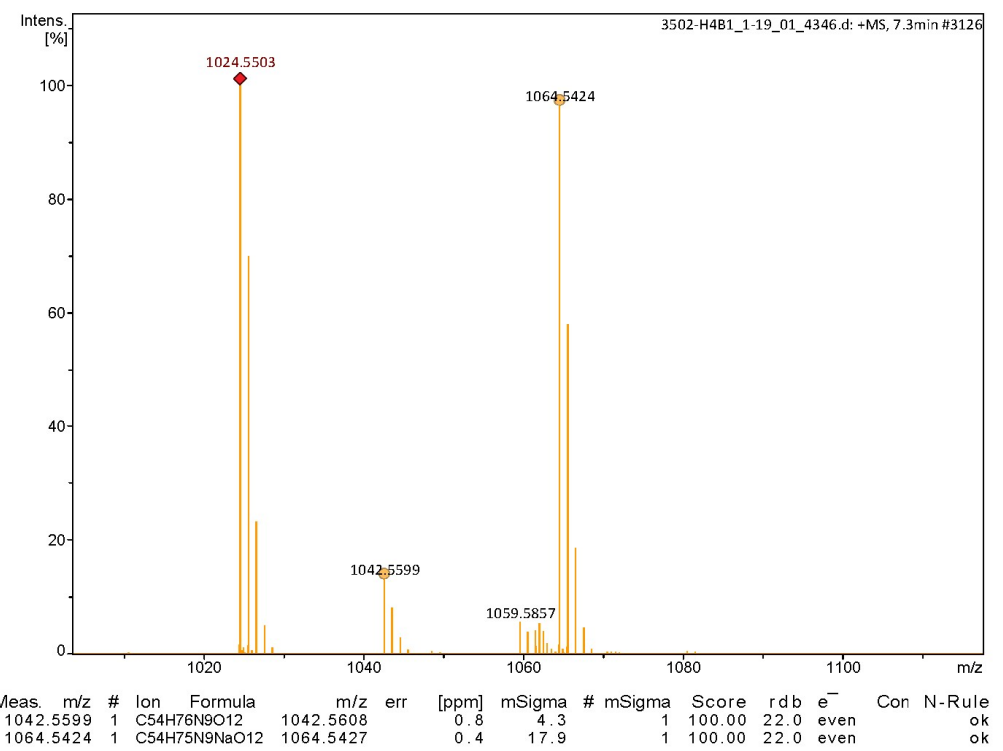


Figure S29. ${ }^{1} \mathrm{H}$ NMR spectrum of rufomycinSS 1 in $\mathrm{CD}_{3} \mathrm{OD}$ at $600 \mathrm{MHz}$

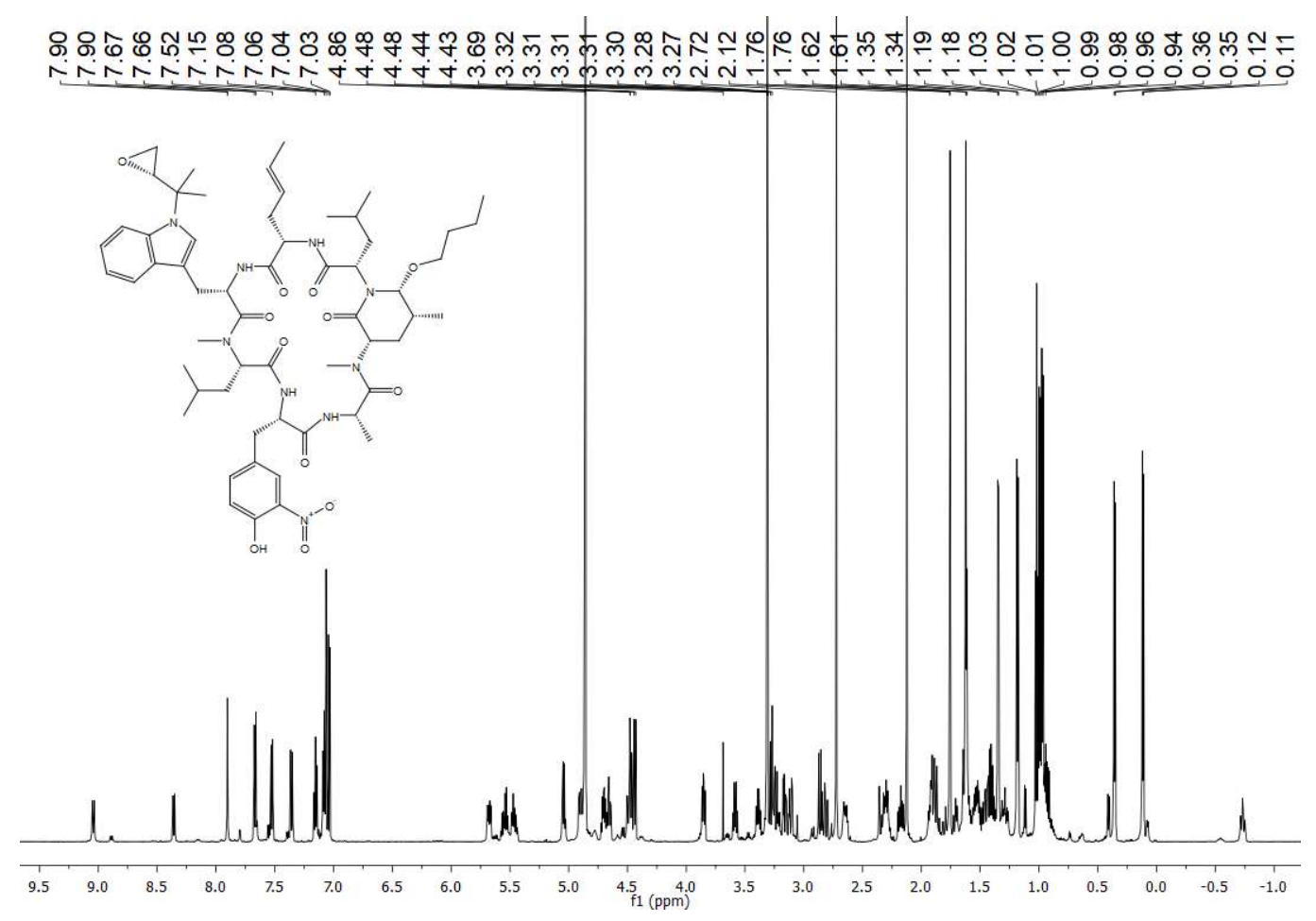

Figure S30. ${ }^{13} \mathrm{C}$ NMR spectrum of rufomycinSS 1 in $\mathrm{CD}_{3} \mathrm{OD}$ at $150 \mathrm{MHz}$

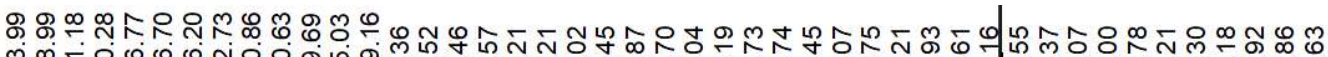

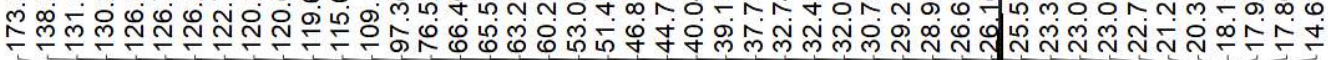
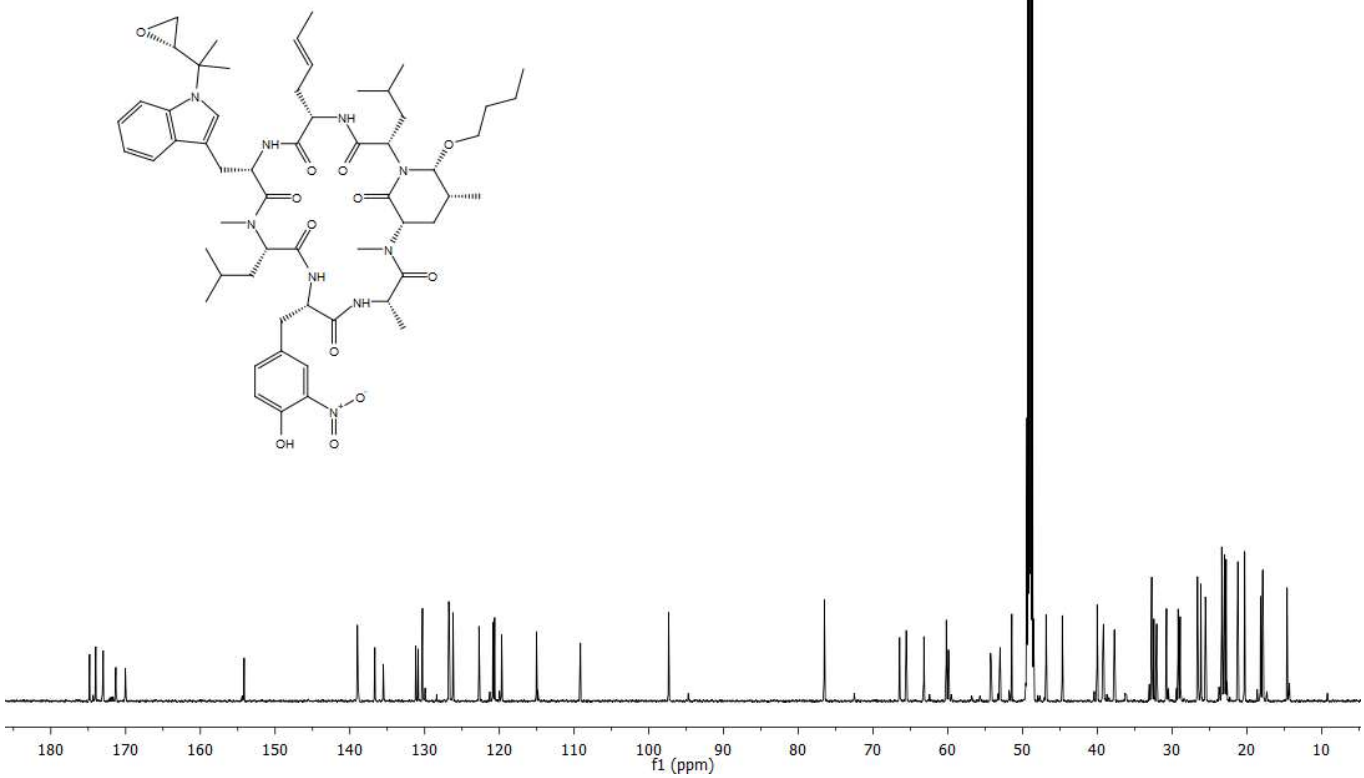
Figure S31. TOCSY spectrum of rufomycinSS 1 in $\mathrm{CD}_{3} \mathrm{OD}$

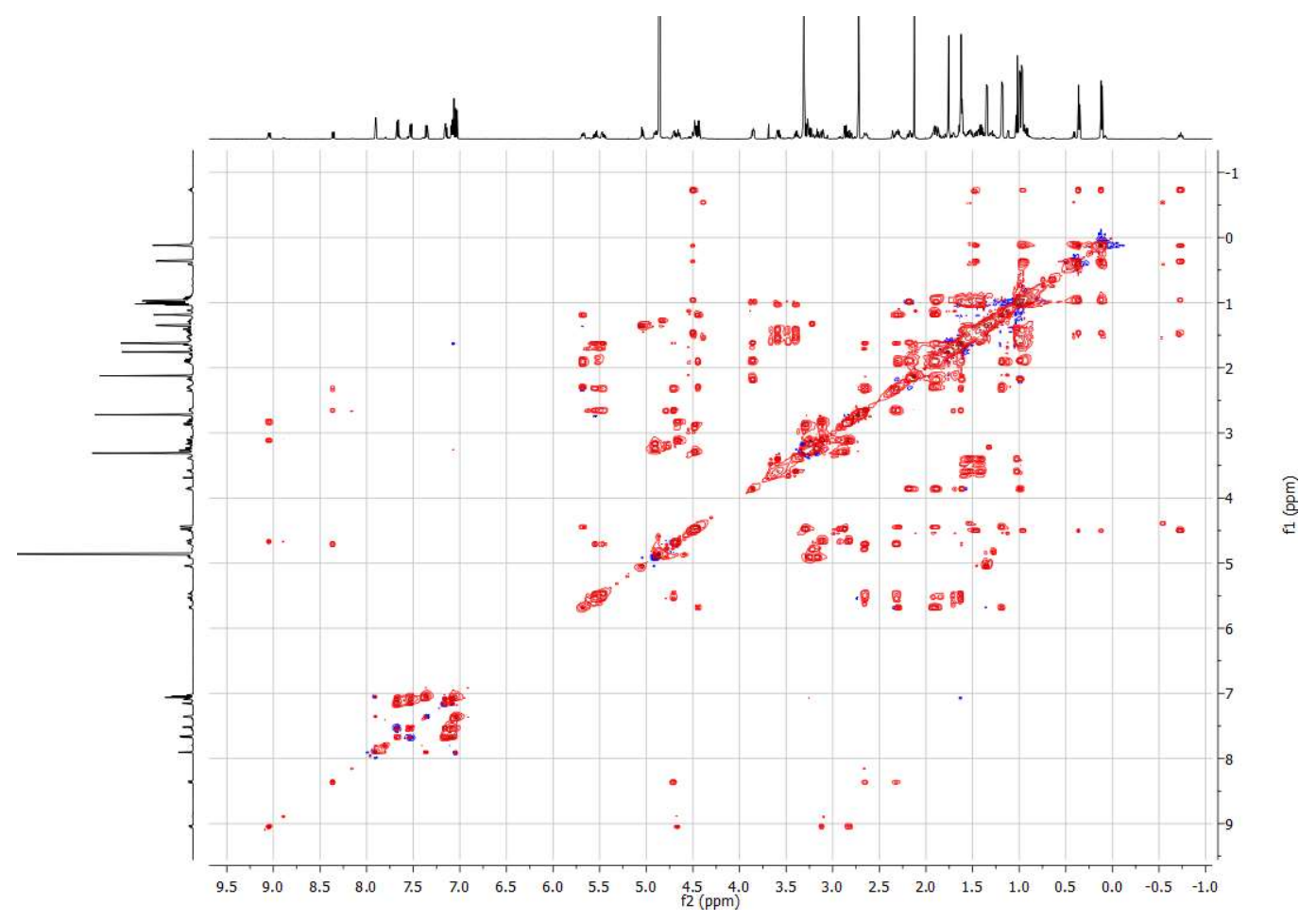

Figure S32. HSQC spectrum of rufomycinSS 1 in $\mathrm{CD}_{3} \mathrm{OD}$

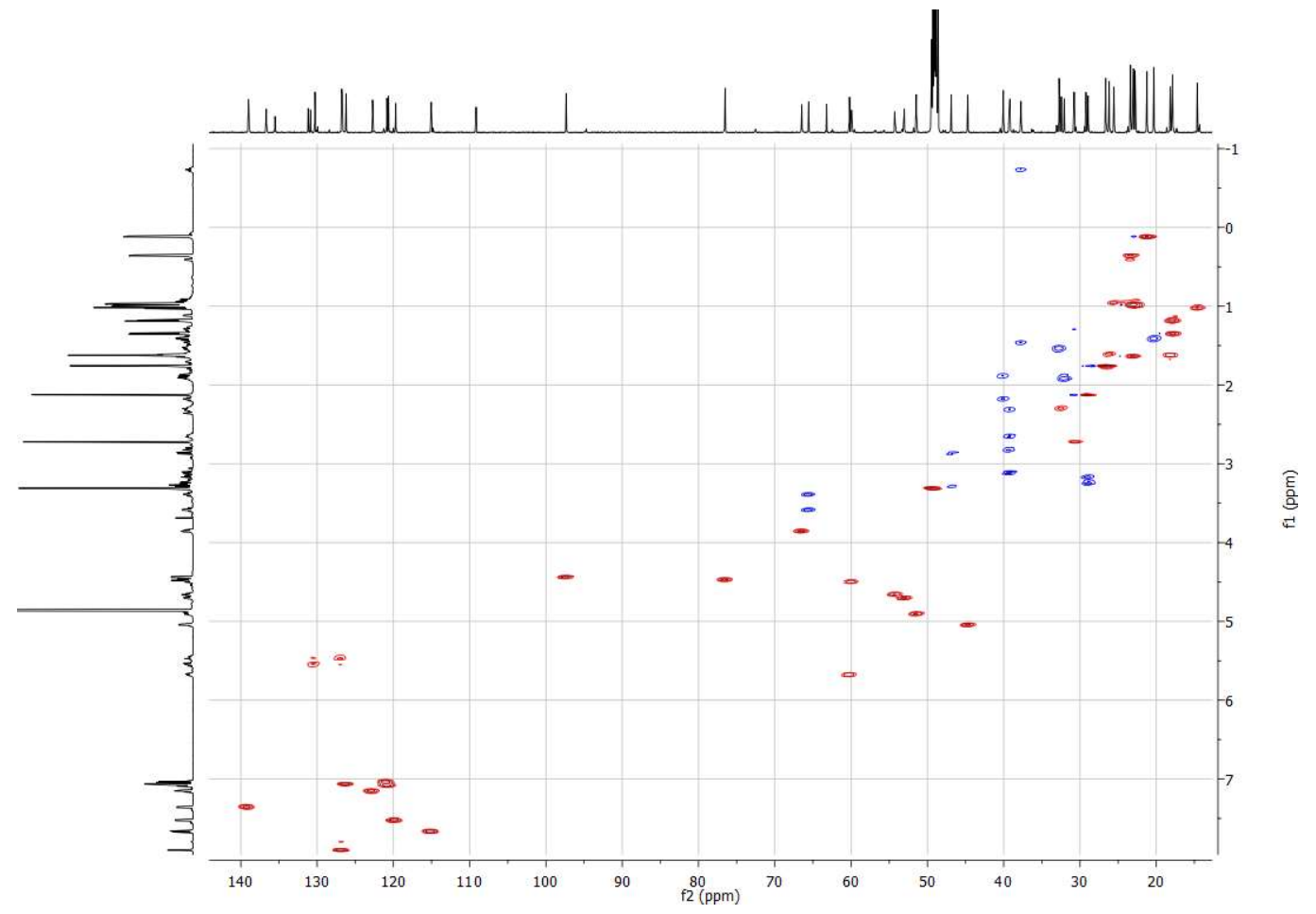


Figure S33. $\mathrm{HMBC}$ spectrum of rufomycinSS 1 in $\mathrm{CD}_{3} \mathrm{OD}$

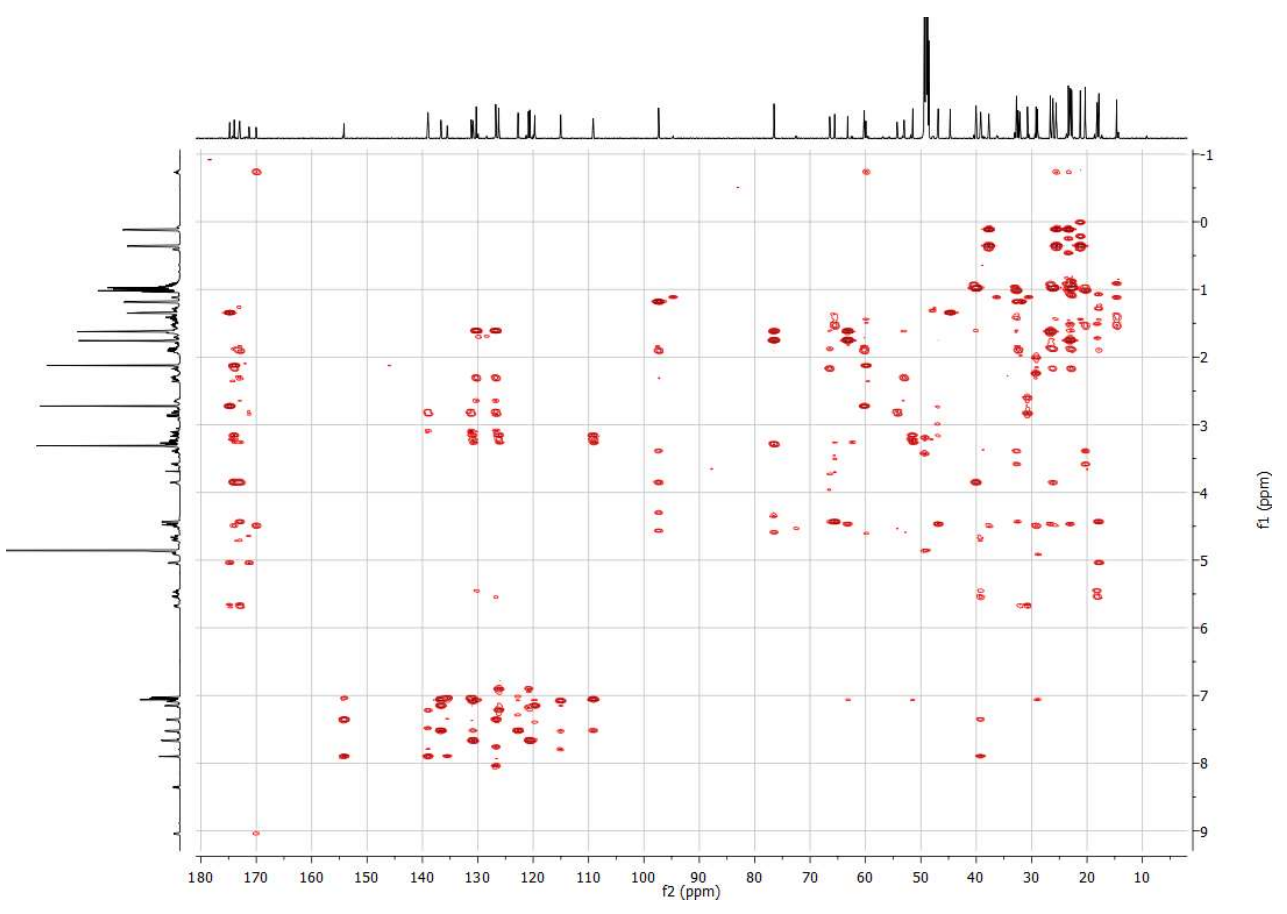

Figure S34. ROESY spectrum of rufomycinSS 1 in $\mathrm{CD}_{3} \mathrm{OD}$

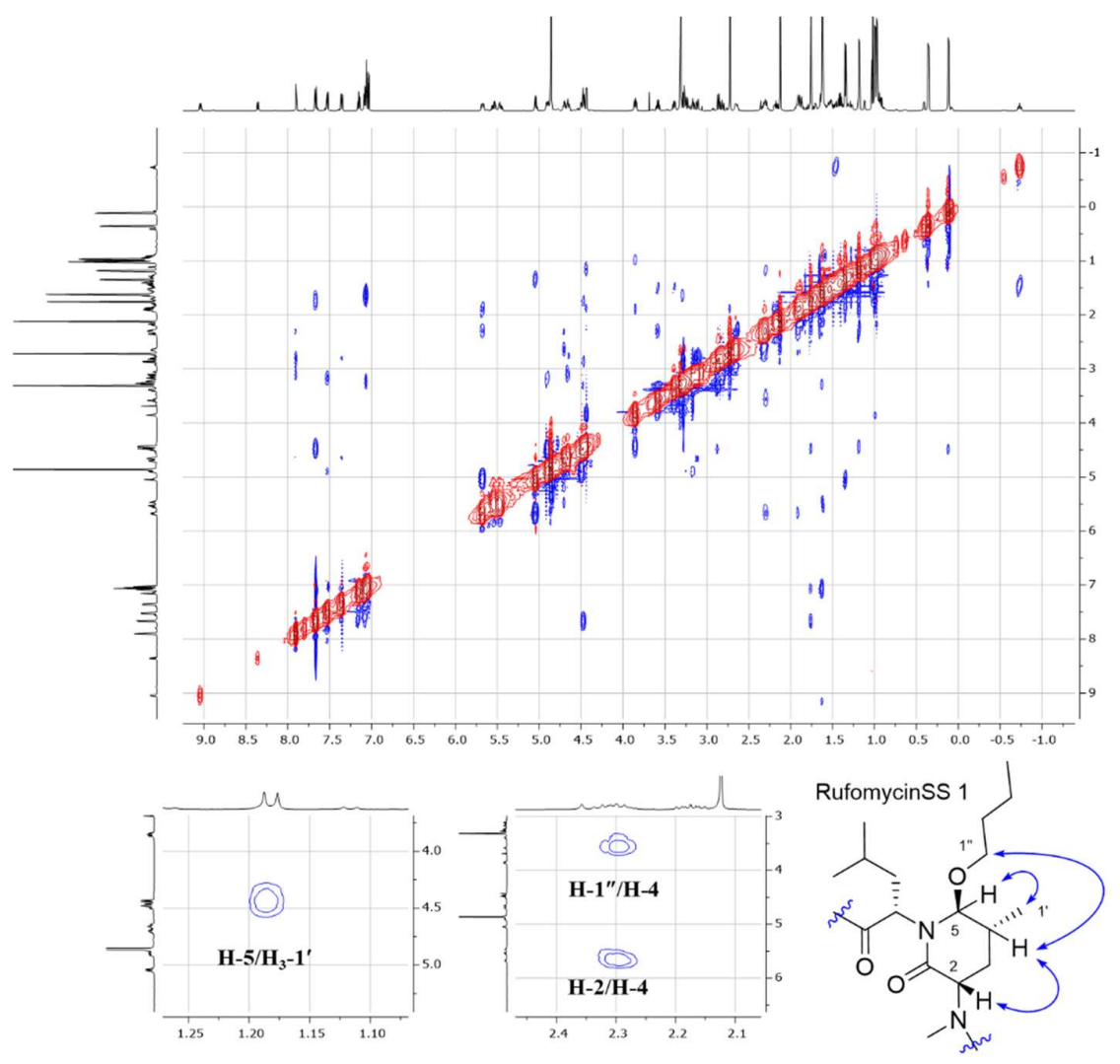


Figure S35. HRMS (ESI) spectrum of rufomycinSS 1

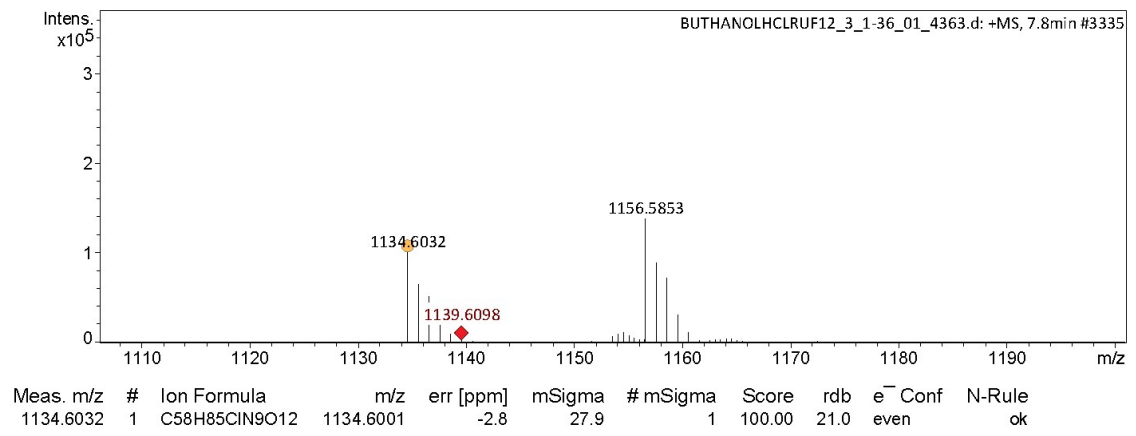

Figure S36. ${ }^{1} \mathrm{H}$ NMR spectrum of rufomycinSS 2 in $\mathrm{CD}_{3} \mathrm{OD}$ at $600 \mathrm{MHz}$

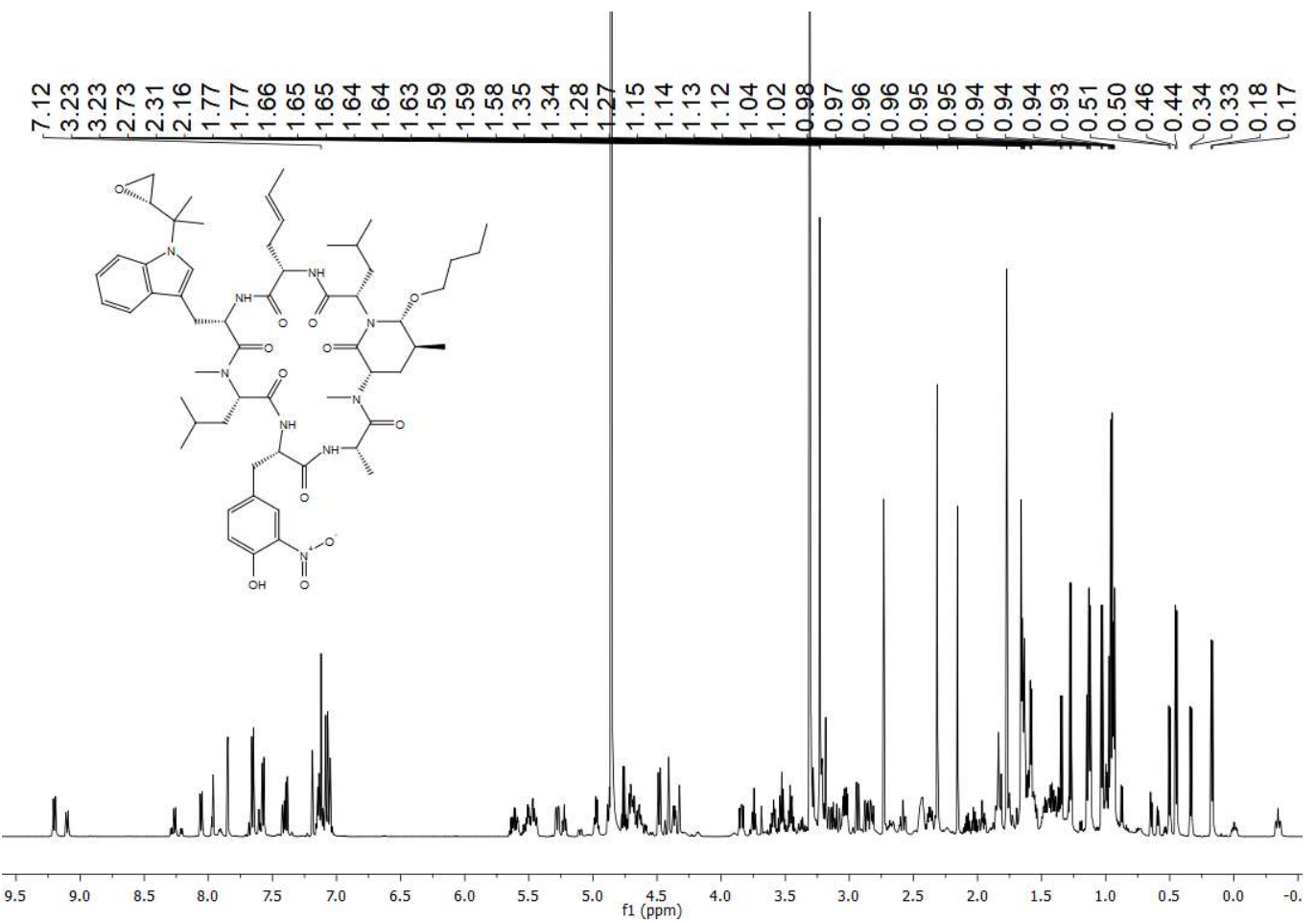


Figure S37. ${ }^{13} \mathrm{C}$ NMR spectrum of rufomycinSS 2 in $\mathrm{CD}_{3} \mathrm{OD}$ at $150 \mathrm{MHz}$

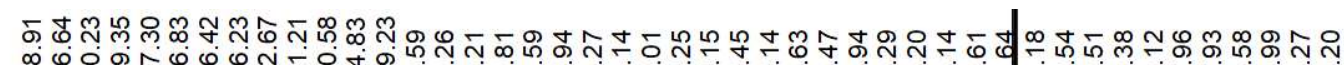
m
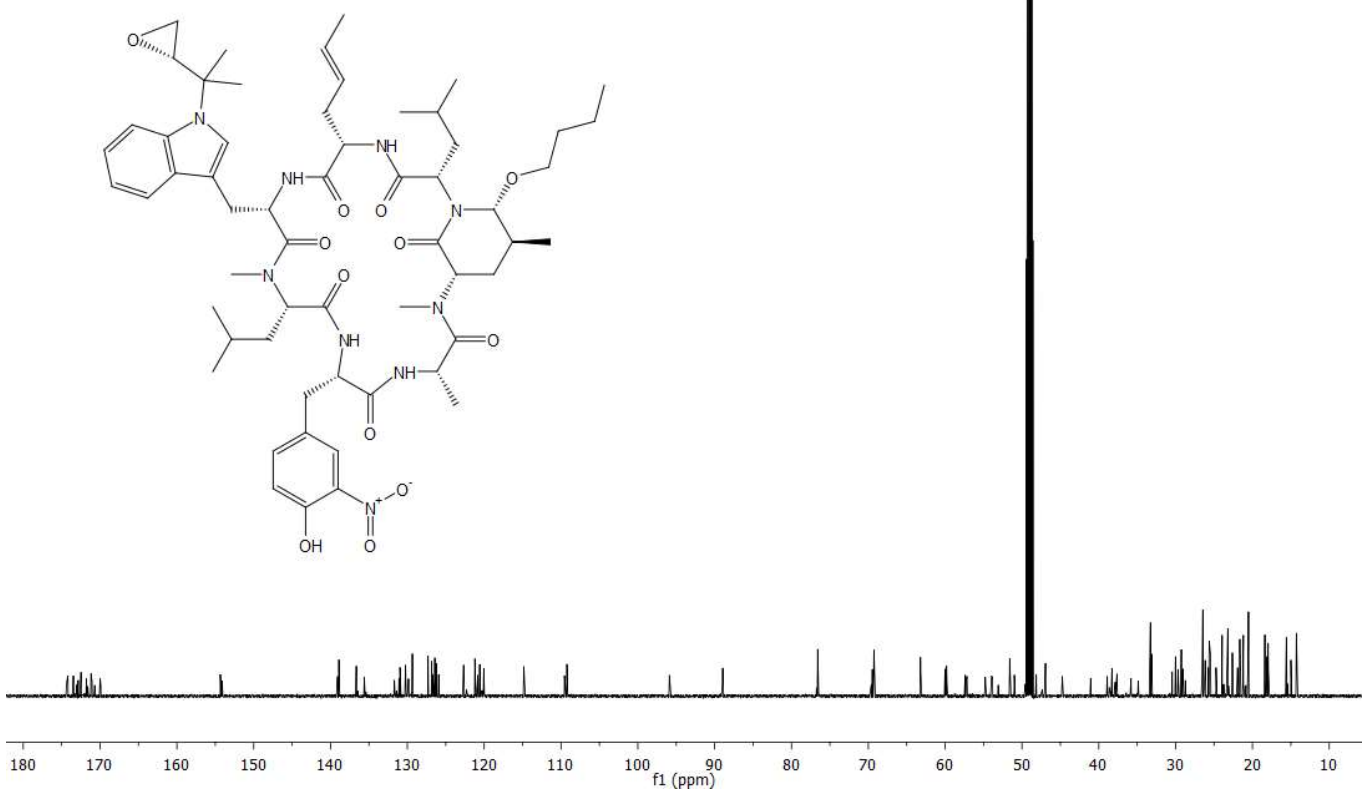

Figure S38. TOCSY NMR spectrum of rufomycinSS 2 in $\mathrm{CD}_{3} \mathrm{OD}$

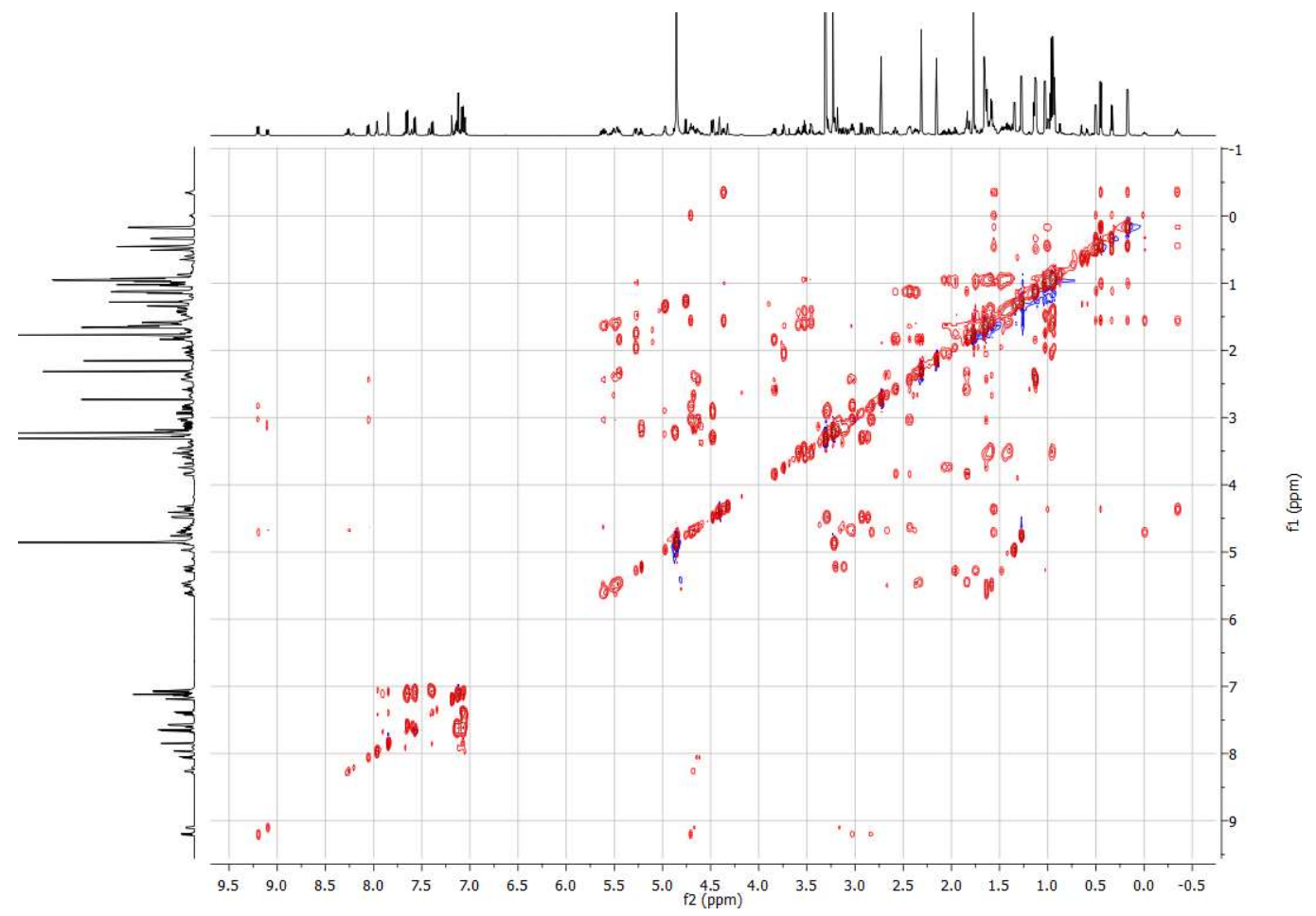


Figure S39. HSQC spectrum of rufomycinSS 2 in $\mathrm{CD}_{3} \mathrm{OD}$

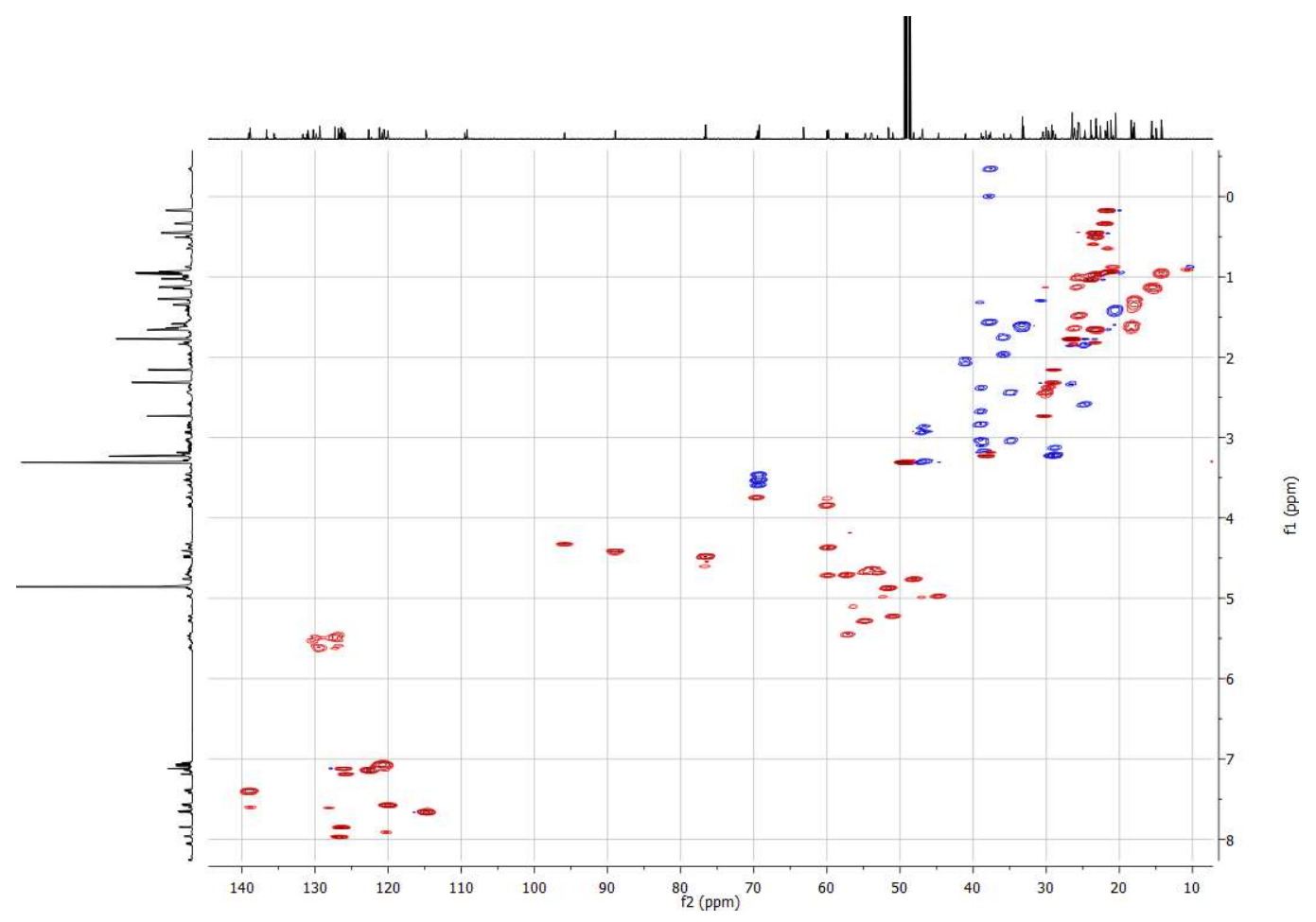

Figure S40. HMBC spectrum of rufomycinSS 2 in $\mathrm{CD}_{3} \mathrm{OD}$

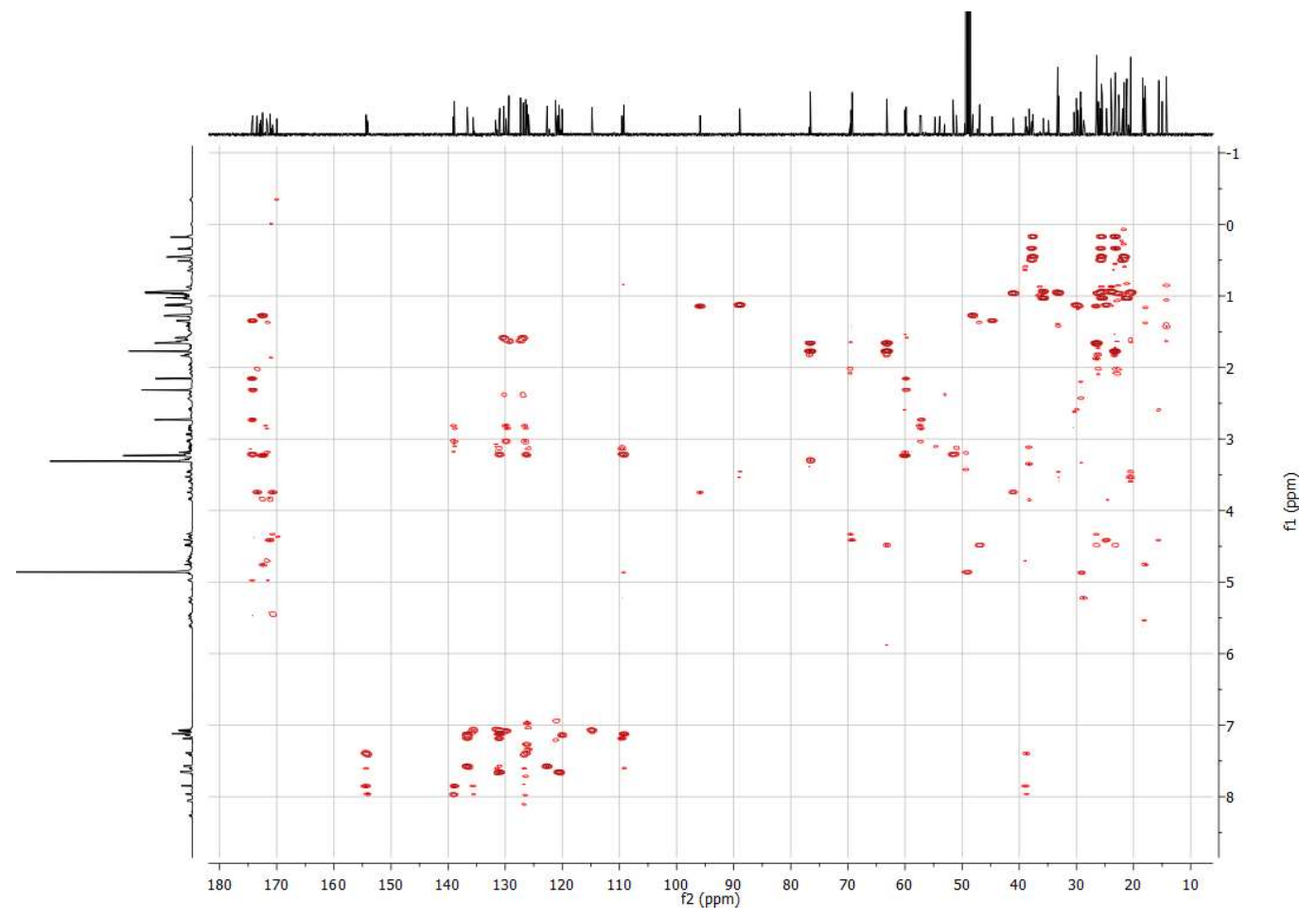


Figure S41. ROESY spectrum of rufomycinSS 2 in $\mathrm{CD}_{3} \mathrm{OD}$

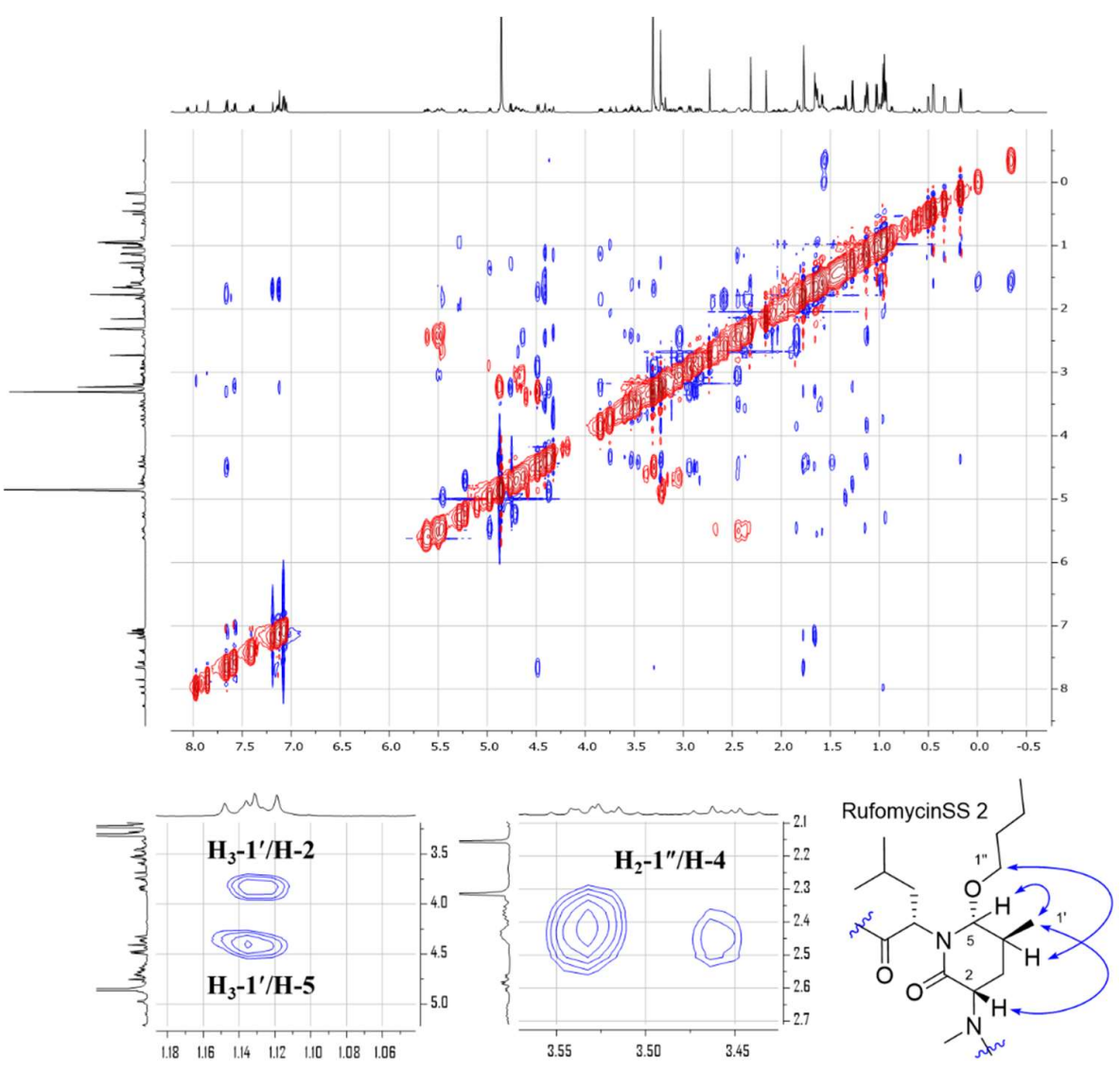

Figure S42. HRMS (ESI) spectrum of rufomycinSS 2

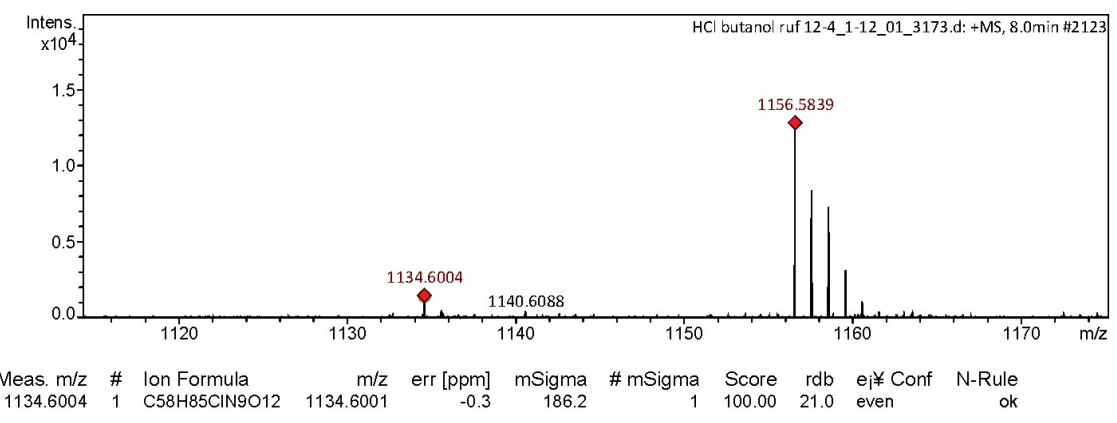


Figure S43. ${ }^{1} \mathrm{H}$ NMR spectrum of rufomycinSS 3 in $\mathrm{CD}_{3} \mathrm{OD}$ at $600 \mathrm{MHz}$

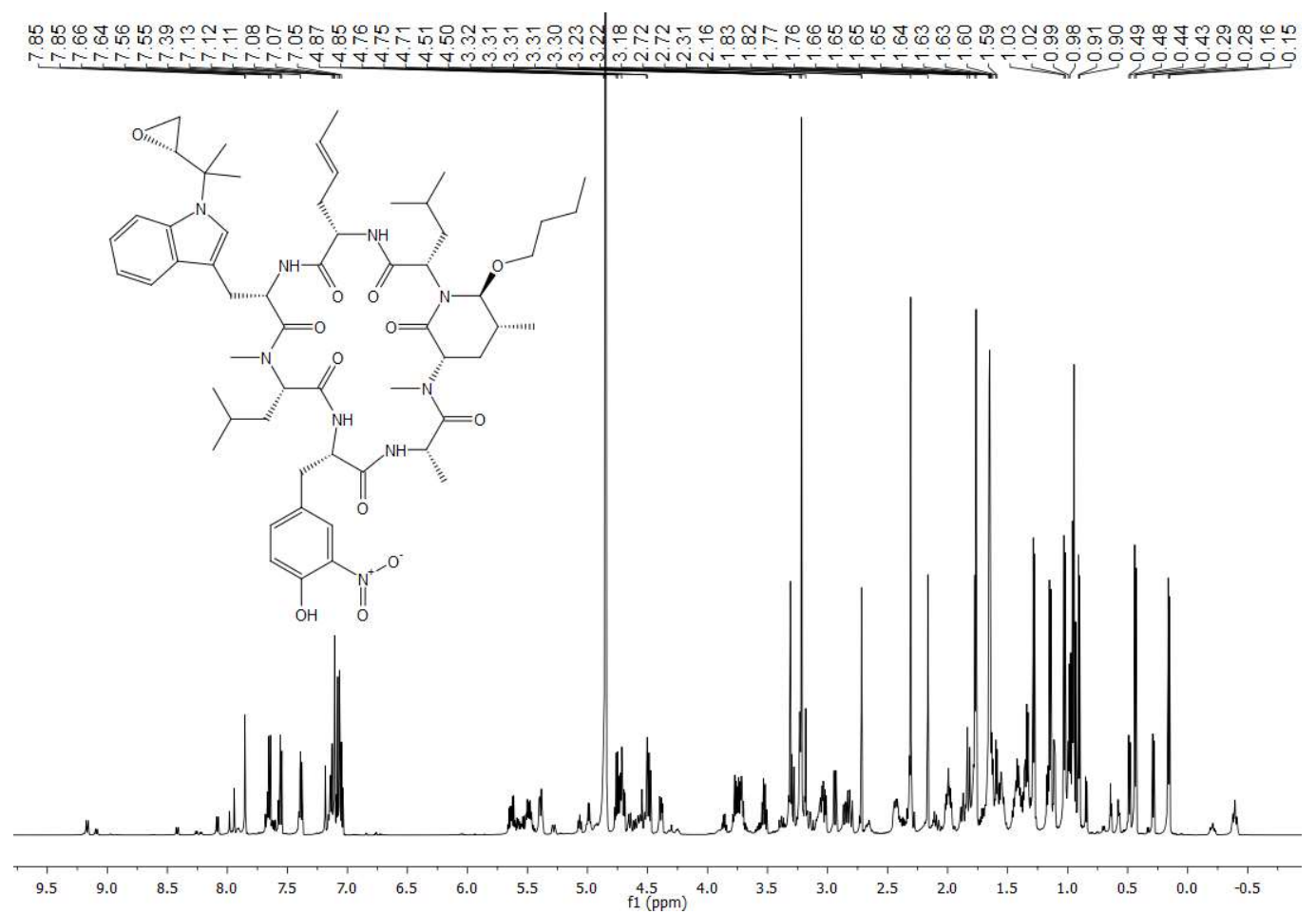

Figure S44. ${ }^{13} \mathrm{C}$ NMR spectrum of rufomycinSS 3 in $\mathrm{CD}_{3} \mathrm{OD}$ at $150 \mathrm{MHz}$

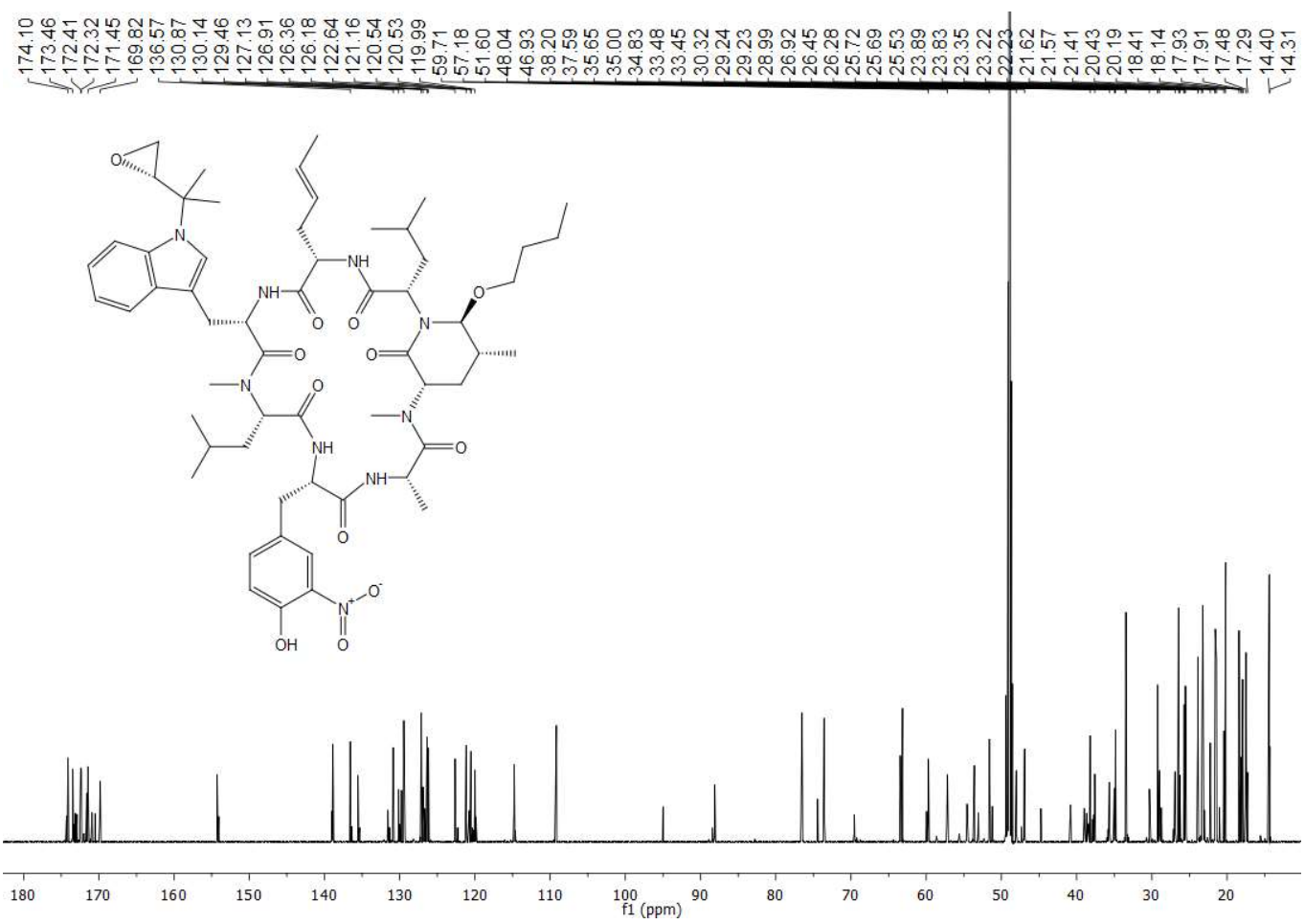


Figure S45. TOCSY NMR spectrum of rufomycinSS 3 in $\mathrm{CD}_{3} \mathrm{OD}$

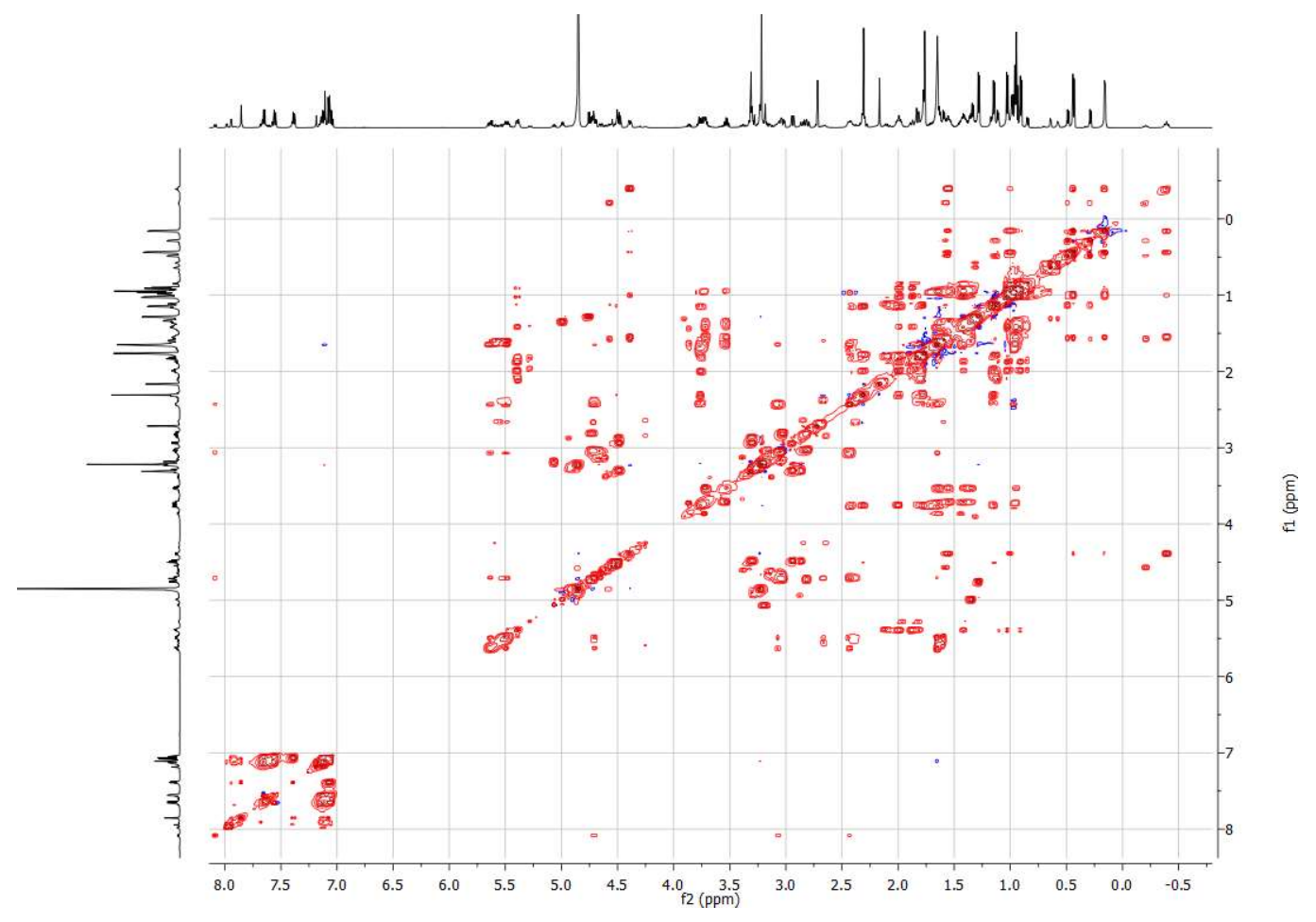

Figure S46. HSQC spectrum of rufomycinSS 3 in $\mathrm{CD}_{3} \mathrm{OD}$

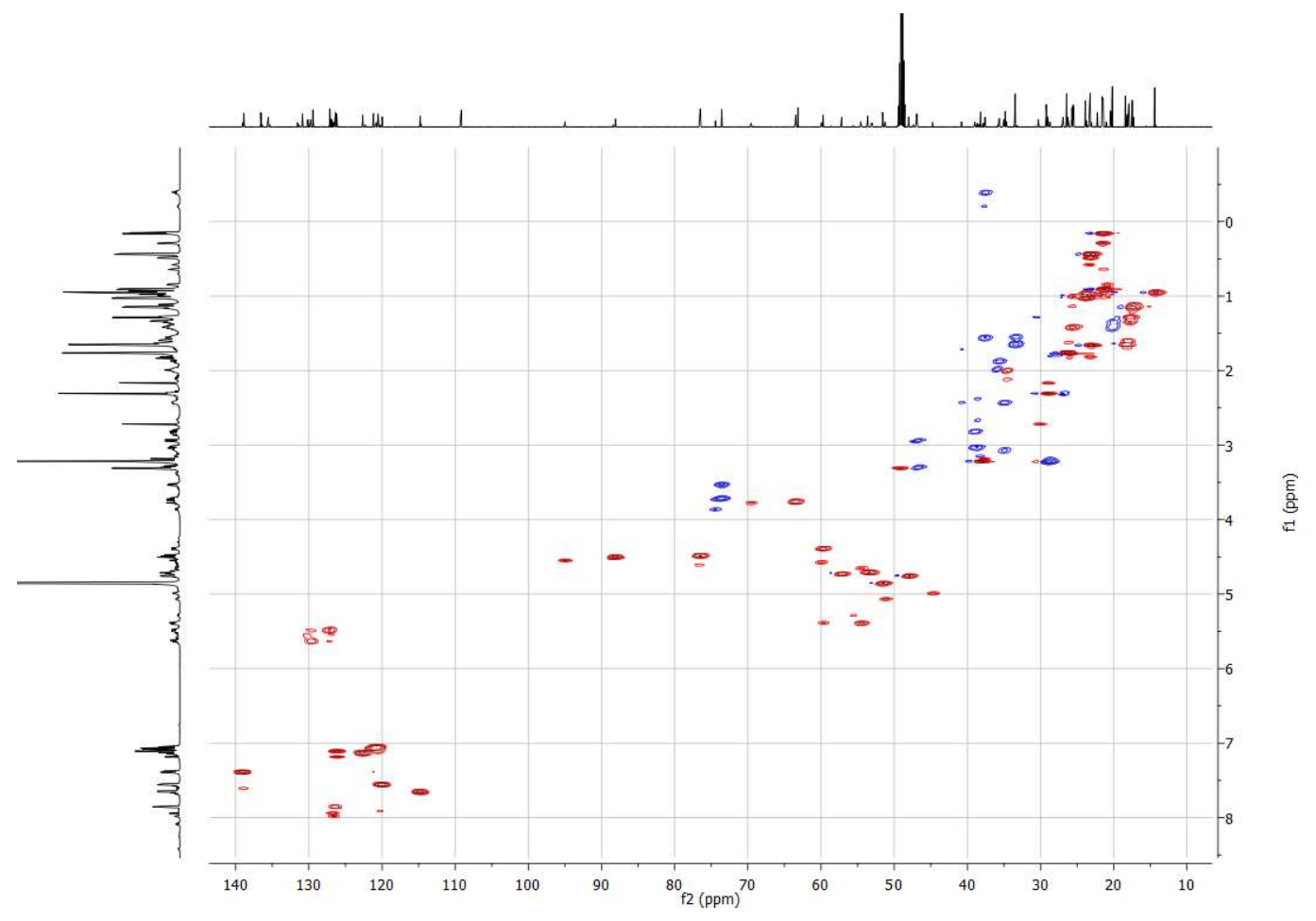


Figure S47. HMBC spectrum of rufomycinSS 3 in $\mathrm{CD}_{3} \mathrm{OD}$

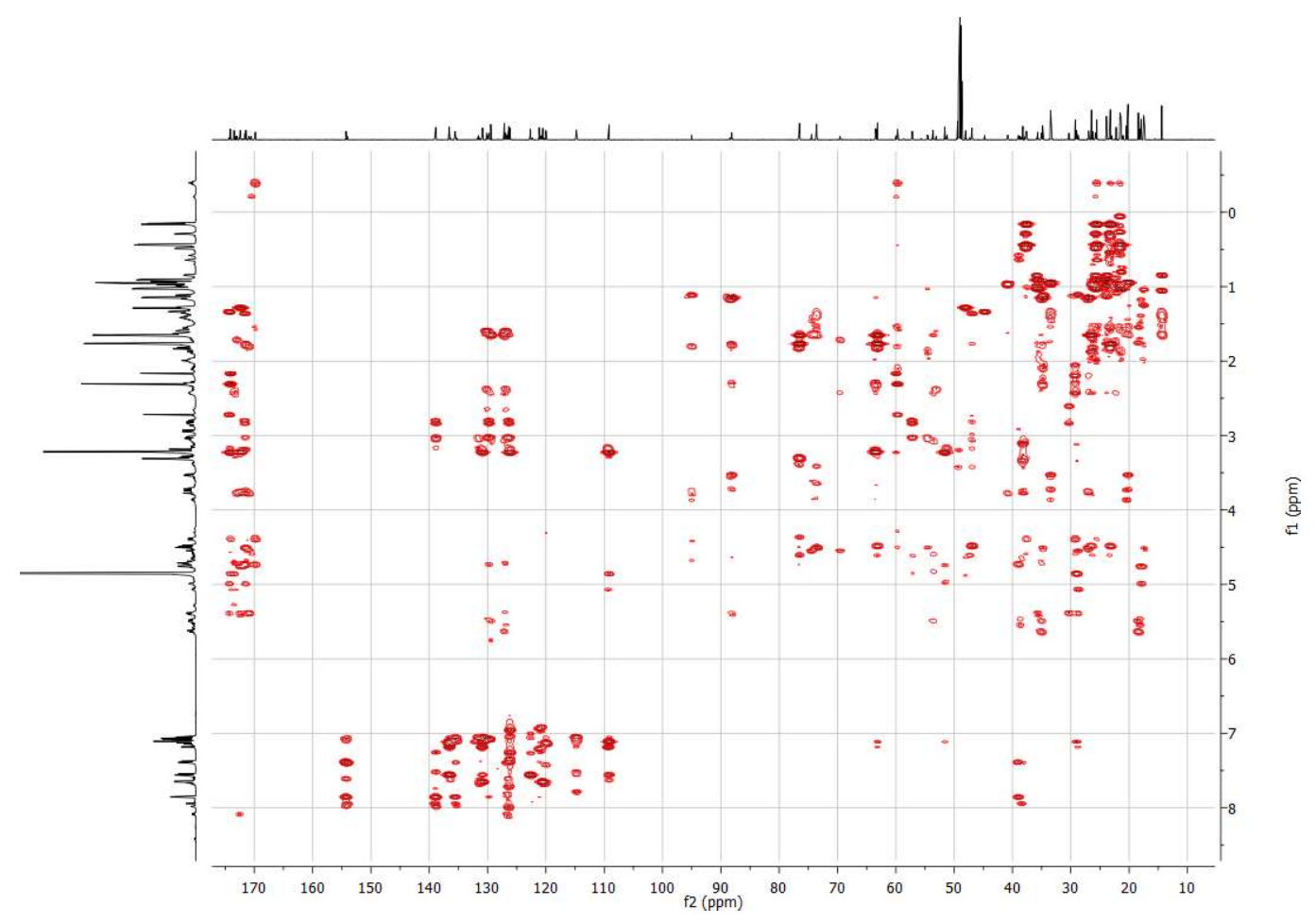

Figure S48. HRMS (ESI) spectrum of rufomycinSS 3

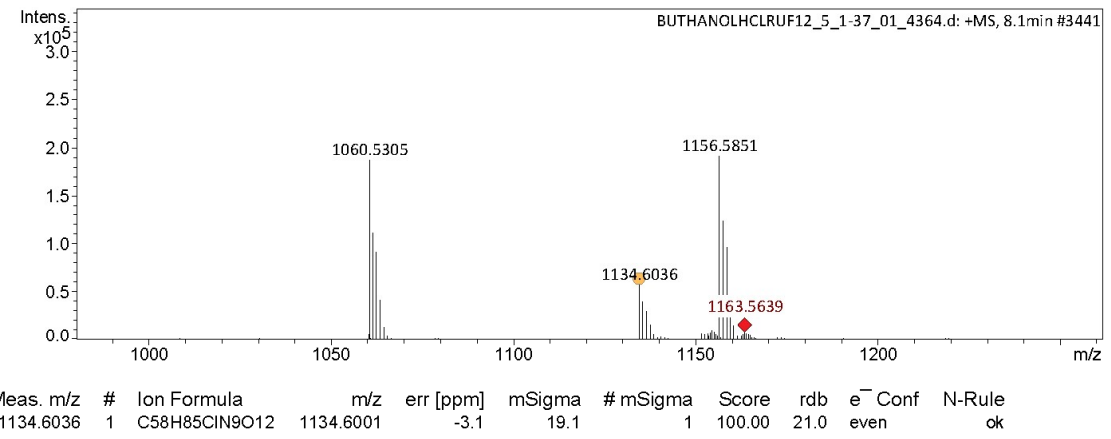


Figure S49. ROESY spectrum of rufomycinSS 3 in $\mathrm{CD}_{3} \mathrm{OD}$

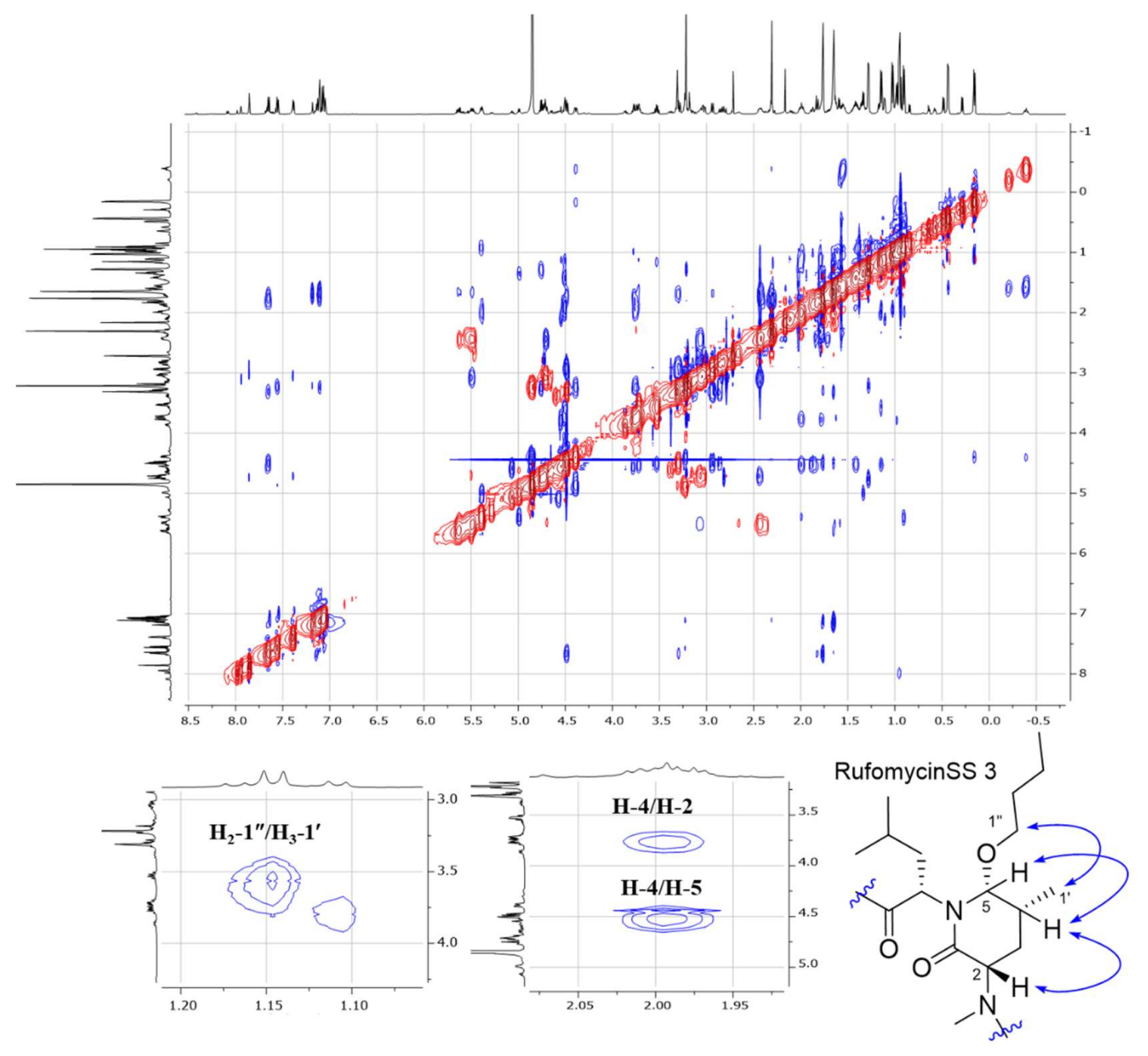

Figure S50. Selected HSQC data of rufomycins 6 and 7
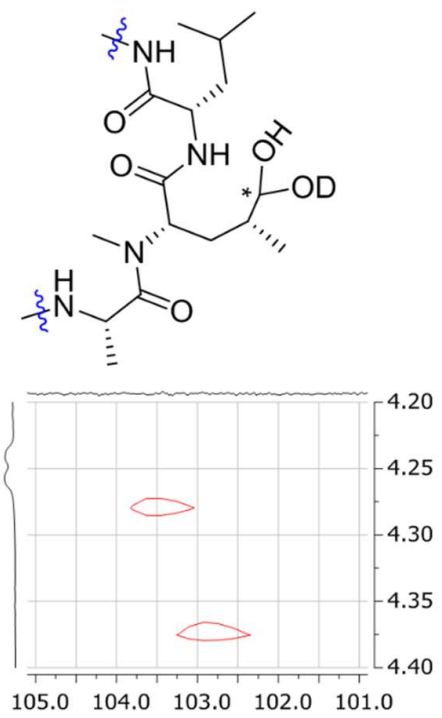

Rufomycin 6
$\delta_{\mathrm{H}} 4.28(\mathrm{~d}, 5.8) ; \delta_{\mathrm{C}} 103.4$

$\delta_{\mathrm{H}} 4.37(\mathrm{~d}, 4.7) ; \delta_{\mathrm{C}} 102.8$

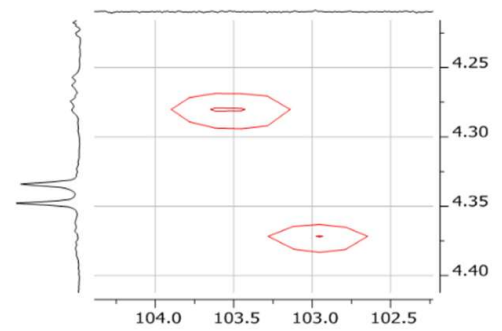

Rufomycin 7 
Figure S51. ${ }^{1} \mathrm{H}$ NMR spectrum of rufomycin 21 in $\mathrm{CD}_{3} \mathrm{OD}$ at $400 \mathrm{MHz}$

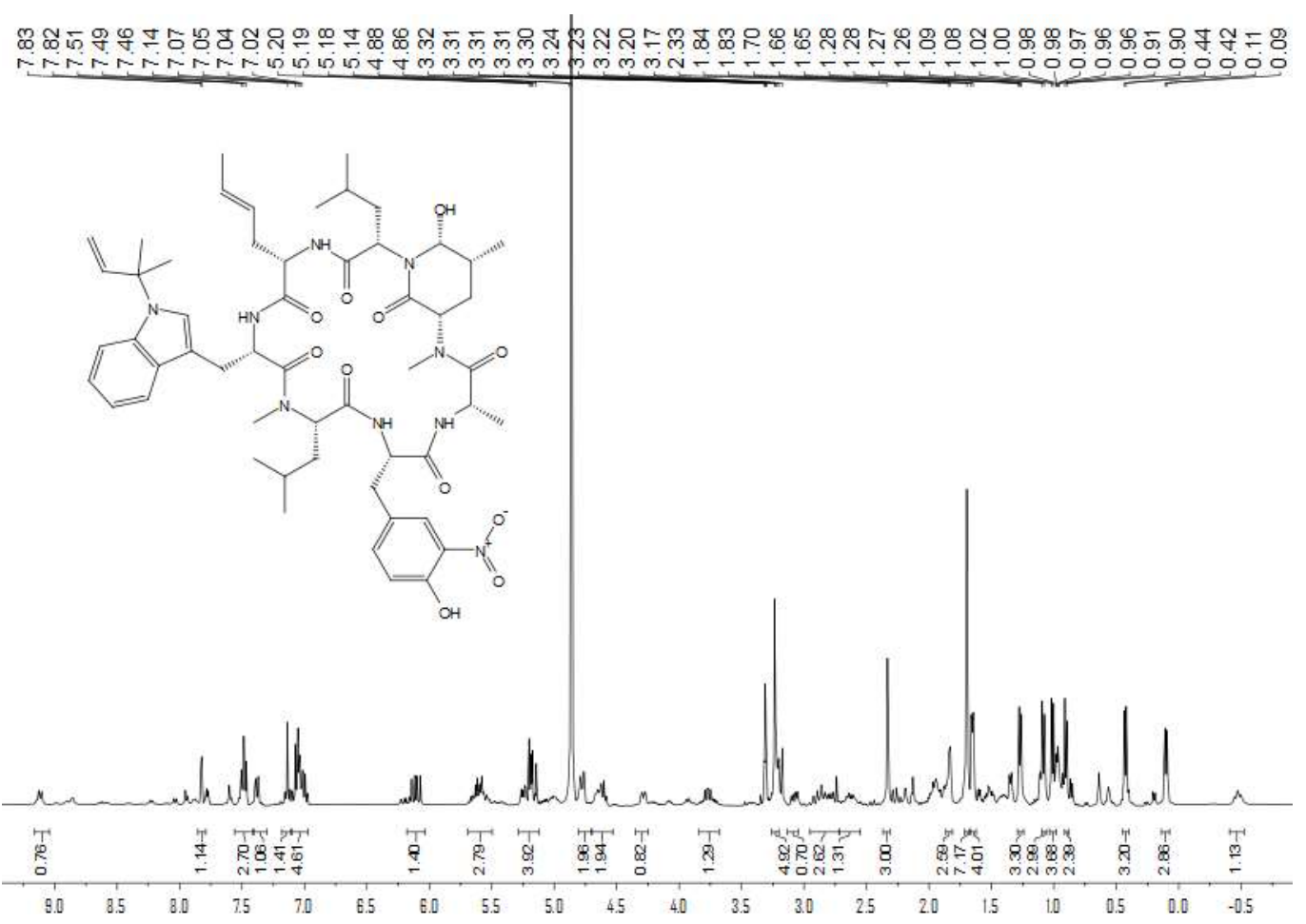

Figure S52. ${ }^{13} \mathrm{C}$ NMR spectrum of rufomycin 21 in $\mathrm{CD}_{3} \mathrm{OD}$ at $100 \mathrm{MHz}$

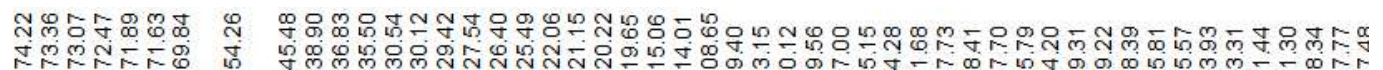

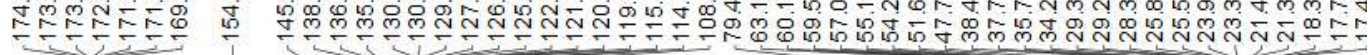

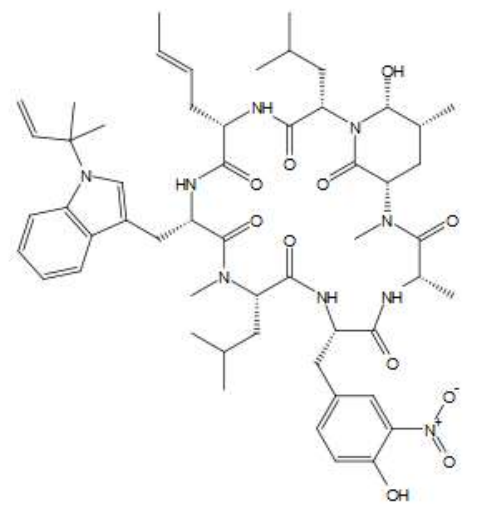

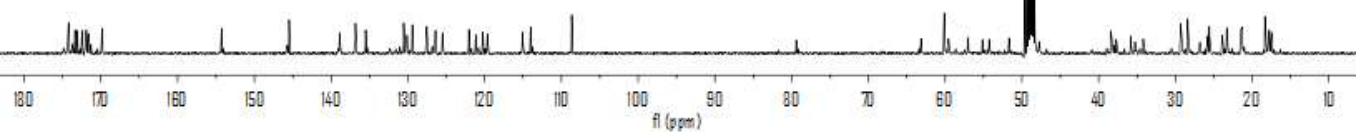


Figure S53. TOCSY NMR spectrum of rufomycin 21 in $\mathrm{CD}_{3} \mathrm{OD}$

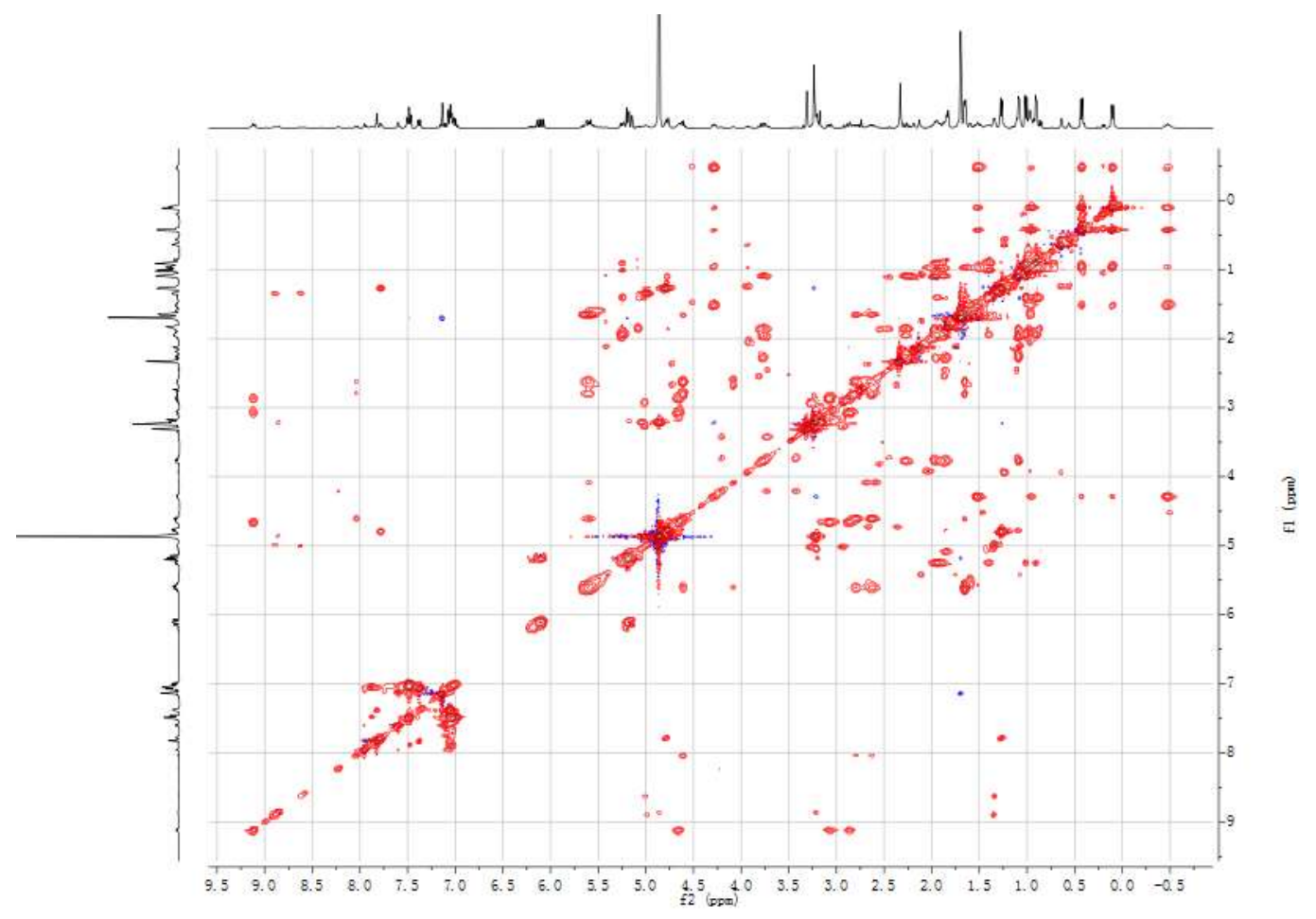

Figure S54. HSQC spectrum of rufomycin 21 in $\mathrm{CD}_{3} \mathrm{OD}$

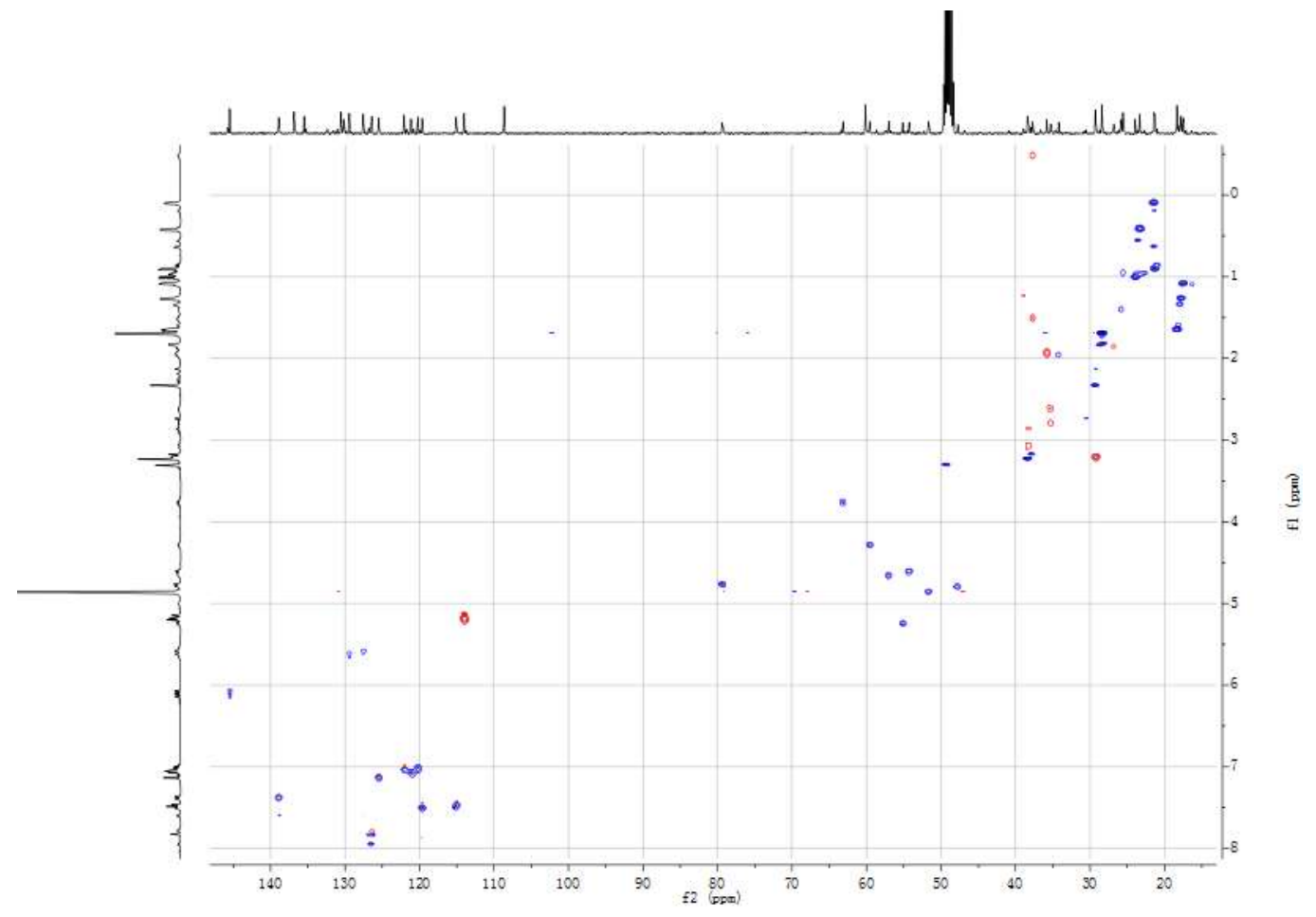


Figure S55. HMBC spectrum of rufomycin 21 in $\mathrm{CD}_{3} \mathrm{OD}$

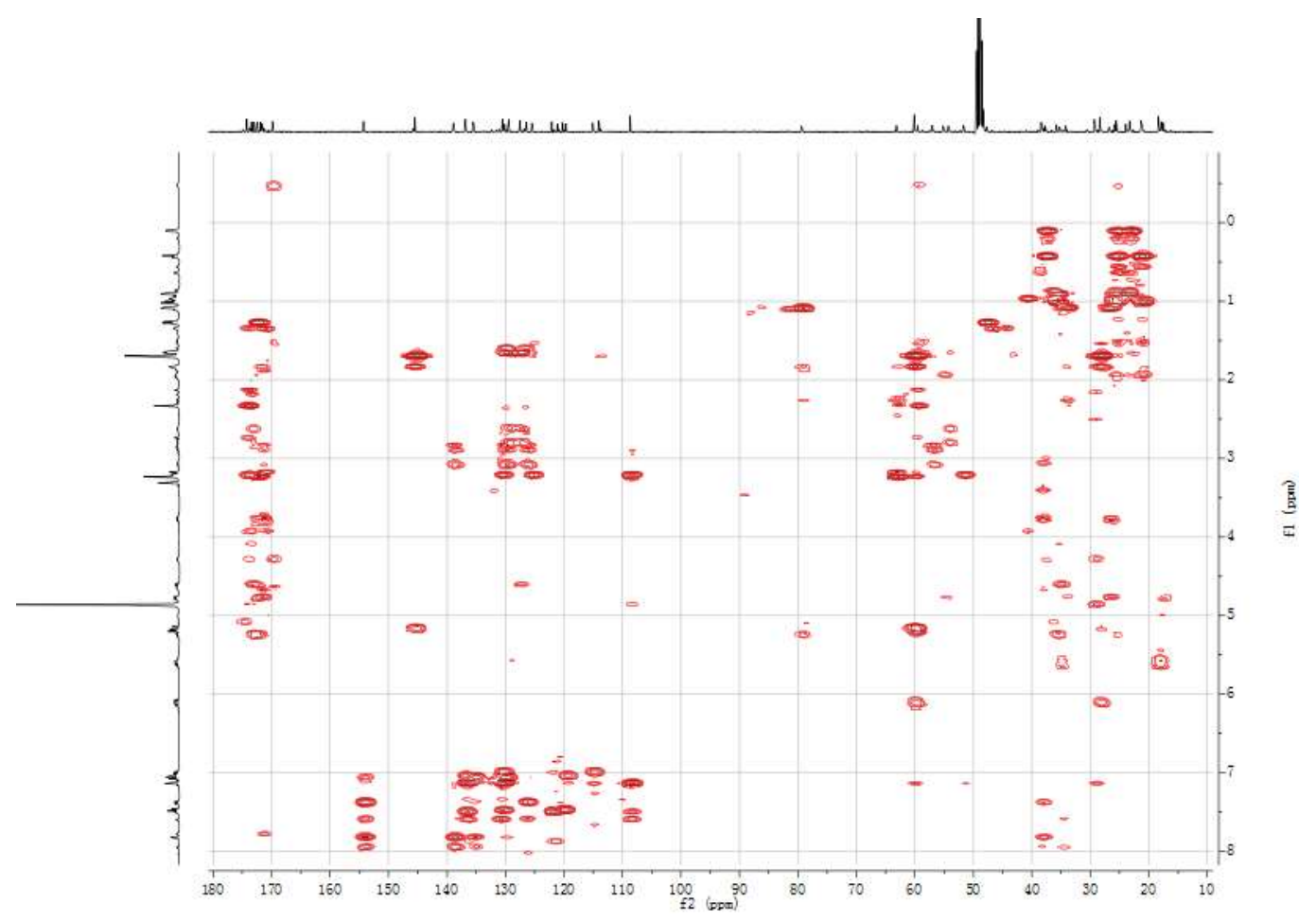

Figure S56. HRMS (ESI) spectrum of rufomycin 21

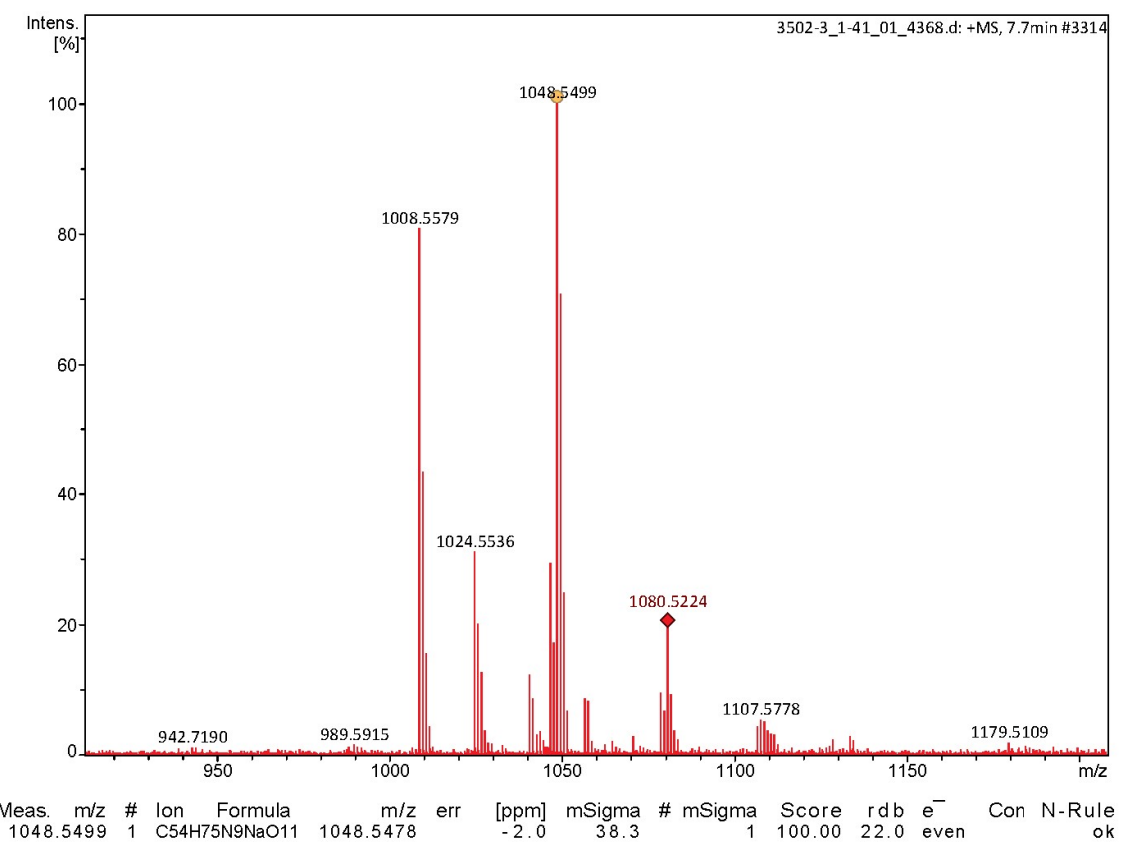


Figure S57. NOESY spectrum of rufomycin 21 in $\mathrm{CD}_{3} \mathrm{OD}$

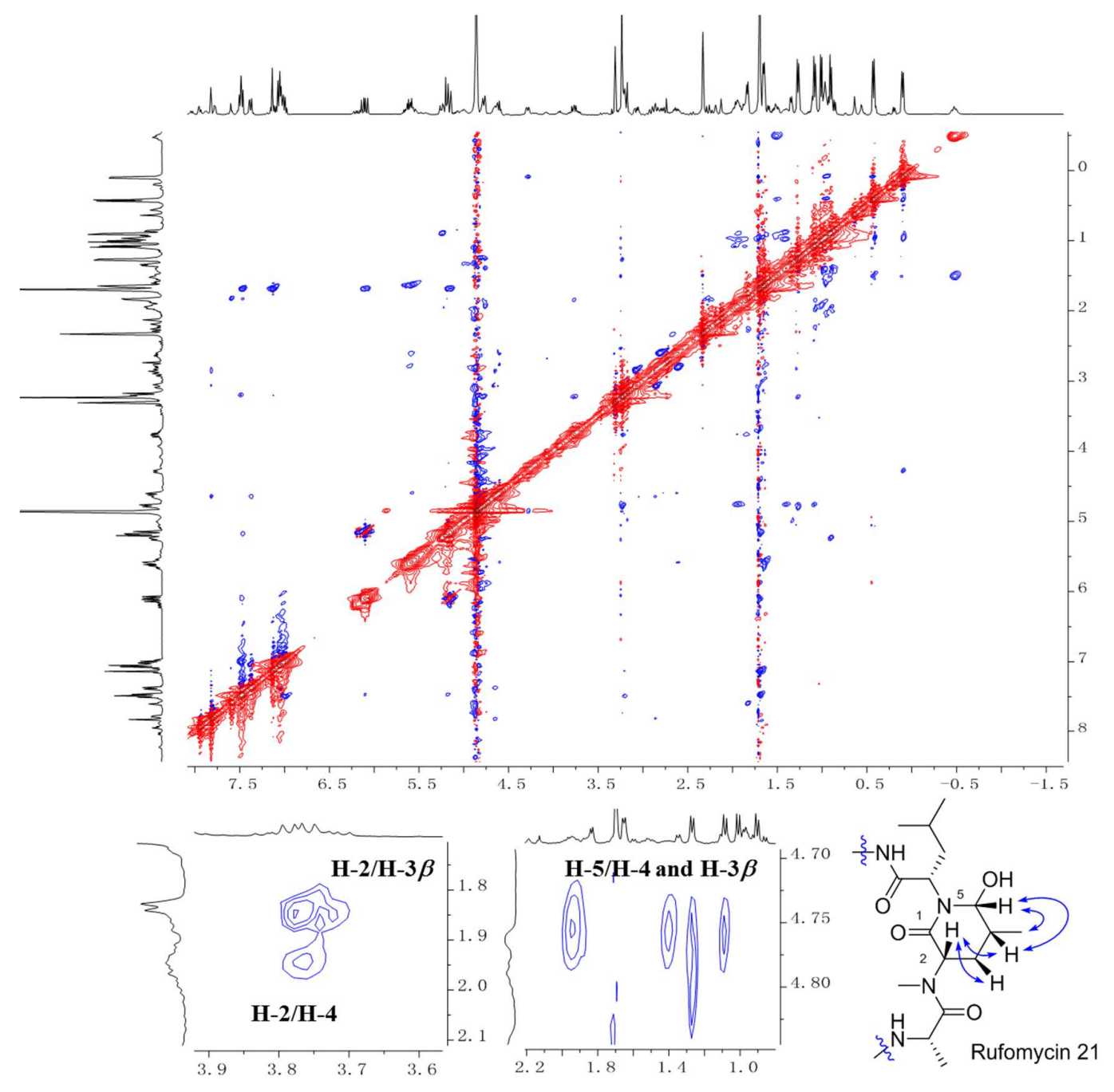


Chart S2. Structure verification of ilamycin E1 and E2

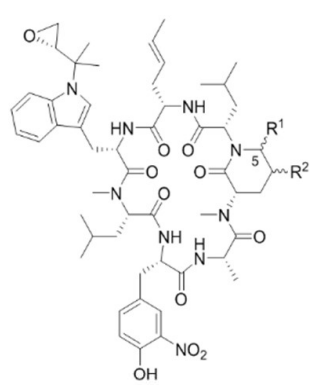

Rufomycin $4 \mathrm{R}^{1}=\alpha-\mathrm{OH} ; \mathrm{R}^{2}=\beta-\mathrm{CH}$

CH-5 $\delta_{\mathrm{C}} 81.7$ and $\delta_{\mathrm{H}} 4.76$, brd, $J=3.7 \mathrm{~Hz}$

Rufomycin $5 \mathrm{R}^{1}=\beta-\mathrm{OH} ; \mathrm{R}^{2}=\beta-\mathrm{CH}_{3}$

CH-5 $\delta_{\mathrm{C}} 82.5$ and $\delta_{\mathrm{H}} 4.63$, brd, $J=2.6 \mathrm{~Hz}$

Rufomycin $6 \mathrm{R}^{1}=\alpha-\mathrm{OH} ; \mathrm{R}^{2}=\alpha-\mathrm{CH}_{3}$

CH-5 $\delta_{\mathrm{C}} 79.4$ and $\delta_{\mathrm{H}} 4.76$, brd, $J=2.1 \mathrm{~Hz}$

Rufomycin $7 \mathrm{R}^{1}=\beta-\mathrm{OH} ; \mathrm{R}^{2}=\alpha-\mathrm{CH}_{3}$

CH-5 $\delta_{\mathrm{C}} 91.2$ and $\delta_{\mathrm{H}} 4.34$, brd, $J=7.9 \mathrm{~Hz}$

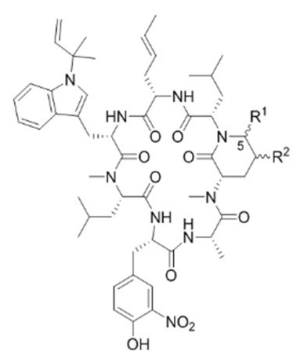

Rufomycin 21=Ilamycin E1 ( $\left.\mathrm{R}^{1}=\alpha-\mathrm{OH} ; \mathrm{R}^{2}=\beta-\mathrm{CH}_{3}\right)$

CH-5 $\delta_{\mathrm{C}} 79.4$ and $\delta_{\mathrm{H}} 4.76$, brd, $J=2.6 \mathrm{~Hz}$

To be $\mathrm{R}^{1}=\alpha-\mathrm{OH} ; \mathrm{R}^{2}=\alpha-\mathrm{CH}_{3}$

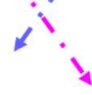

Ilamycin $\mathrm{E} 2\left(\mathrm{R}^{1}=\beta-\mathrm{OH} ; \mathrm{R}^{2}=\beta-\mathrm{CH}_{3}\right)$

CH-5 $\delta_{\mathrm{C}} 82.5$ and $\delta_{\mathrm{H}} 4.65$, brd, $J=1.6 \mathrm{~Hz}$

To be $\mathrm{R}^{1}=\beta-\mathrm{OH} ; \mathrm{R}^{2}=\beta-\mathrm{CH}_{3}$

Accordingly, the structure assigned to ilamycin E1 should be revised to show the (4R,5R, $\alpha-\mathrm{OH}, \alpha-\mathrm{CH}_{3}$, AA5) absolute configuration.
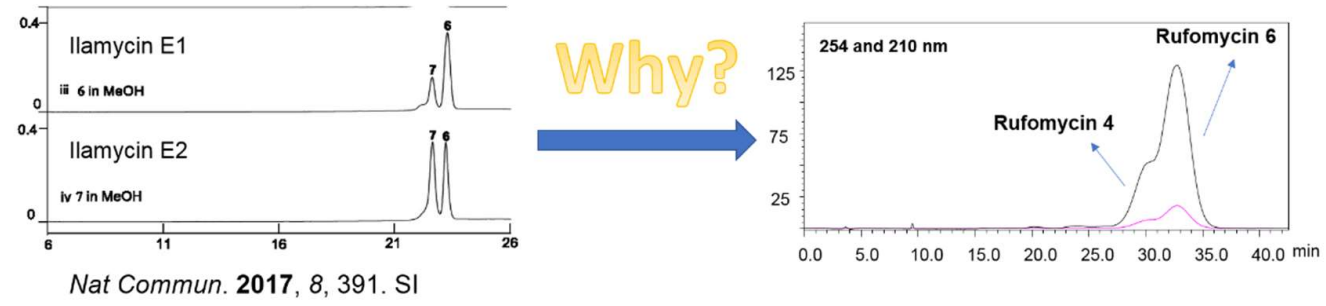

Based on our experiences, rufomycins 4 and 6 are hard to separate. Thus, the "peaks" for ilamycin E1, may not only contain part of the interconverted component from ilamycin E2 $\left(4 R, 5 S ; \alpha-\mathrm{OH}, \beta-\mathrm{CH}_{3}\right)$, but also contain the main component with $(4 R, 5 R$; $\left.\alpha-\mathrm{OH}, \alpha-\mathrm{CH}_{3}\right)$

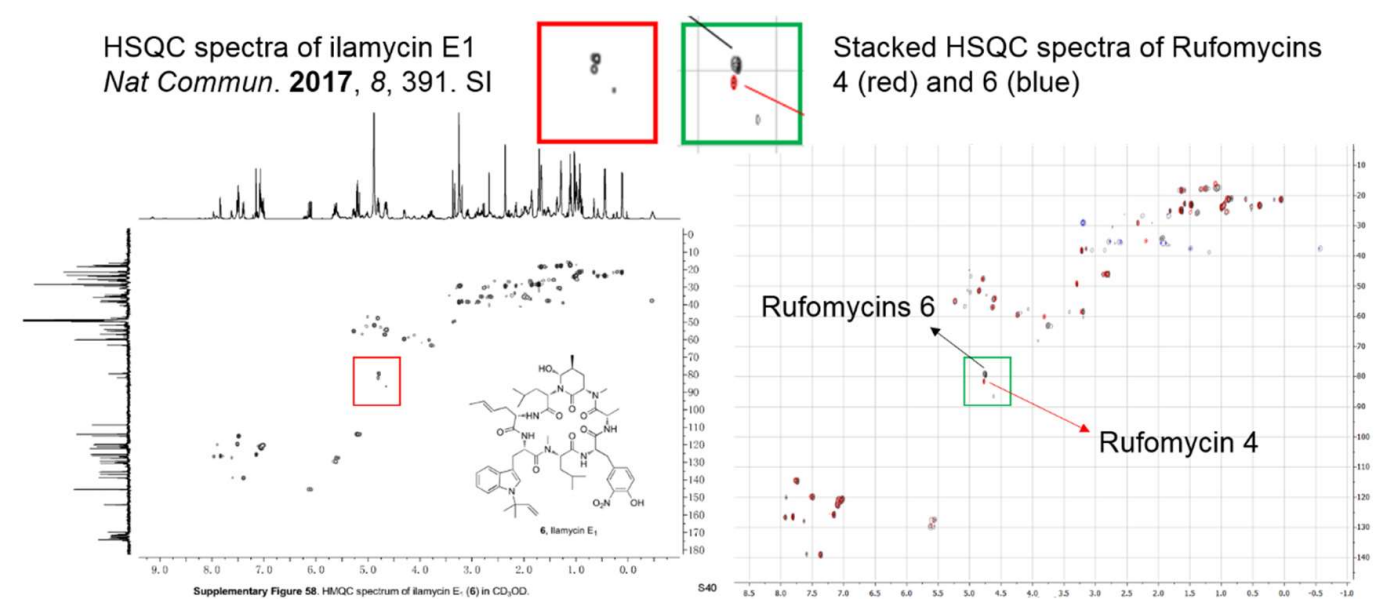


Figure S58. RufomycinSS 2 and 3 showed distinct conformers based on the ${ }^{13} \mathrm{C}$ NMR data
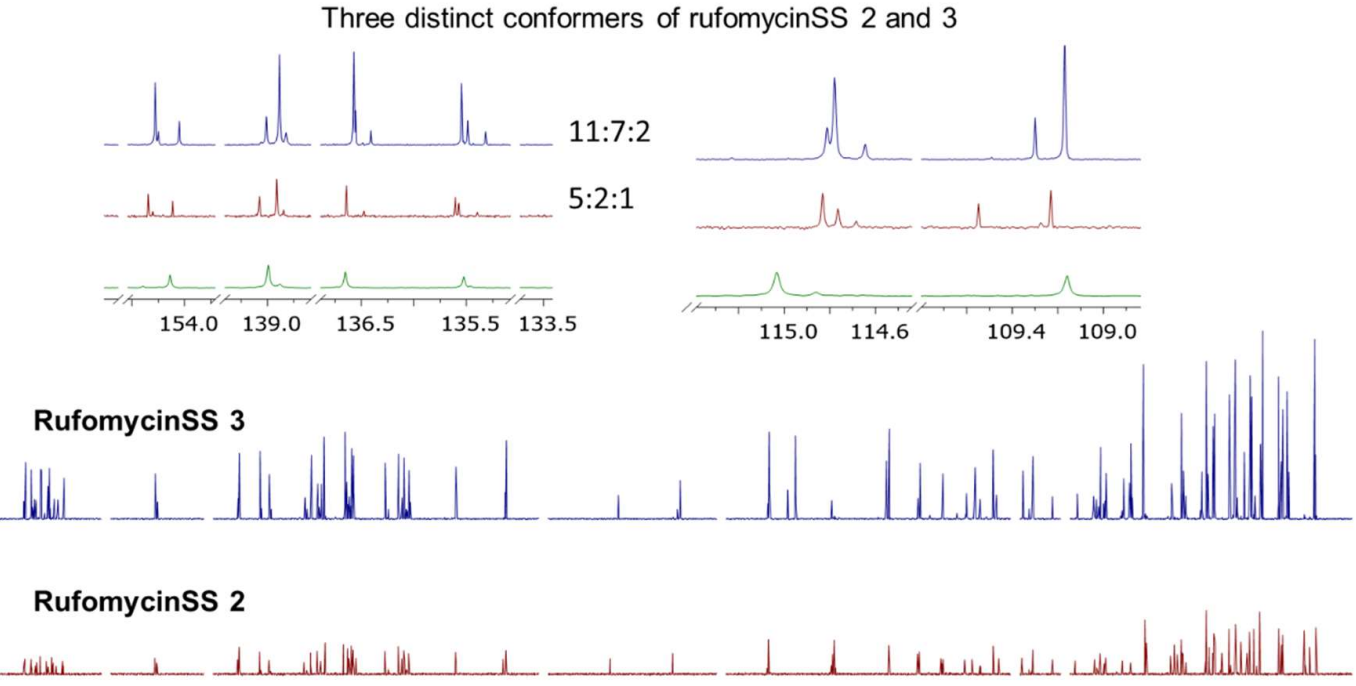

Rufomycinss 1

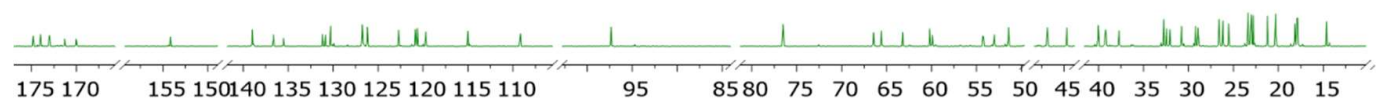


Figure S59. ${ }^{13} \mathrm{C}$ NMR differences $(\Delta \delta$ C) between compound pairs of rufomycins $4 / 5,4 / 6$, and $4 / 7$

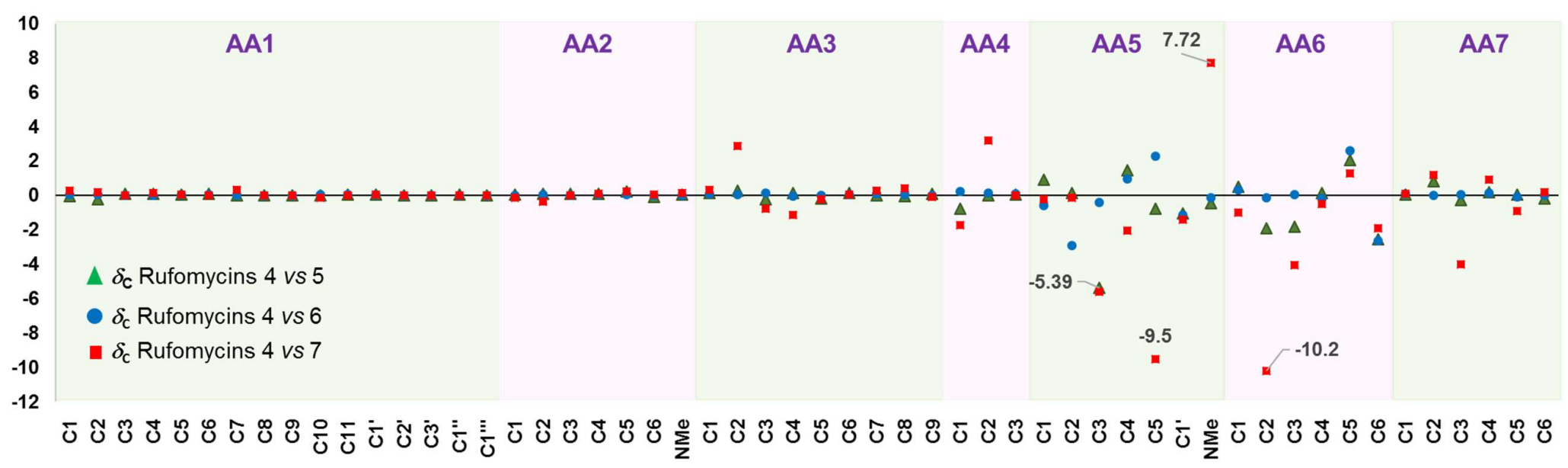


Figure S60. ${ }^{1} \mathrm{H}$ NMR differences $\left(\Delta \delta_{\mathrm{H}}\right)$ between compound pairs of rufomycins $4 / 5,4 / 6$, and $4 / 7$

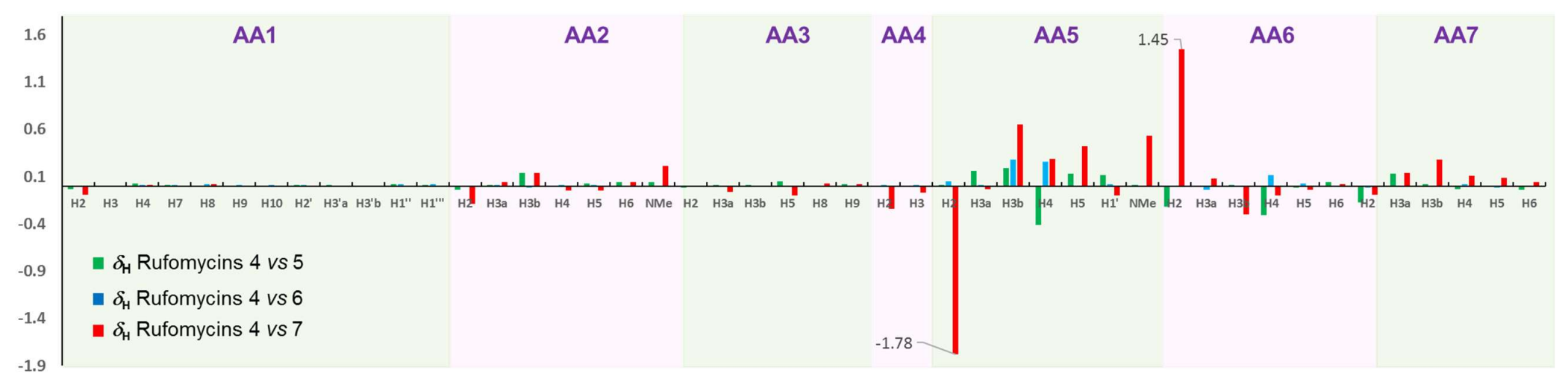


Figure S61. Extracted UV data of rufomycins 4-7
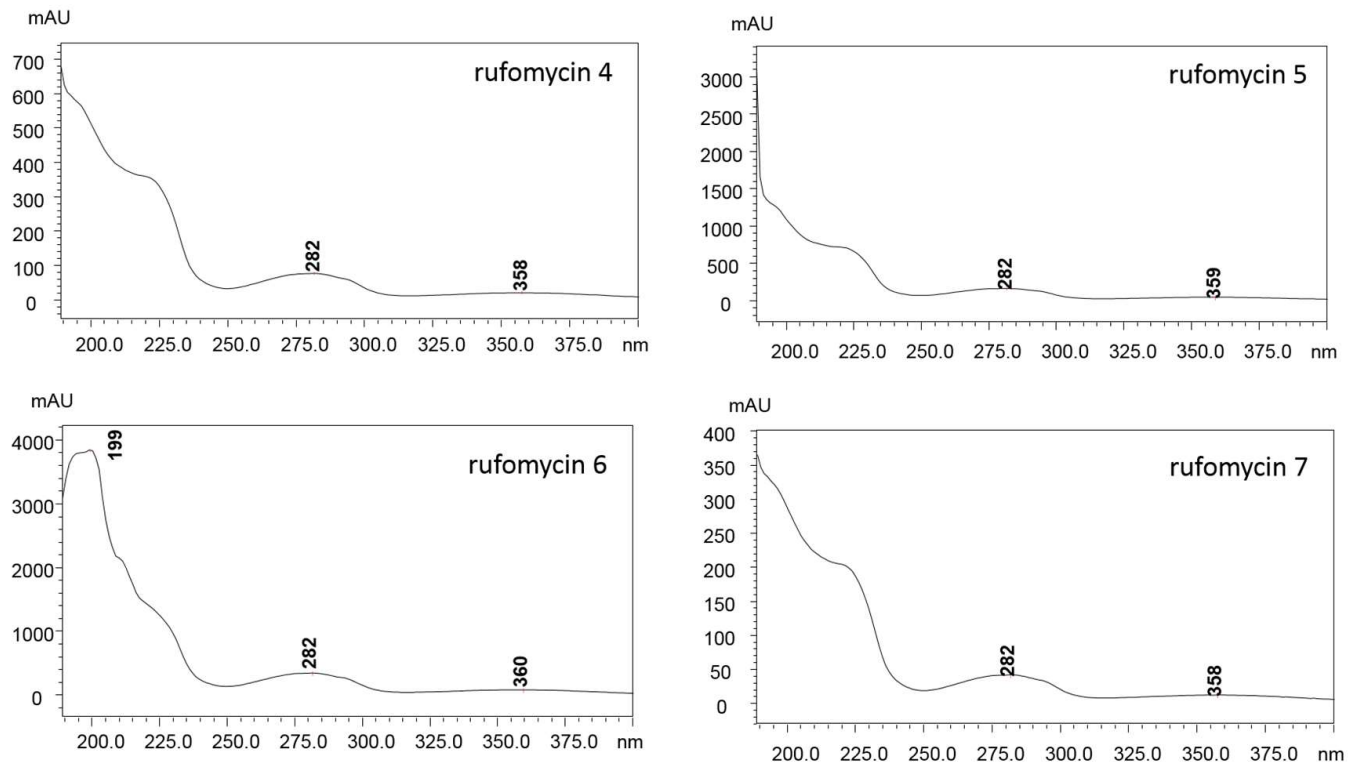

Figure S62. UV spectra of rufomycinSS 1-3 in methanol
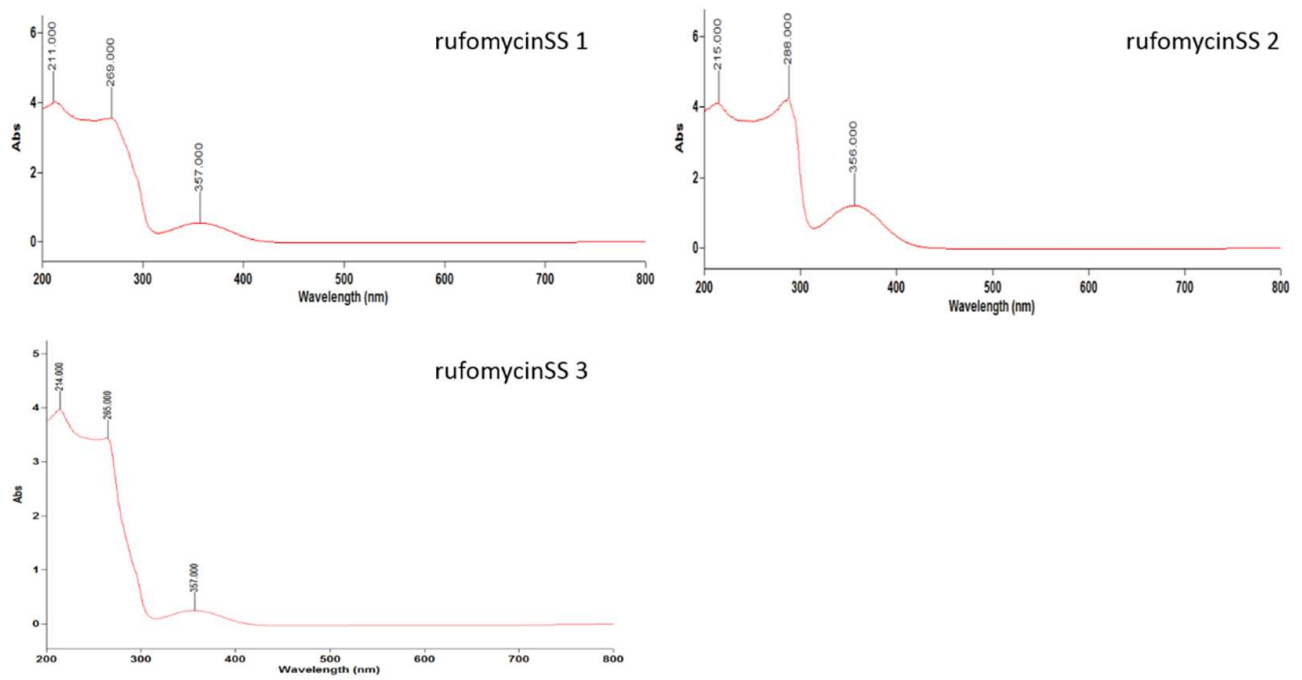
Figure S63. IR spectrum of rufomycin 4

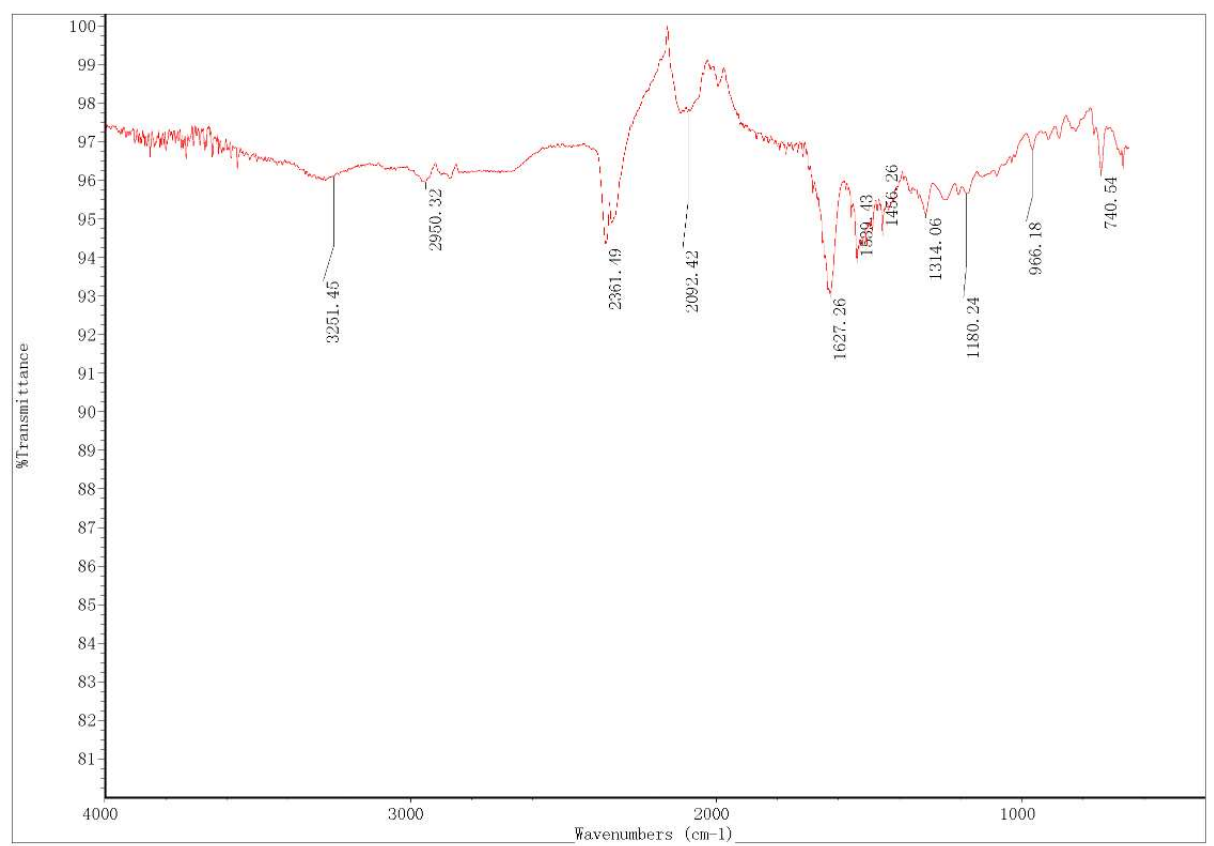

Figure S64. IR spectrum of rufomycin 5

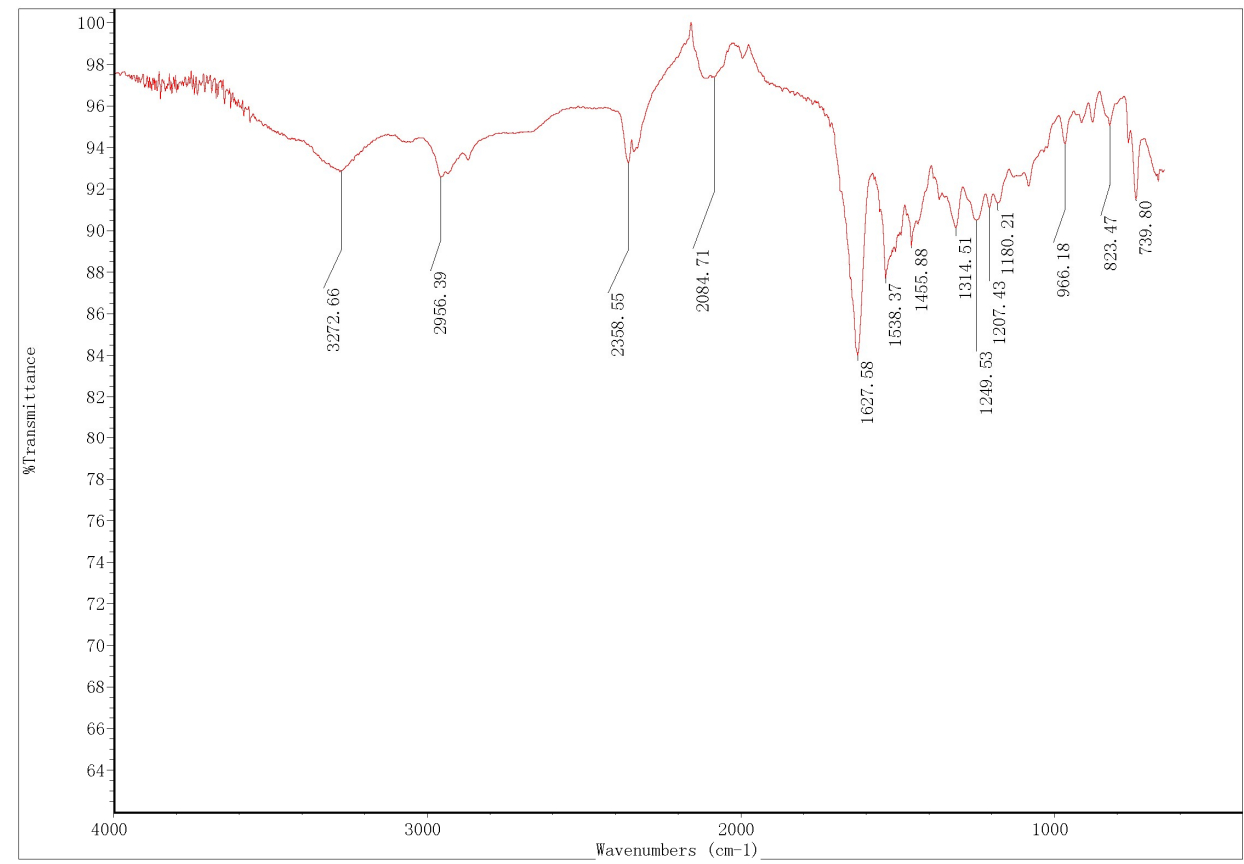


Figure S65. IR spectrum of rufomycin 6

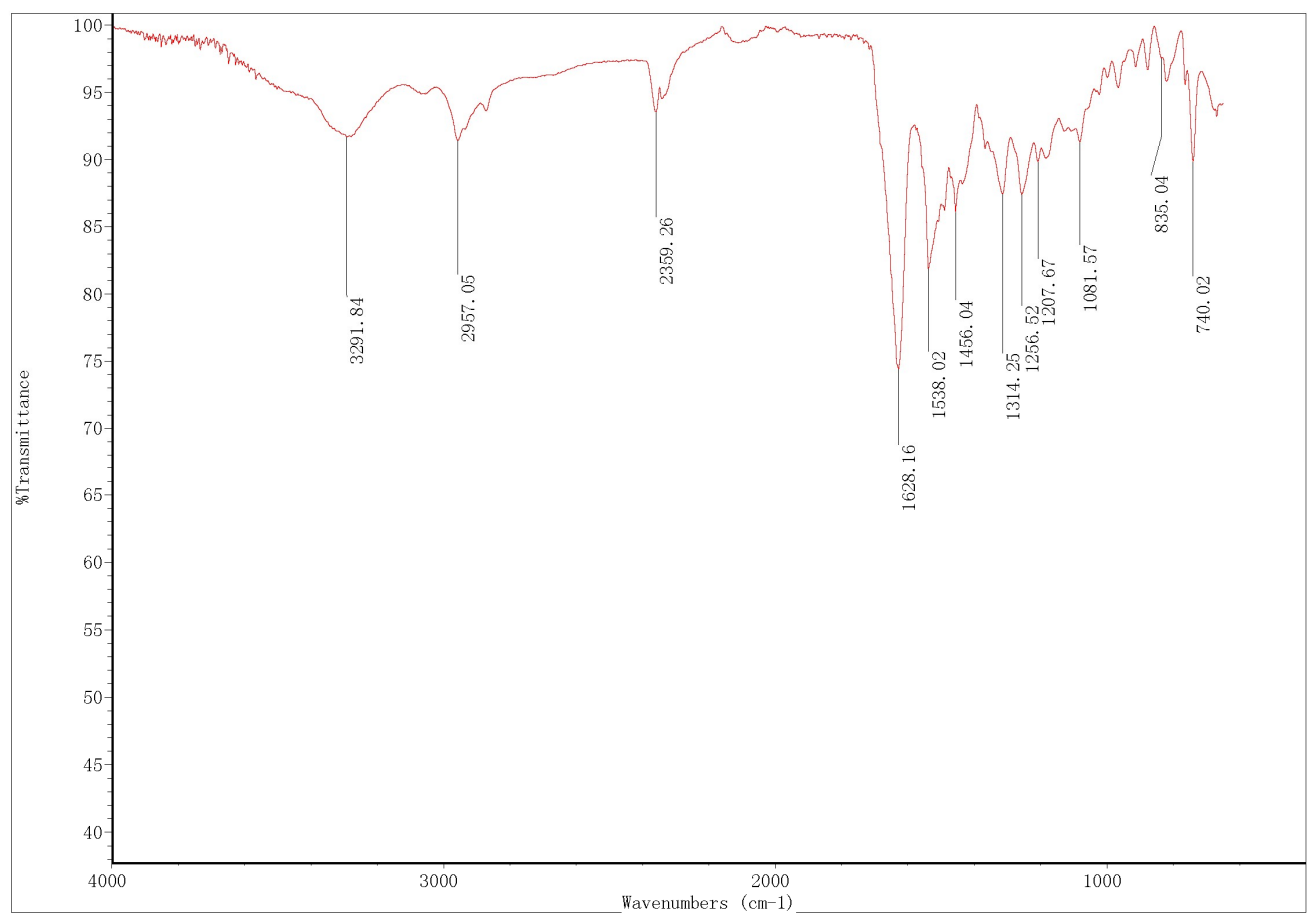

Figure S66. IR spectrum of rufomycinSS 1

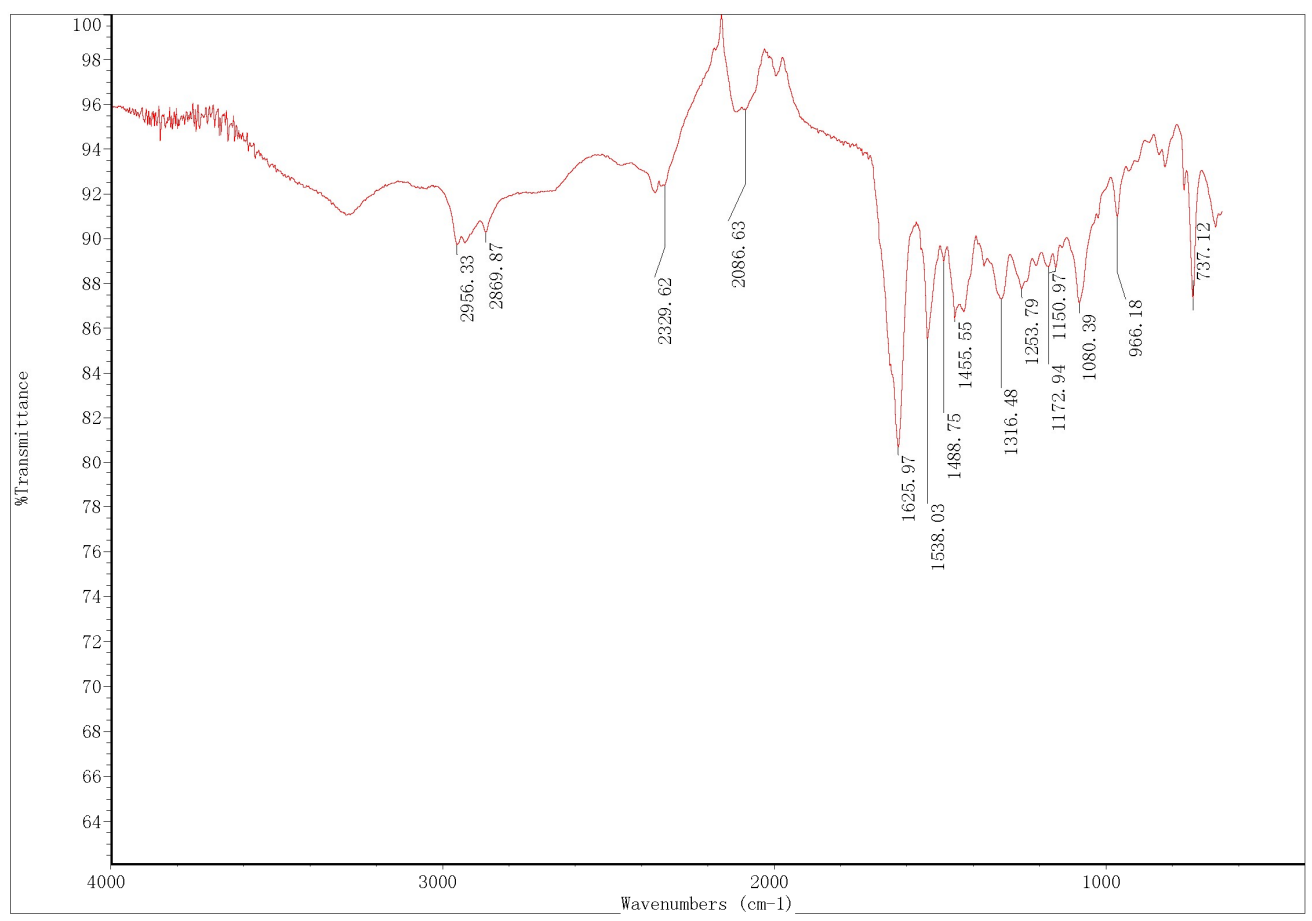


Figure S67. IR spectrum of rufomycinSS 2

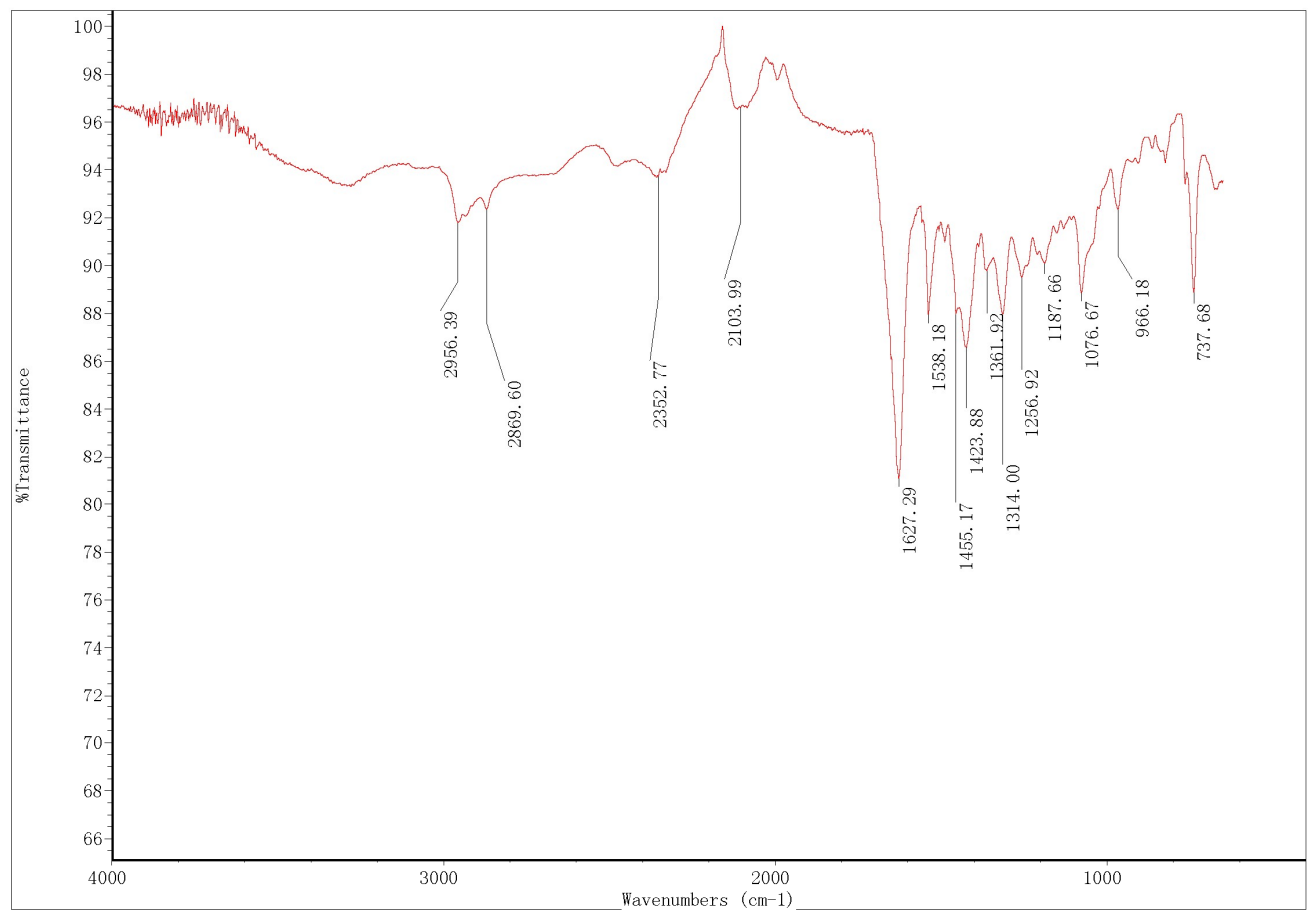

Figure S68. IR spectrum of rufomycinSS 3

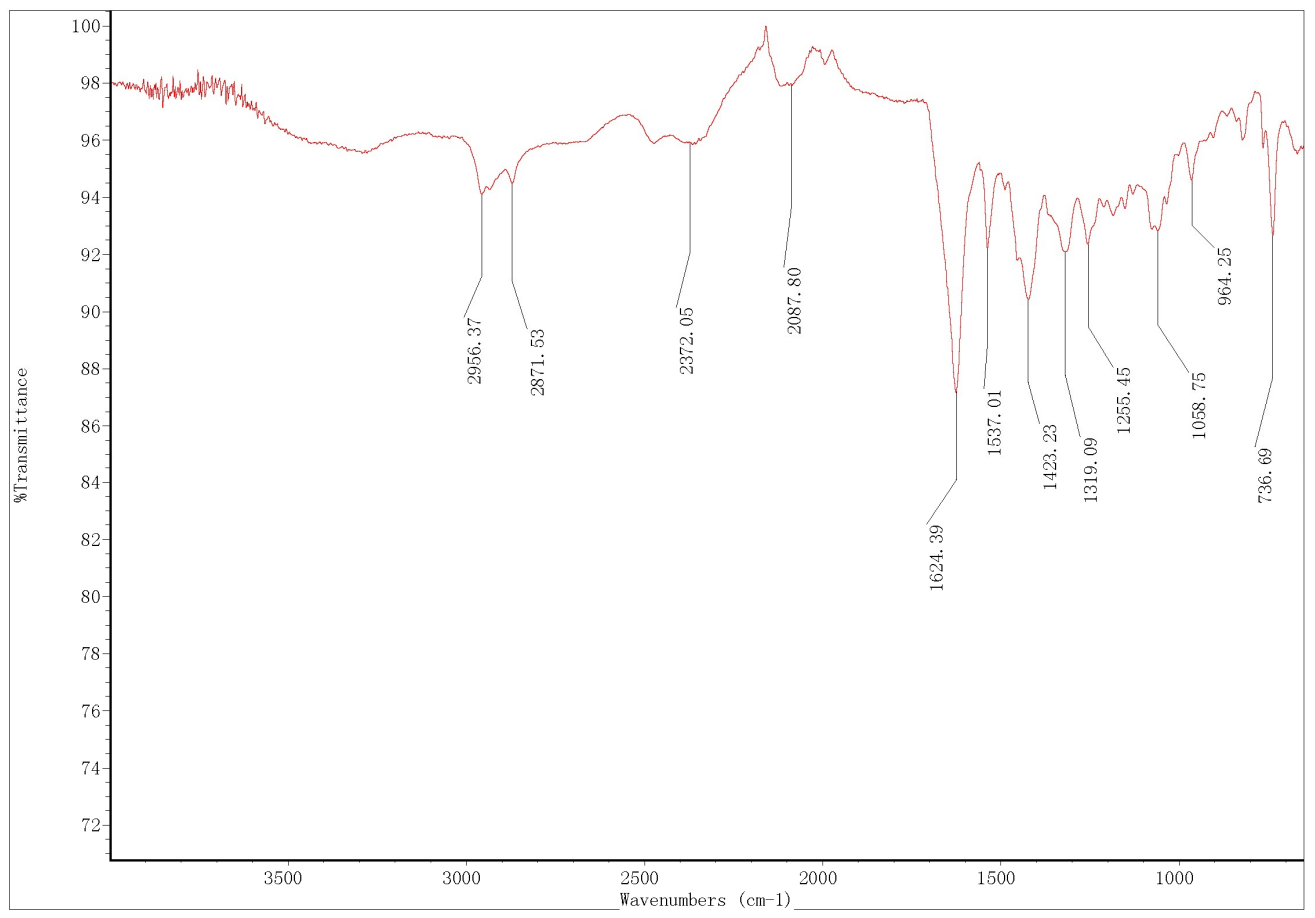

